\title{
Christian Witschel
}

\section{Der Kaiser und die Inschriften}

\section{Einführung}

In diesem Überblick soll anhand einiger Einzelbeobachtungen beleuchtet werden, welchen Beitrag Inschriften, die einen Bezug zum Princeps aufweisen (im Folgenden als ,Kaiserinschriften 'bezeichnet), bei der Erforschung des römischen Kaisertums leisten können ${ }^{1}$. Der Vorteil der Inschriften gegenüber anderen Quellengattungen liegt dabei auf der Hand, handelt es sich bei ihnen doch um in großer Zahl vorhandene, zumeist zeitgenössische Zeugnisse, die einen scheinbar direkten und ungefilterten Blick auf die Gestalt der einzelnen Herrscher erlauben. Zudem waren sie bis in den letzten Winkel des Imperium Romanum verbreitet, was helfen sollte, der Rom-zentrierten Sichtweise der literarischen Quellen entgegenzuwirken. Auf der anderen Seite werfen Inschriften durch ihren zumeist stark formelhaften Charakter sowie durch ihre Eigenart, mit wenigen (und dann häufig retrospektiven) Ausnahmen nur Positives - gerade in Hinblick auf den regierenden Princeps - zu berichten, Interpretationsprobleme eigener Art auf, die es im Folgenden anzusprechen gilt.

Als ,Inschriften' lassen sich generell Texte definieren, die aufgrund einer bewussten Entscheidung von Gemeinschaften oder Einzelpersonen in einem dauerhaften Material (in der Regel Stein oder Bronze) aufgezeichnet wurden, um sie einem größeren Publikum zu präsentieren und ihren

\footnotetext{
${ }^{1}$ Mein herzlicher Dank gilt dem Herausgeber Aloys Winterling für die Einladung zu dem Kolloquium sowie für den Langmut, mit dem er auf mein arg verspätetes Manuskript gewartet hat. Ebenfalls danken möchte ich Isabelle Oelschläger für die sorgfältige Durchsicht des Textes. Wie viel dieser Überblick schließlich den wegweisenden Untersuchungen von Géza Alföldy und Werner Eck verdankt, dürfte durchgehend deutlich werden. - Die folgenden Ausführungen konzentrieren sich auf den lateinischen Westen des Imperium Romanum (unter besonderer Berücksichtigung der gallischen und hispanischen Provinzen), versuchen aber, wo möglich auch die östlichen, griechischsprachigen Reichsteile einzubeziehen. Den chronologischen Rahmen bilden die Regierungszeiten der Kaiser von Augustus bis Commodus mit einem Schwerpunkt im frühen Prinzipat und gelegentlichen Ausblicken auf das 3.Jahrhundert. Aus der Fülle des Quellenmaterials konnten nur wenige Beispiele ausgewählt werden; ebenso selektiv sind die Literaturangaben gehalten. - Abgekürzt zitierte Literatur: CarthNova: Juan Manuel Abascal Palazón, Sebastián F. Ramallo Asensio, La ciudad de Carthago nova. La documentación epigráfica (Murcia 1997); Eck u.a., Senatus consultum: Werner Eck u.a., Das senatus consultum de Cn. Pisone patre (München 1996); Oliver, Constitutions: James H. Oliver, Greek Constitutions of Early Roman Emperors from Inscriptions and Papyri (Philadelphia 1989); Witschel, Augustus: Christian Witschel, Die Wahrnehmung des Augustus in Gallien, im Illyricum und in den Nordprovinzen des römischen Reiches, in: Detlev Kreikenbom u.a. (Hg.), Augustus - der Blick von außen. Die Wahrnehmung des Kaisers in den Provinzen des Reiches und in den Nachbarstaaten. Akten der internationalen Tagung Mainz 2006 (Wiesbaden 2008) 41-119. - Inschriftencorpora werden in der Regel nach der Aufstellung bei François Bérard u.a., Guide de l'épigraphiste. Bibliographie choisie des épigraphies antiques et médiévales (Paris $\left.{ }^{3} 2000\right) 17 f$. abgekürzt. Angegeben werden nur die jeweiligen Standardeditionen einer Inschrift, um ausufernde Belegreihen zu vermeiden.
} 
Inhalt für die Nachwelt zu bewahren. Diese auf eine breite Öffentlichkeit ausgerichtete, epigraphische Praxis' (epigraphic habit) war ein den antiken Kulturen eigentümliches Phänomen, das jedoch nicht in allen Epochen und Regionen gleichermaßen stark ausgeprägt war ${ }^{2}$. Auf den römischen Kulturraum bezogen lässt sich feststellen, dass die Zahl der Inschriftensetzungen in den Jahrhunderten der Republik gering blieb und auch im Laufe des 1.Jahrhunderts v. Chr. zunächst nur langsam anstieg. Erst mit der augusteischen Zeit kam es zu einem wahren ,Boom' in der Inschriftenproduktion, der von Rom in den Westen des Imperium Romanum ausstrahlte, während sich in weiten Teilen der östlichen Provinzen schon in der vorangegangenen hellenistischen Periode eine komplexe Inschriftenkultur herausgebildet hatte. Während des 1. und 2. Jahrhunderts n. Chr. nahm die Zahl der (datierbaren) Inschriften - auf das gesamte Reich gesehen - beständig zu, während sie im Laufe des 3. Jahrhunderts wieder zurückging ${ }^{3}$. Für den hier betrachteten Zeitraum zwischen Augustus und Commodus bedeutet dies, dass wir mit einer breit ausdifferenzierten und quantitativ bedeutsamen epigraphischen Praxis rechnen können, an der, wie zu zeigen sein wird, die auf den Kaiser bezogenen Tituli einen erheblichen Anteil hatten.

Auf der anderen Seite darf nicht vergessen werden, dass uns mit Sicherheit nur ein geringer Ausschnitt (insgesamt schätzungsweise maximal drei bis fünf Prozent) ${ }^{4}$ des einstmals vorhandenen

${ }^{2}$ Zum epigraphic habit im römischen Reich vgl. Ramsay MacMullen, The Epigraphic Habit in the Roman Empire, in: AJPh 103 (1982) 233-246; Elizabeth A. Meyer, Explaining the Epigraphic Habit in the Roman Empire. The Evidence of Epitaphs, in: JRS 80 (1990) 74-96; David Cherry, Re-figuring the Roman Epigraphic Habit, in: AHB 9 (1995) 132-156; Greg Woolf, Monumental Writing and the Expansion of Roman Society in the Early Empire, in: JRS 86 (1996) 22-39.

${ }^{3}$ Vgl. hierzu die - allerdings nicht unproblematische - Zusammenstellung von Stanistaw Mrozek, A propos de la répartition chronologique des inscriptions latines dans le Haut-Empire, in: Epigraphica 35 (1973) 113-118. ${ }^{4}$ Genauer bestimmen lässt sich die Überlebensrate bestimmter Inschriftengruppen nur dann, wenn die einstmals vorhandene Ausgangsmenge einigermaßen präzise bestimmt werden kann, was jedoch nur selten vorkommt. Die wenigen etwas besser nachvollziehbaren Fälle ergeben zudem ein disparates Bild. So war es in einigen Provinzhauptstädten, in denen sich das jeweilige concilium provinciae versammelte, üblich, jeden aus seinem Jahresamt ausscheidenden Oberpriester des provinzialen Kaiserkults (flamen provinciae) mit einem Standbild und einem Titulus auf dessen Basis zu ehren (vgl. auch unten Anm. 200). Wir erfahren dies explizit aus der inschriftlich überlieferten Regelung für die Provinz Gallia Narbonensis (CIL XII 6038 = ILS 6964). Gerade in Narbo, der Hauptstadt der Narbonensis, haben sich aber bislang keine entsprechenden Statuenbasen gefunden; vgl. Jürgen Deininger, Die Provinziallandtage der römischen Kaiserzeit von Augustus bis zum Ende des dritten Jahrhunderts n. Chr. (München 1965) 107-110. In großer Zahl sind solche Monumente hingegen aus Tarraco, der Hauptstadt der Provinz Hispania citerior, bekannt, nämlich ca. 70 aus der Zeit zwischen Vespasian und dem Ende des 2.Jahrhunderts, d.h. für (mindestens) etwa die Hälfte der in diesem Zeitraum amtierenden flamines, was einer - sehr beachtlichen - Überlebensrate von um die 50 Prozent entspricht; vgl. hierzu Géza Alföldy, Flamines provinciae Hispaniae citerioris (Madrid 1973). Allerdings ist zu bemerken, dass es schon vor Vespasian, und zwar seit der tiberischen Epoche, Provinzialoberpriester in Hispania citerior gegeben haben muss und solche auch noch im 3. Jahrhundert gewählt wurden - in diesen Zeiten war es jedoch augenscheinlich nicht üblich, ihnen ein Ehrenmonument zu errichten. Wiederum eine andere epigraphische Praxis findet sich in der Nachbarprovinz Lusitania, wo der provinziale Kaiserkult etwa zur selben Zeit eingerichtet worden sein dürfte: Hier finden sich tatsächlich frühe (Ehren-)Inschriften für Provinzialoberpriester, aber zunächst vor allem in deren Heimatgemeinden; vgl. die Übersicht bei Sabine Lefebvre, Q. (Lucceius Albinus), flamen provinciae Lusitaniae? L'origine sociale des flamines provinciaux de Lusitanie, in: Milagros Navarro Caballero, Ségolène Demougin (Hg.), Élites hispaniques (Bordeaux 2001) 217-239. In der Provinzhauptstadt Augusta Emerita sind flamines provinciae hingegen vornehmlich aus Weih- und Grabinschriften bekannt, und dies in eher geringer Zahl. Auf die sich hier andeutenden Diskrepanzen in der Inschriftenkultur, aber vielleicht eben auch bei den Überlieferungsbedingungen in den hispanischen Provinzhauptstädten hat bereits Walter Trillmich, „Foro provincial“ und „Foro municipal“ in den Hauptstädten der drei hispanischen Provinzen. Eine Fiktion, in: Ciudad y comunidad cívica en Hispania, siglos II y III d.C. (Madrid 1993) 115-124 hingewiesen. - Sehr 
Inschriftenbestandes erhalten geblieben ist ${ }^{5}$. Die Frage dabei ist, ob es im Überlieferungsprozess $\mathrm{zu}$ erheblichen Verzerrungen gekommen ist, durch die bestimmte Inschriftengruppen in dem uns bekannten Bestand besser repräsentiert sind als andere. Obwohl dies generell nur schwierig nachzuweisen ist, lässt es sich gerade in Bezug auf die Kaiserinschriften an einem gut bekannten Phänomen aufzeigen, nämlich der Gedächtnistilgung (der sogenannten damnatio memoriae), die postum über bestimmte Kaiser verhängt wurde und die dazu führte, dass viele ihrer Inschriften im öffentlichen Raum mehr oder minder vollständig vernichtet (und nicht nur durch eine Eradierung des Kaisernamens verändert) wurden. Dies macht sich auch quantitativ durchaus bemerkbar, so dass die Tituli ,schlechter' Kaiser im Gesamtbestand der Kaiserinschriften gegenüber denjenigen der principes boni unterrepräsentiert sein dürften ${ }^{6}$.

Hinzu kommt ein weiterer wichtiger Punkt: Wie schon bemerkt, ging der Anfertigung einer Inschrift, also der Verewigung eines Textes in dauerhaftem Material, in der Regel eine bewusste Entscheidung hierfür voraus (vgl. auch unten Kap.2). Selbst wichtige kaiserliche Botschaften mussten aber nicht notwendigerweise in dieser Form publiziert werden - um eine solche Nachricht bekannt zu machen, genügte es zumeist, deren Inhalt auf einem Papyrus anzuschlagen oder ihn auf eine geweißte Holztafel zu übertragen und diese für eine Weile öffentlich aufzustellen ${ }^{7}$. Solche auf

geringe Überlebensraten weisen verständlicherweise Inschriften auf, die regelmäßig in wertvollere Materialien eingraviert wurden. Dazu zählen beispielsweise die aus Bronze gefertigten Militärdiplome (s. unten Anm. 83), die zwischen dem mittleren 1. und dem frühen 3. Jahrhundert in großen Mengen an Veteranen ausgegeben worden sein müssen. Hierbei lässt sich die Zahl der einstmals vorhandenen Dokumente ziemlich genau berechnen und mit den erhaltenen Diplomen in Relation setzen, woraus sich in aller Regel Überlebensraten von unter einem Prozent ergeben. Noch sehr viel weniger hat sich von den kaiserlichen Konstitutionen über die Bürgerrechtsverleihung an ausgeschiedene Soldaten erhalten, die den Militärdiplomen zugrunde lagen und die auf großen Bronzetafeln in Rom publiziert worden waren. Von diesen haben sich nur ganz geringe Bruchstücke erhalten, nämlich in einigen Fällen, in denen sie für spätere Militärdiplome wiederverwendet wurden - bei dieser gewiss nicht unwichtigen Inschriftengruppe geht die Überlebensrate somit gegen Null. Vgl. zu dieser Problematik Werner Eck, Der Kaiser als Herr des Heeres. Militärdiplome und die kaiserliche Reichsregierung, in: John J. Wilkes (Hg.), Documenting the Roman Army. Essays in Honour of Margaret Roxan (London 2003) 55-87.

${ }^{5}$ Vgl. zum Folgenden auch die Überlegungen von Werner Eck, Befund und Realität. Zur Repräsentativität unserer epigraphischen Quellen in der römischen Kaiserzeit, in: Chiron 37 (2007) 49-64.

${ }^{6}$ Allgemein zur sog. damnatio memoriae im Imperium Romanum vgl. Friedrich Vittinghoff, Der Staatsfeind in der römischen Kaiserzeit. Untersuchungen zur damnatio memoriae (Berlin 1936); Eric R. Varner, Mutilation and Transformation. Damnatio memoriae and Roman Imperial Portraiture (Leiden 2004); ferner Mika Kajava, Some Remarks on the Erasure of Inscriptions in the Roman World (with special reference to the case of Cn. Piso, cos. 7 B.C.), in: Heikki Solin u.a. (Hg.), Acta colloquii epigraphici Latini, Helsinki 1991 (Helsinki 1995) 201-210; Harriet I. Flower, Rethinking damnatio memoriae. The Case of Cn. Calpurnius Piso Pater in A.D. 20, in: ClAnt 17 (1998) 155-186; Stéphane Benoist, Titulatures impériales et damnatio memoriae. L'enseignement des inscriptions martelées, in: CCG 15 (2004) 175-189. Die gegen bestimmte, bereits verstorbene Herrscher vom Senat angeordnete Gedächtnis- und Namenstilgung wurde zwar im Einzelfall je nach zeitlichem Kontext und lokalem Umfeld sehr unterschiedlich strikt gehandhabt (s. dazu unten Anm. 249), führte aber augenscheinlich in der Regel doch dazu, dass eine größere Zahl von epigraphischen Monumenten vor allem im öffentlichen Bereich gänzlich vernichtet wurde. Aufzeigen lässt sich dies beispielsweise an den Inschriften für Nero in Rom, von denen nur sehr wenige erhalten geblieben sind, und dies teilweise durch außergewöhnliche Umstände, etwa weil sie im Privatbereich aufgestellt waren; dazu Werner Eck, Die Vernichtung der memoria Neros. Inschriften der neronischen Zeit aus Rom, in: Jean-Michel Croisille, Yves Perrin (Hg.), Neronia, Bd. 6: Rome à l'époque néronienne (Brüssel 2002) 285-295.

${ }^{7}$ Vgl. Werner Eck, Inschriften auf Holz. Ein unterschätztes Phänomen der epigraphischen Kultur Roms, in: Peter Kneissl, Volker Losemann (Hg.), Imperium Romanum. Studien zu Geschichte und Rezeption. Festschrift Karl Christ (Stuttgart 1998) 203-217. Eines der wenigen erhaltenen Exemplare einer in Holz eingravierten 
vergänglichem Material geschriebenen Texte sind für uns jedoch mit wenigen Ausnahmen (etwa in Ägypten) unwiederbringlich verloren. Somit repräsentieren die (erhaltenen) Inschriften auf Stein oder Bronze wiederum nur einen Ausschnitt des in der Antike für ein breites Publikum sichtbaren, auf den Kaiser bezogenen Textbestandes.

Inschriften dienten verschiedenen Bevölkerungsgruppen im Imperium Romanum als ein bedeutsames Medium der Kommunikation und Repräsentation ${ }^{8}$. Das galt in besonderem Maße für die Zurschaustellung des Kaisers als Zentralfigur des gesamten Reiches9. Hierbei wirkte nicht nur der Inhalt des Textes (der ohnehin nur der relativ kleinen Schicht der Lesekundigen direkt zugänglich war) ${ }^{10}$ auf den Rezipienten, sondern auch seine - oft sehr eindrucksvolle - Gestaltung als epigraphisches Monument. Die Macht des Herrschers konnte dem Betrachter durch ein über die Norm herausragendes Format ${ }^{11}$, ein auffälliges Design der Buchstaben (etwa in Form vergoldeter Bronzelettern, der litterae aureae bzw. auratae ${ }^{12}$ ) oder eine besondere Hervorhebung des

Inschrift ist ein Bautitulus mit Nennung des Kaisers vom Hadrianswall in Britannien (RIB 1935), wo es solche Inschriften in größerer Zahl gegeben haben dürfte.

${ }^{8}$ Vgl. hierzu Géza Alföldy, Silvio Panciera (Hg.), Inschriftliche Denkmäler als Medien der Selbstdarstellung in der römischen Welt (Stuttgart 2001); Heike Niquet, Inschriften als Medium von ,Propaganda ' und Selbstdarstellung im 1.Jahrhundert n. Chr., in: Gregor Weber, Martin Zimmermann (Hg.), Propaganda - Selbstdarstellung - Repräsentation im römischen Kaiserreich des 1.Jahrhunderts n. Chr. (Stuttgart 2003) 145-173; Werner Eck, Herrschaft und Kommunikation in antiken Gesellschaften - das Beispiel Rom, in: Ulrike Peter, Stephan J. Seidlmayer (Hg.), Mediengesellschaft Antike? Information und Kommunikation vom Alten Ägypten bis Byzanz (Berlin 2006) 11-33.

${ }^{9}$ Zur Bedeutung der Inschriften als Medien der kaiserlichen Repräsentation vgl. Géza Alföldy, Augustus und die Inschriften. Tradition und Innovation. Die Geburt der imperialen Epigraphik, in: Gymnasium 98 (1991) 289-324; ders., Studi sull'epigrafia augustea e tiberiana di Roma (Rom 1992); ders., Die Repräsentation der kaiserlichen Macht in den Inschriften Roms und des Imperium Romanum, in: Lukas De Blois u.a. (Hg.), The Representation and Perception of Roman Imperial Power (Amsterdam 2003) 3-19.

${ }^{10} \mathrm{Zu}$ der umstrittenen Frage, wie viele Einwohner des römischen Reiches wenigstens rudimentäre Lesekenntnisse besaßen, vgl. Mireille Corbier, L'ecriture dans l'espace public romain, in: L'Urbs. Espace urbain et histoire ( ${ }^{\text {er }}$ siècle av. J.-C.-III' siècle ap. J.-C.). Actes du Colloque Roma 1985 (Rom, Paris 1987) 27-60; William V. Harris, Ancient literacy (Cambridge, Mass., London 1989) sowie die Beiträge in den folgenden Sammelbänden: John H. Humphrey (Hg.), Literacy in the Roman World (Ann Arbor 1991) und Alan K. Bowman, Greg Woolf (Hg.), Literacy and Power in the Ancient World (Cambridge 1994). Die meisten Autoren stimmen trotz im Einzelnen stark divergierender Meinungen über die quantitativen Aspekte darin überein, dass eine echte Litteralität, die zu einer vollständigen Erfassung auch komplexerer Texte befähigt hätte, in der römischen Welt wesentlich weniger stark verbreitet war, als man früher angenommen hat. Auf der anderen Seite kann durchaus vermutet werden, dass nicht wenige Stadtbewohner über eine Art von Grundlesekenntnissen verfügten, die es ihnen ermöglichten, kürzere Inschriften zumindest ansatzweise zu verstehen und die darin enthaltenen stereotypen Wendungen wiederzuerkennen (nach Corbier, L’ecriture 59f. handelte es sich hierbei um eine „alphabétisation pauvre“; vgl. jedoch auch William V. Harris, Literacy and epigraphy I, in: ZPE 52 [1983] 87-111).

${ }^{11}$ Unter den Kaiserinschriften, insbesondere den kaiserlichen Ehren- und Bauinschriften, finden sich die monumentalsten Tituli, die wir überhaupt aus dem Imperium Romanum kennen; vgl. Alföldy, Repräsentation (wie Anm.9) 11f. und ders., Die Bauinschriften des Aquäduktes von Segovia und des Amphitheaters von Tarraco (Berlin, New York 1997); ferner unten Kap. 3 sowie Anm. 158.

${ }^{12}$ Die Verwendung von solchen litterae aureae kam in Italien erstmals gegen Ende der Republik auf, gewann dann aber vor allem in der augusteischen Epoche stark an Popularität, als diese besonders ins Auge fallende Gestaltungsform vor allem für Kaiserinschriften Verwendung fand, da sie in ihrem semantischen Gehalt hervorragend zu der von Augustus propagierten aurea aetas passte; dazu Géza Alföldy, Der Obelisk auf dem Petersplatz in Rom. Ein historisches Monument der Antike (Heidelberg 1990) 68-74; Alfoldy, Augustus (wie Anm.9) 297-299, ders., Eine Bauinschrift aus dem Colosseum, in: ZPE 109 (1995) 205f. Von Italien aus verbreitete sich die Praxis rasch in die Westprovinzen des Reiches, wie man nunmehr besonders deutlich in Hispanien sehen kann, wo sich die Zahl der frühkaiserzeitlichen Inschriften mit litterae aureae in den letzten Jahren stark 
Kaisernamens (durch Schriftgröß ${ }^{13}$ oder farbige Gestaltung ${ }^{14}$ ) bildhaft vor Augen geführt werden. Dadurch waren die Worte des Kaisers oder die ihn auszeichnenden Ehrungen im öffentlichen Raum visuell äußerst präsent, auch wenn der genaue Wortlaut der Inschriften für viele Menschen unverständlich blieb. Dieser Aspekt ist erst in den letzten Jahren von der epigraphischen Forschung deutlicher herausgearbeitet worden. Zuvor hatte man lange Zeit Inschriften vornehmlich als isolierte Texte betrachtet und als solche publiziert. Auch heute fällt es vielfach immer noch schwer - gerade beim Fehlen einer modernen Edition - genauere Angaben zum Inschriftenträger zu ermitteln und dadurch den Monumentcharakter einer Inschrift zu bestimmen. Hinzu kommt ein weiteres, ebenfalls oft vernachlässigtes Phänomen: Die meisten Inschriften wurden von dem antiken Betrachter nicht als vereinzelte Schriftzeugnisse wahrgenommen, sondern eingebunden in einen weiteren Kontext, in dem sie mit anderen, etwa bildlichen oder architektonischen Bedeutungsträgern, in Interaktion traten. So waren beispielsweise Ehreninschriften sehr häufig auf Statuenbasen angebracht und somit gemeinsam mit einer statuarischen Darstellung des Geehrten zu sehen. Bauinschriften waren in aller Regel direkt an dem Gebäude angebracht, dessen Errichtung oder Restaurierung sie kommemorierten. Gerade im Falle der kaiserlichen Repräsentation muss also immer im Auge behalten werden, dass verschiedene Medien - unter denen den Inschriften nur eine partielle, wenn auch nicht zu unterschätzende Bedeutung zukam - zusammenspielten, um vor dem antiken Publikum das ,Image' des Herrschers zu evozieren; und dass wir versuchen müssen, diese ursprünglichen Wirkungszusammenhänge zu rekonstruieren, indem etablierte disziplinäre Grenzen wie etwa diejenige zwischen Klassischer Archäologie und Epigraphik überwunden werden.

vermehrt hat. Eine Vorreiterrolle könnte hierbei die Kaiserfamilie selbst gespielt haben, wie wir insbesondere in der lusitanischen Provinzhauptstadt Augusta Emerita sehen können, deren Theater von Agrippa erbaut wurde. An mehreren prominenten Stellen des Gebäudes wurden im Jahre 16 v. Chr. Bauinschriften angebracht, die den Namen des Stifters teilweise in vergoldeten Bronzebuchstaben vorführten (andere waren stuckiert und mit roter Farbe nachgezogen): José Luis Ramírez Sádaba, Catálogo de las inscripciones imperiales de Augusta Emerita (Mérida 2003) Nr. 4 und 5/6 (auch Reste von vergoldeten Buchstaben wurden gefunden: ebd. Nr. 7). Aufgegriffen wurde die Praxis rasch von den lokalen Eliten, und zwar sowohl in den größeren Städten wie Carthago nova (s. José Miguel Noguera, Juan Manuel Abascal, Fragmentos de epígrafes e inscripción con litterae aureae del foro y del augusteum de Carthago nova, in: Mastia 2 [2003] 53-58) als auch in kleineren Gemeinden des Hinterlandes wie Segobriga (Juan Manuel Abascal u.a., La inscripción con letras de bronce y otros documentos epigráficos del foro de Segobriga, in: AEA 74 [2001] 117-130). In den germanischen Provinzen wurde eine solche Gestaltung ebenfalls bei Inschriften zur Verehrung des Kaisers genutzt; vgl. Michael A. Speidel, Goldene Lettern in Augst, in: ZPE 95 (1993) 179-189. Gleichzeitig verbreitete sich das Phänomen auch im Osten des Reiches, wo es wiederum vor allem bei solchen Tituli Verwendung fand, die in direkter Beziehung zum Kaiserhaus standen. Als Beispiele hierfür lassen sich nennen: Eine Restaurierungsinschrift des Agrippa am Zeus-Tempel in Olympia (IvOlympia 913); die Inschrift eines frühkaiserzeitlichen Tempels auf Samos (IG XII 6, 1, 481) sowie die Inschrift für Nero, die an der Ostseite des Parthenon auf dessen Architrav angebracht war (IG II/III 2 3277). Ein weiteres Beispiel ist die Weiheinschrift des großen Zeus-Tempels von Aizanoi: Auch hier haben sich auf dem Architrav des Baues Dübellöcher für vergoldete Bronzebuchstaben erhalten, aus denen sich die Inschrift mit einer Weihung an Zeus und Kaiser Domitian rekonstruieren lässt; vgl. Richard Posamentir, Michael Wörrle, Der Zeustempel von Aizanoi, ein Großbau flavischer Zeit, in: MDAI(I) 56 (2006) 227-246.

${ }^{13}$ Durch eine besondere Buchstabengröße herausgehoben ist der Name des Herrschers etwa in der neronischen Bauinschrift des Leuchtturms von Patara, die zudem ebenfalls mit vergoldeten Bronzebuchstaben ausgeführt war (s. unten Anm. 136).

${ }^{14}$ Beobachten kann man dies etwa an einigen Statuenbasen der tetrarchischen Zeit aus dem diokletianischen Militärlager im altägyptischen Tempel von Luxor: Auf der geweißten Oberfläche der Basen waren die Buchstaben der Inschrift in Rot nachgezogen, während die Kaisernamen hiervon noch einmal mit gelber Farbe abgesetzt waren, was hier sicherlich als Ersatz für eine goldene Fassung gemeint war; vgl. Johannes G. Deckers, Die Wandmalereien im Kaiserkultraum von Luxor, in: JDAI 94 (1979) 604f. A. 16. 
Da der Princeps der allseits anerkannte Mittelpunkt des Imperium Romanum war, verwundert es nicht, dass er und seine Familienangehörigen auf zahlreichen Inschriften Erwähnung fanden. Als ,Kaiserinschriften' im weitesten Sinne können dabei sämtliche Tituli angesprochen werden, in denen der Name des regierenden oder eines verstorbenen Herrschers vorkommt, ob nun als agierende Figur im Nominativ, als geehrte Person oder gar Gottheit im Dativ (bzw. im Akkusativ im Griechischen), oder aber in einem Hinweis auf eine vom Kaiser ausgehende Wohltat, Beförderung und Ähnliches mehr ${ }^{15}$. Im engeren Sinne lassen sich die Kaiserinschriften verschiedenen Untergruppen zuordnen, die in den nächsten Abschnitten ausführlicher vorgestellt werden (s. unten Kap. 2-6). Mit ihrer Hilfe können zahlreiche Felder kaiserlichen Handelns bzw. die Reaktionen hierauf beleuchtet werden, von denen hier nur einige wenige kursorisch aufgeführt seien, auf die im Folgenden nicht näher eingegangen wird: Im Bereich der Ereignisgeschichte können Inschriften, insbesondere inschriftlich aufgezeichnete Fasten und Kalender ${ }^{16}$, wichtige Informationen zum Auftreten des Kaisers liefern und dadurch die Angaben der literarischen Quellen ergänzen bzw. diese - gerade in Hinblick auf die genaue Datierung bestimmter Ereignisse - präzisieren. So verzeichnen beispielsweise die Fasti Ostienses zum Jahr 2 n. Chr. mit einigem Detail, wie der Leichnam des am 20. August in Marseille verstorbenen Lucius Caesar (vgl. unten Kap. 2) in Ostia eintraf und von dort unter großer Anteilnahme der Bevölkerung weitergeleitet wurde ${ }^{17}$. Auch die Aufenthaltsorte der Kaiser und insbesondere ihre Reisen lassen sich vornehmlich mit Hilfe des epigraphischen Quellenmaterials rekonstruieren ${ }^{18}$. Für die Beziehungen des Kaisers zum Heer und für die militärischen Aktionen einzelner Herrscher bieten Inschriften ebenfalls wichtige Hinweise ${ }^{19}$. Dasselbe gilt für die administrativen Strukturen im Umfeld des Kaisers, so etwa die Zusammensetzung des

\footnotetext{
${ }^{15}$ Solche Inschriften, in denen der Kaiser als Urheber eines beneficium herausgestellt wurde, kamen sehr häufig vor, da hierdurch ein von dem kaiserlichen Namen ausgehender Glanz auf den Empfänger der Wohltat oder Beförderung fiel, welcher in der Regel die Setzung des Titulus veranlasste. Als ein frühes Beispiel s. die Grabinschrift CIL III 5232 = ILS 1977 aus Celeia (Noricum): C(aius) Iulius Vepo donatus / civitate Romana viritim / et inmunitate ab divo Aug(usto) / vivos fecit sibi et / Boniatae Antoni fll(iae) coniugi / et suis. Für den militärischen Bereich vgl. Werner Eck, Monumente der Virtus. Kaiser und Heer im Spiegel epigraphischer Denkmäler, in: Géza Alföldy u.a. (Hg.), Kaiser, Heer und Gesellschaft in der Römischen Kaiserzeit. Gedenkschrift für E. Birley (Stuttgart 2000) 483-496.

${ }^{16}$ Vgl. die Übersicht bei Dietmar Kienast, Römische Kaisertabelle. Grundzüge einer römischen Kaiserchronologie (Darmstadt ${ }^{2}$ 1996) 1-10; ferner InscrIt XIII zu den Fasten sowie John Scheid, Commentarii fratrum Arvalium qui supersunt. Les copies épigraphiques des protocoles annuels de la confrérie arvale, 21 av.-304 ap. J.-C. (Rom, Paris 1998) zu den auch für die Kaisergeschichte ergiebigen Akten der Priesterschaft der fratres Arvales, die in Marmorstelen graviert und im Heiligtum der Dea Dia aufgestellt worden waren.

${ }_{17}$ FastOst frgmt. Ba Z.1-4: Hominu[m plus ---]/inta millia can[delis ardentibus] obviam processe[runt. Magistratus] / Ostiensium pulla[ti corpus tulerunt]; vgl. die Neuedition von Barbara Bargagli, Cristiana Grosso, I Fasti Ostienses. Documento della storia di Ostia (Rom 1997).

${ }^{18}$ Grundlegend hierzu Helmut Halfmann, Itinera principum. Geschichte und Typologie der Kaiserreisen im römischen Reich (Stuttgart 1986).

${ }^{19}$ Vgl. beispielsweise zur Rekonstruktion der Kriege Domitians, Trajans und Hadrians auf (vornehmlich) epigraphischer Grundlage Karl Strobel, Der Chattenkrieg Domitians. Historische und politische Aspekte, in: Germania 65 (1987) 423-452; ders., Die Donaukriege Domitians (Bonn 1989); ders., Untersuchungen zu den Dakerkriegen Trajans (Bonn 1984); Michael P. Speidel, The Captor of Decebalus. A New Inscription From Philippi, in: JRS 60 (1970) 142-153; Werner Eck, The Bar Kokhba Revolt. The Roman Point of View, in: JRS 89 (1999) 76-89. Siehe ferner unten Anm. 45 zu der inschriftlich erhaltenen Ansprache Hadrians an die afrikanische Armee.
} 
Personals am Kaiserhof ${ }^{20}$ oder die Verwaltung des großen kaiserlichen Besitzes, in die der Herrscher bisweilen direkt eingriff ${ }^{21}$. Generell ist die Administration des Imperium Romanum, an deren Spitze der Kaiser stand, sowie die Auswahl der Verwaltungsbeamten durch den Herrscher fast ausschließlich aufgrund von Inschriften rekonstruierbar ${ }^{22}$.

\section{Die Verbreitung wichtiger kaiserlicher Botschaften und deren inschriftliche Fixierung}

Im Folgenden sollen die wichtigsten Arten von Kaiserinschriften vorgestellt werden. Dabei wird vor allem danach zu fragen sein, wer jeweils für die Konzeption einer Inschrift und für die Erstellung bzw. Gestaltung des entsprechenden epigraphischen Monuments verantwortlich zeichnete. Beginnen möchte ich mit der Gruppe der kaiserlichen Mitteilungen und der vom Herrscher ausgehenden administrativen Dokumente ${ }^{23}$. An erster Stelle zu nennen sind hierbei umfangreiche kaiserliche Botschaften, die mittels einer inschriftlichen Fassung an die Bevölkerung kommuniziert

\footnotetext{
${ }^{20}$ Dazu Aloys Winterling, Aula Caesaris. Studien zur Institutionalisierung des römischen Kaiserhofes in der Zeit von Augustus bis Commodus, 31 v. Chr.-132 n. Chr. (München 1999). Zu den Vorstehern und zur Arbeitsweise der kaiserlichen Kanzleien vgl. Walter Seitz, Studien zur Prosopographie und zur Sozial- und Rechtsgeschichte der großen kaiserlichen Zentralämter bis hin zu Hadrian (Augsburg 1970); Anthony R. Birley, Locus virtutibus patefactus? Zum Beförderungssystem in der hohen Kaiserzeit (Opladen 1992); zu den zahlreichen kaiserlichen Sklaven und Freigelassenen sowie ihren Funktionen vgl. Otto Hirschfeld, Die kaiserlichen Verwaltungsbeamten bis auf Diocletian (Berlin $\left.{ }^{2} 1905\right)$ 318-342; Gérard Boulvert, Esclaves et affranchis imperiaux sous le HautEmpire romain. Rôle politique et administratif (Neapel 1970); Paul R. C. Weaver, Familia Caesaris. A Social Study of the Emperor's Freedmen and Slaves (Cambridge 1972); Graham P. Burton, Slaves, Freedmen and Monarchy, in: JRS 67 (1977) 162-166.

${ }^{21}$ Ein Beispiel hierfür sind die Inschriften, die die Situation der kaiserlichen Güter und der auf ihnen lebenden coloni in Africa während des 2. Jahrhunderts beleuchten; vgl. dazu Dieter Flach, Inschriftenuntersuchungen zum römischen Kolonat in Nordafrika, in: Chiron 8 (1978) 441-492; Dennis P. Kehoe, The Economics of Agriculture on Roman Imperial Estates in North Africa (Göttingen 1988).

${ }^{22}$ Hieraus hat sich eine intensive - und wichtige - Diskussion über den Wert prosopographischer Studien entwickelt, die insbesondere um die Frage kreist, ob sich der Kaiser und seine Berater bei der Auswahl der Amtsträger an bestimmten, objektivierbaren Kriterien orientierten (und sich deshalb gewisse Karriere-Schemata ausmachen lassen) oder hierbei vor allem Patronage-Beziehungen wirksam wurden. Vgl. Brian Campbell, Who Were the viri militares?, in: JRS 65 (1975) 11-31; Graham P. Burton, in: JRS 70 (1980) 203-207; Richard P. Saller, Personal Patronage under the Early Empire (Cambridge 1982); Birley, Beförderungssystem (wie Anm. 20) sowie zusammenfassend Werner Eck, Imperial Administration and Epigraphy. In Defence of Prosopography, in: Alan K. Bowman u.a. (Hg.), Representations of Empire. Rome and the Mediterranean World (Oxford 2002) 131-152 und die Beiträge in Lukas De Blois (Hg.), Administration, Prosopography and Appointment Policies in the Roman World (Amsterdam 2001). Zudem lässt sich durch prosopographische Untersuchungen nachweisen, dass es in der Regel bei Kaiserwechseln - selbst bei Principes mit sehr unterschiedlichen Herrschaftsauffassungen - nicht zu größeren Brüchen in der Personalauswahl kam; vgl. etwa zur flavisch-trajanischen Epoche Werner Eck, Senatoren von Vespasian bis Hadrian (München 1970); Brian W. Jones, Domitian and the Senatorial Order (Philadelphia 1979); Ronald Syme, Domitian. The Last Years, in: Chiron 13 (1983) 121-146.

${ }^{23}$ Vgl. hierzu auch die weiterführenden Beobachtungen von Werner Eck, Administrative Dokumente. Publikation und Mittel der Selbstdarstellung, in: Ders., Die Verwaltung des römischen Reiches in der hohen Kaiserzeit. Ausgewählte und erweiterte Beiträge, Bd.2 (Basel 1998) 359-381. Zu spät zu meiner Kenntnis gelangte ein Band, in dem zahlreiche wichtige Beiträge zum Thema versammelt sind: Rudolf Haensch (Hg.), Selbstdarstellung und Kommunikation. Die Veröffentlichung staatlicher Urkunden auf Stein und Bronze in der römischen Welt (München 2009).
} 
werden sollten. Das berühmteste Schriftstück dieser Art ist ohne Zweifel der Text der Res gestae divi Augusti, den Augustus mit eigener Hand verfasst und für den er testamentarisch eine epigraphische Fassung vorgesehen hatte ${ }^{24}$ : Der Text sollte auf zwei imposanten bronzenen Pfeilern eingraviert werden, die vor dem Mausoleum Augusti - mithin im Kontext zahlreicher weiterer Inschriften, die zu diesem Zeitpunkt bereits an dem Gebäude angebracht waren ${ }^{25}$ - zur Aufstellung kamen ${ }^{26}$. Eine epigraphische Publikation außerhalb Roms war hingegen von Augustus anscheinend nicht vorgesehen. Dennoch kennen wir den Text der Res gestae divi Augusti ausschließlich durch drei in frühtiberischer Zeit angefertigten Kopien auf Stein, die in der inneranatolischen Provinz Galatia gefunden wurden und jeweils eine unterschiedliche Form aufwiesen. Alle drei Kopien waren offenbar im Kontext von Kaiserkultanlagen angebracht: Im lateinischen Original sowie in einer griechischen Übersetzung auf der Innen- und Außenwand des provinzialen Kaiserkulttempels in Ancyra (Ankara); nur in Latein im Bereich des Propylon eines munizipalen Kaiserkulttempels in der römischen Kolonie Antiochia ad Pisidiam; sowie nur in Griechisch in der Stadt Apollonia auf dem Sockel einer großen Statuenbasis, die verschiedene Bildnisse der kaiserlichen Familie trug und vermutlich im Bereich eines temenos zur Verehrung der Kaiser aufgestellt war. Warum der Text nur in Galatia - dort aber an einer ganzen Reihe von Orten - in ein dauerhaftes Material übertragen wurde ${ }^{27}$, wissen wir nicht genau, aber wir können zumindest einige begründete Vermutungen hierzu anstellen: Am wahrscheinlichsten dürfte sein, dass dabei ein Statthalter von Galatien die treibende Kraft war, der hierdurch seine besondere Loyalität zum Kaiserhaus demonstrieren wollte ${ }^{28}$. Er hatte vermutlich eine Kopie des Textes auf Papyrus aus Rom erhalten, ihn vor Ort ins Griechische übersetzen und dann in der Provinzhauptstadt Ancyra anschlagen lassen. Mittels eines begleitenden statthalterlichen Edikts sowie vielleicht auch eines Rundbriefs ließ er sodann die Bevölkerung der einzelnen Städte seiner Provinz wissen, dass er die Herstellung von Kopien in dauerhaften Materialien wünsche oder zumindest begrüß $\mathrm{e}^{29}$. Allerdings konnte er dies kaum im Alleingang durchsetzen; vielmehr war er für die Verbreitung des Textes auf die Kooperation mit lokalen Institutionen angewiesen. Ein wichtiger Ansprechpartner scheint hierbei das koinon, zu dem die einzelnen Gemeinden der Region ihre Vertreter entsandten, gewesen zu sein, und es ist sicher kein Zufall, dass die umfangreichste Kopie der Res gestae divi Augusti gerade auf den Wänden des vom koinon verwalteten provinzialen Tempels der Roma und des Augustus in Ancyra angebracht wurde.

${ }^{24}$ Vgl. zum Folgenden ausführlicher Christian Witschel, The Res Gestae Divi Augusti and the Roman Empire, in: Fritz-Heiner Mutschler, Achim Mittag (Hg.), Conceiving the Empire. China and Rome Compared (Oxford 2008) 241-266 (mit den Angaben und weiterer Literatur); ferner Paula Botteri, Ancyra, Antiochia e Apollonia. La rappresentazione delle Res Gestae Divi Augusti, in: Lukas De Blois u.a. (Hg.), The Representation and Perception of Roman Imperial Power (Amsterdam 2003) 240-249.

${ }^{25} \mathrm{Vgl}$. Henner von Hesberg, Silvio Panciera, Das Mausoleum des Augustus. Der Bau und seine Inschriften (München 1994) bes. 52, 66, 112, $174 \mathrm{f}$.

${ }^{26}$ S. Suet. Aug. 101; Cass. Dio 56, 33, 1.

${ }^{27}$ Wäre dies auch in anderen Provinzen geschehen, hätten sich hiervon zumindest geringe Reste erhalten sollen, die bei einem solchen Text selbst in sehr fragmentarischem Zustand leicht zuweisbar sein dürften.

${ }^{28}$ Für einen weiteren vergleichbaren Fall s. unten Anm.39.

${ }^{29}$ Eine solche statthalterliche Anweisung ist uns im Kontext der Verbreitung des diokletianischen Preisedikts bekannt, von dem sich Abschriften auf Stein ebenfalls nur in bestimmten Provinzen im Ostteil des Reiches gefunden haben. Einer dieser Kopien im phrygischen Aizanoi ist ein Schreiben des Statthalters beigefügt, mit dem dieser der Gemeinde eine Kopie des Preisedikts überstellt, den Sinn der kaiserlichen Maßnahme erläutert und anordnet, dass das Edikt proponiert werden solle; vgl. Michael H. Crawford, Joyce Reynolds, The Publication of the Prices Edict. A New Copy from Aezani, in: JRS 65 (1975) 160-163. Von einer inschriftlichen Fassung ist hier allerdings nicht explizit die Rede. 
Eine solche Zusammenarbeit zwischen Statthalter und koinon bei der Verbreitung von wichtigen Botschaften in Bezug auf den Kaiser hat auch andernorts stattgefunden, so nur wenige Jahre zuvor in der benachbarten Provinz Asia, von wo ein umfangreiches Dossier bekannt ist, das auf die Initiative des Paullus Fabius Maximus, Prokonsul der Provinz im Jahre 10/9 v. Chr., zurückging $^{30}$. Dieser wandte sich zunächst in einem Edikt an das koinon von Asia. Er hob darin die hohe Bedeutung hervor, die der Geburtstag des Kaisers Augustus für das Wohlergehen des gesamten Erdkreises habe, und schlug dann eine neue Prozedur vor, um diesen Tag gebührend zu feiern: Es scheine ihm gut, wenn ab jetzt alle Städte in der Provinz denselben Neujahrstag (also den Tag, an dem die lokalen Beamten ihr Amt antraten) beachteten, und zwar eben den Geburtstag des göttlichen Kaisers am 23. September, wofür ein neuer Kalender einzuführen sei. Das „müsse“ durch einen Beschluss des koinon zusammen mit einer Lobpreisung des Augustus verabschiedet werden, damit der von Maximus entwickelte Plan für die Ewigkeit bestehen bleibe; er selbst wolle dafür sorgen, dass dieser Beschluss zusammen mit seinem Edikt an einem zentralen Ort auf einer steinernen Stele veröffentlicht werde. Das koinon hat hierauf tatsächlich mit einem psēphisma geantwortet, das die Vorschläge (eigentlich waren es mehr oder minder direkte Anweisungen) des Maximus umsetzte und diesen daraufhin besonders belobigte, weil er eine solch innovative Form der Verehrung des Gottes Augustus gefunden hatte. Ferner feierte dieser Beschluss den Kaiser und dessen Leistungen - auch hierin die Anregung des Maximus aufgreifend - in überschwänglichen Worten als göttlichen Retter der Menschheit und Friedensbringer. Gleichzeitig wurde festgelegt, dass das Edikt des Statthalters und der Beschluss des koinon auf einer Stele aufgezeichnet werden sollten, die man im zentralen Kaiserkulttempel der Provinz in Pergamon aufstellen wollte, wie es ebenfalls schon Maximus vorgesehen hatte. Zur Verbreitung des nunmehr aus mehreren Schriftstücken bestehenden Gesamtdossiers in den Gemeinden von Asia wurde ferner angeordnet, dass Abgesandte des koinon dafür sorgen sollten, dass es in den conventus-Zentren auf geweißten Steinen publiziert und diese in den lokalen Heiligtümern des Kaiserkults aufgestellt würden. Man scheint aber auf lokaler Ebene über diese Publikationsanordnung noch hinausgegangen zu sein, denn einige der Abschriften des Dossiers (von denen sich insgesamt sechs erhalten haben) sind an kleinen, relativ unbedeutenden Orten gefunden worden - man hatte hier offenbar ebenfalls das Bedürfnis, sich eine Abschrift des für das städtische Leben so wichtigen Beschlusses zu besorgen und diesen in Stein zu verewigen ${ }^{31}$. Diese Zeugnisse geben uns somit einen hervorragenden Einblick darin, wie ein Statthalter die Gemeinden seiner Provinz bei der Ehrung des Kaisers beeinflussen und ihnen entsprechende Wünsche mitteilen

\footnotetext{
${ }^{30}$ OGIS II 458; s. ferner die ausführlichen Editionen (unter Einschluss der lateinischen Teile) des Textes durch Robert K. Sherk, Roman Documents From the Greek East. Senatus consulta and epistulae to the Age of Augustus (Baltimore 1969) 328-337 Nr. 65 und insbesondere von Umberto Laffi, Le iscrizioni relative all'introduzione nel 9 a.C. del nuovo calendario della provincia d'Asia, in: SCO 16 (1967) 5-98. Zu einer vergleichbaren Publikationsanordnung s. das Edikt des Augustus über die Juden von Asia: Ios. ant. Iud. 16, 160-166. Zur lokalen Ausführung eines psēphisma des koinon s. auch GIBM IV 894; auf städtischer Ebene waren hierfür die Archonten zuständig.

${ }^{31}$ Eine weitere Abschrift aus Metropolis, die jedoch nur einen Teil des Dossiers enthielt, ist erst vor Kurzem vorgelegt worden: Boris Dreyer, Helmut Engelmann, Augustus und Germanicus im ionischen Metropolis, in: ZPE 158 (2006) 175-182. Die Inschriftenstele wurde im Hof des Vereinslokals der presbyteroi von Metropolis gefunden, mithin an einem eher privaten Ort, der nicht den Vorgaben der Publikationsanordnung entsprach. Ausgewählt wurden für die Übertragung in Stein gerade jene Passagen des Gesamtdossiers, die die glücksbringende Rolle des Augustus besonders deutlich hervortreten ließen - darauf kam es den Erstellern der Inschrift offenbar vor allem an. Der in den Stein gravierte Text bricht mitten im Satz ab, aber auch dies war offenbar so geplant.
} 
konnte. Ähnliches ist im Falle der Res gestae divi Augusti vorstellbar: Vom koinon von Galatia mag ebenfalls eine weitere Initiative zur Verbreitung des Textes in der Provinz ausgegangen sein, so wie in Asia der Provinziallandtag anordnete, dass das soeben erwähnte Kalenderdekret in den städtischen Kaisareia aufgestellt werden sollte. Die Entscheidung darüber, wie genau das hieraus entstehende epigraphische Monument auszusehen hatte, welche Sprache hierfür Verwendung finden sollte und in welchem Kontext es aufzurichten war, lag dann aber augenscheinlich weitgehend bei den lokalen Behörden, die hierfür unterschiedliche Vorkehrungen trafen.

Eine weitere in diesem Zusammenhang wichtige Textsorte waren Senatsbeschlüsse, die für das Kaiserhaus wichtige Vorgänge oder Ehrungen des Herrschers und seiner Familienmitglieder betrafen. An der Entstehung solcher senatus consulta hatte der Princeps oft mehr oder minder direkt mitgewirkt ${ }^{32}$, und ihr Inhalt trug erheblich zur Formung seines ,Images' bei. Zudem enthielten sie in der Regel eine Publikationsanweisung, so dass in diesem Falle der Verbreitungsprozess der Texte einigermaßen rekonstruiert werden kann. Ein gutes Beispiel hierfür stellen die durch den Tod des Germanicus im Oktober 19 n. Chr. ausgelösten Senatsbeschlüsse dar. Zunächst wurden im Dezember desselben Jahres - nach ausführlichen Beratungen des Senats mit dem regierenden Kaiser Tiberius - zwei senatus consulta verabschiedet, die die postumen Ehrungen für den verstorbenen Prinzen regelten. Dies war bereits seit Langem aus Tacitus bekannt ${ }^{33}$; inzwischen kennen wir aber auch mehrere inschriftliche Kopien dieser Beschlüsse, aus denen entnommen werden kann, welche Vorkehrungen der Senat (und damit indirekt auch der Kaiser) traf, damit der Text im gesamten Reich bekannt würde: Eine Kopie des $S C$ sollte auf einer Bronzetafel eingraviert und in Rom in der Portikus des Apollon-Tempels angebracht werden; weiterhin hatten die Konsuln den Text zusammen mit ihrem Edikt zu proponieren und Befehl zu geben, dass die (offenbar bereits in Rom anwesenden) Magistrate und Gesandten der municipia und coloniae in Italien sowie der Kolonien in den Provinzen eine Kopie des Textes in ihre Heimatstädte senden sollten ${ }^{34}$; und schließlich sollten die Provinzstatthalter den Text an einem möglichst prominenten Platz (d.h. vermutlich am Forum des jeweiligen Statthaltersitzes) anschlagen. Von einer Fixierung des Textes in Bronze ist in den letzteren Anweisungen allerdings nicht explizit die Rede. Kopien dieses $S C$ (bzw. eines aus mehreren Einzeldokumenten bestehenden Gesamtdossiers) auf Bronzetafeln haben sich in Rom, in Heba in Etrurien (tabula Hebana) sowie in der Kleinstadt Siarum in der südspa-

${ }^{32}$ Vgl. dazu die wichtigen Bemerkungen von Fergus Millar, Imperial Ideology in the tabula Siarensis, in: Julián González, Javier Arce (Hg.), Estudios sobre la tabula Siarensis. Actas de las Jornadas celebradas en Sevilla 1986 (Madrid 1988) 11-19, bes. 17. Zur (vereinzelten) Korrektur einer als übermäßig empfundenen Ehrung des Senates für Germanicus durch Tiberius s. Tac. ann. 2, 83, 3. Einen ähnlichen Vorgang schildert Cass. Dio 56, 47, 1 hinsichtlich der Ehrenbeschlüsse für den toten Augustus: Nominell habe diese der Senat gefasst, aber die eigentliche Entscheidung hätten Tiberius und Livia getroffen, an die die verschiedenen in der Senatsversammlung geäußerten Vorschläge in schriftlicher Form (biblia) geschickt wurden, damit sie daraus auswählen konnten.

${ }^{33}$ Tac. ann. 2, 83, 1f.

${ }^{34}$ Zur Nachrichtenübermittlung zwischen Rom und den Städten des Reiches vgl. Werner Eck, Zur Durchsetzung von Anordnungen und Entscheidungen in der hohen Kaiserzeit. Die administrative Informationsstruktur, in: Ders., Die Verwaltung des römischen Reiches in der hohen Kaiserzeit. Ausgewählte und erweiterte Beiträge, Bd. 1 (Basel 1995) 55-79, bes. 62, 66-68. Der hier geschilderte Fall stellte allerdings wohl eine Sondersituation dar, bedingt durch den Tod des Germanicus, weil wegen des Trauerfalles im Kaiserhaus viele Gemeinden ohnehin ihre Vertreter nach Rom entsandt hatten. Vertreter auswärtiger Städte in Rom sind aber auch in anderen Quellen bezeugt, etwa bei Ios. ant. Iud. 19, 291. Aus solchen Angaben kann man wohl erschließen, dass viele - jedoch mit Sicherheit nicht alle - Städte eine Art von dauerhafter Gesandtschaft in der Reichshauptstadt unterhielten und sich so die nötigen Informationen über wichtige Neuigkeiten, aber auch über routinemäßige Veränderungen etwa in der Kaisertitulatur (vgl. unten Anm. 251) verschafften. 
nischen Provinz Baetica (tabula Siarensis) gefunden ${ }^{35}$. Das Vorhandensein einer Kopie in Rom überrascht nicht, und auch Heba fällt - obwohl die Stadt eher unbedeutend war - als colonia in Italien unter die Publikationsanordnung des $S C$. Das gilt jedoch mit großer Sicherheit nicht für Siarum, denn in tiberischer Zeit war diese Gemeinde offenbar lediglich ein municipium ${ }^{36}$. Eine besondere Nahbeziehung zwischen Germanicus und der Baetica gab es im Übrigen nicht. Warum also die Anfertigung einer aufwändigen Bronzekopie des ihn betreffenden $S C$ in einer abgelegenen Provinzgemeinde, die hierzu augenscheinlich nicht verpflichtet war? Wir wissen es in diesem Fall nicht, aber die Entscheidung muss entweder auf lokaler Ebene getroffen worden oder aufgrund einer Initiative des Statthalters erfolgt sein.

Dass Letzterer hierbei erneut eine bedeutsame Rolle gespielt haben könnte, legt der nun zu beschreibende Vorgang nahe: Etwa ein Jahr später verurteilte der Senat den vermeintlichen Mörder des Germanicus, Cn. Calpurnius Piso, und verabschiedete hierzu - nachdem Piso durch Selbstmord aus dem Leben geschieden war - ein umfangreiches Konvolut von Beschlüssen, die gleichzeitig dazu dienten, den regierenden Kaiser Tiberius in panegyrischen Wendungen zu feiern. Erneut wurden Vorkehrungen getroffen, um diese für das Kaiserhaus wichtige Botschaft im Reich zu verbreiten. Eine Version derselben sollte, eingraviert in Bronze, in Rom an einem Platz errichtet werden, den der Kaiser selbst bestimmen konnte. Weitere Bronzekopien sollten in der wichtigsten Stadt einer jeden Provinz an deren zentralem Platz angebracht werden ${ }^{37}$. Die Kopien des Textes auf Bronzetafeln,

${ }^{35}$ Die Ehrenbeschlüsse des Senats für den toten Germanicus sind zusammen mit der zugehörigen rogatio in folgenden Kopien (jeweils in Ausschnitten) überliefert: CIL VI $911=31999=40348$ (Rom); AE 1949, 215 = AE 1952, 164 (Heba); CIL XI 4632 (bei Todi; dazu Michael H. Crawford, The End of the rogatio Valeria Aurelia, in: Augusto Fraschetti [Hg.], La commemorazione di Germanico nella documentazione epigrafica. Tabula Hebana e Tabula Siarensis; Convegno internazionale di studi Cassino 1991 [Rom 2000] 163-171); AE 1984, 508 (Siarum). Zusammenfassende Edition: Michael H. Crawford (Hg.), Roman Statutes, Bd. 1 (London 1996) 507-543 Nr. 37; vgl. ferner Alvaro Sánchez-Ostiz Gutiérrez, Tabula Siarensis. Edicíon, traducción y comentario (Pamplona 1999) sowie die Studie von Greg Rowe, Princes and Political Cultures. The New Tiberian Senatorial Decrees (Ann Arbor 2002). Dabei handelt es sich um ein Gesamtdossier, das zumindest das zweite senatus consultum vom Ende des Jahres 19 und die rogatio/lex von Anfang 20 umfasste. Ob auch das erste $S C$ vom 16. Dezember 19 hierin inkorporiert war, ist umstritten. Zu dem Publikationsvermerk, dessen genaue Form wir nur für das zweite $S C$ aus dem Jahre 19 kennen, der aber für das in den Kopien vorliegende Gesamtdossier ähnlich ausgesehen haben wird, vgl. Eck u.a., Senatus consultum 265 A. 864; Crawford, Roman Statutes 536; ferner Wolfgang D. Lebek, Sub edicto suo proponere. Tab. Siar. frg. II col. B 12 und Suet. Aug. 89, 2, in: ZPE 77 (1989) 39-41.

${ }^{36} \mathrm{Zu}$ Siarum vgl. Patrick Le Roux, Siarum et la tabula Siarensis. Statut politique et honneurs religieux en Bétique sous Tibère, in: Julián González, Javier Arce (Hg.), Estudios sobre la tabula Siarensis. Actas de las Jornadas celebradas en Sevilla 1986 (Madrid 1988) 21-33; Hartmut Galsterer, The tabula Siarensis and Augustan Municipalization in Baetica, in: ebd. 61-74. Beide vertreten die Meinung, dass Siarum in der frühen Kaiserzeit ein municipium (eventuell civium Romanorum) war und deswegen von der Publikationsanordnung des $S C$ nicht direkt erfasst wurde.

37 Wie ein solcher locus celeberrimus, an dem wichtige Nachrichten temporär angeschlagen und zentrale Dokumente auf Bronzetafeln für längere Zeit ausgestellt wurden, ausgesehen haben könnte, zeigt eine mit Verdübelungslöchern übersäte Wand am Rande des Hauptplatzes von Asisium (Assisi): Pierre Gros, Dinu Theodorescu, Le mur nord du ,forum 'd'Assise. Ornamentation pariétale et spécialisation des espaces, in: MEFRA 97 (1985) 879-896. Trotz des in solchen Inschriften mehrfach angesprochenen Hinweises, man solle die Tafeln so anbringen, dass sie „vom Boden aus gut gelesen werden könnten“, scheint es mir nicht sicher, dass dies wirklich ihre vorrangige Funktion war, denn die in winzigen Buchstaben aufgezeichneten und kompliziert formulierten Texte waren sicherlich nur einer kleineren Gruppe von Menschen direkt zugänglich (vgl. oben Anm. 10). Wichtiger dürfte es gewesen sein, dass ein Eingravieren in Bronze (in aes incidere) den Texten und damit den Worten des Herrschers oder den für ihn beschlossenen Ehrungen Dauer verlieh. Zudem waren solche 
die wir bislang kennen (es sind mittlerweile mindestens acht) ${ }^{38}$, wurden jedoch alle in einer einzigen Provinz, nämlich der Baetica, gefunden; und sie stammen darüber hinaus auch nicht (wie im Publikationsvermerk vorgesehen) aus der Provinzhauptstadt Corduba (Córdoba), sondern aus kleineren und teilweise ganz unbedeutenden Gemeinden. Auf einer der Kopien ist dem Text des $S C$ ein Titel vorangestellt, der darauf hinweist, dass offenbar der Provinzstatthalter der Baetica, N. Vibius Serenus, eine entscheidende Rolle dabei gespielt hat, dass der Text in seiner Provinz nicht nur an seinem Residenzort, sondern auch in zahlreichen weiteren Gemeinden in Bronze graviert wurde ${ }^{39}$. Die Initiative einzelner Provinzgouverneure im Zusammenspiel mit den lokalen Behörden scheint also für die Frage, wann und wo solche aus Rom kommenden Texte eine inschriftliche Fassung in dauerhaftem Material erhielten, sehr bedeutsam gewesen zu sein, was wiederum die sehr ungleichmäßige regionale Verteilung der erhaltenen Abschriften der Res gestae divi Augusti oder des $S C$ de Cn. Pisone patre zu erklären vermag.

Bisweilen verfasste der Kaiser auch selbst eine Anordnung, um die reichsweite Verbreitung eines $S C$ zu befördern, dessen Inhalt ihm wichtig erschien. Ein Beispiel hierfür bietet eine auf der Agora von Kyrene gefundene Stele, die mehrere Edikte des Augustus und ein $S C$ des Jahres 4 v. Chr. enthält ${ }^{40}$. Letzterem geht ein Edikt des Kaisers voran, in dem dieser sagt, er habe den Text zur besseren Kenntnis der Untertanen in alle Provinzen versenden und seinem Schreiben anfügen lassen. Aber selbst mit einer solchen, an sich recht klaren Regelung konnte (und wollte) der Kaiser nicht festlegen, wann und in welcher Form ein Text dieser Art in den einzelnen Städten des Reiches in ein dauerhaftes Material übertragen und damit für die Nachwelt bewahrt wurde (falls dies überhaupt geschah). Die Entscheidung hierüber wurde wiederum vornehmlich auf provinzialer und lokaler Ebene getroffen.

Ähnliches lässt sich in Bezug auf die inschriftliche Verewigung kaiserlicher Reden feststellen, wofür wir nur wenige Zeugnisse besitzen. Das bekannteste unter diesen ist wohl die von Kaiser Claudius im Jahr 48 vor dem Senat gehaltene Rede über das ius honorum der gallischen Aristokraten, die uns sowohl durch den Bericht des Tacitus ${ }^{41}$ als auch durch eine Abschrift auf einer

Bronzetafeln visuell eindrucksvolle Monumente, die jedem Besucher des Platzes sofort ins Auge fallen mussten und denen dadurch eine eigene, gleichsam magische Kraft innewohnte; vgl. zu diesen Aspekten Mary Beard, Writing and Ritual, in: PBSR 53 (1985) 114-162; Callie Williamson, Monuments of Bronze. Roman Legal Documents on Bronze Tablets, in: ClAnt 6 (1987) 160-183.

${ }^{38} \mathrm{Vgl}$. Armin U. Stylow, Sebastian Corzo Pérez, Eine neue Kopie des senatus consultum de Cn. Pisone patre, in: Chiron 29 (1999) 23-28.

${ }^{39}$ Kopie A: S(enatus) c(onsultum) de Cn(aeo) Pisone patre propositum N(umerio) Vibio Sereno proco(n)s(ule); s. ferner $\mathrm{CIL} \mathrm{II}^{2} / 5,64$. Vgl. zu den einzelnen Kopien ausführlich Eck u.a., Senatus consultum 1-37. Zu dem Publikationsvermerk (Z.165-172) vgl. ebd. 254-272; zu der Frage, warum gerade in der Baetica so viele Abschriften dieses $S C$ auch in ganz kleinen Gemeinden angefertigt wurden und welche Rolle der Prokonsul dabei gespielt haben könnte, vgl. ebd. 126-130, 279-287 sowie Werner Eck, Das S.C. de Cn. Pisone patre und seine Publikation in der Baetica, in: CCG 4 (1993) 189-208.

${ }^{40}$ Fernand De Visscher, Les édits d'Auguste découverts à Cyrene (Louvain, Paris 1940) = Oliver, Constitutions Nr. 8-12.

${ }^{41}$ Tac. ann. 11, 23-25. Hier bietet sich - wie auch im Falle der Vorgänge, die den Tod des Germanicus begleiteten - die relativ seltene Gelegenheit, die Berichte der literarischen Quellen mit den Aussagen der ausführlichen epigraphischen Zeugnisse vergleichen zu können, wobei die unterschiedlichen Perspektiven und die dadurch jeweils bewirkten Umformungen des historischen Geschehens deutlich werden: Miriam Griffin, The Lyons Tablet and Tacitean Hindsight, in: CQ 32 (1982) 404-418; Eck u.a., Senatus consultum 109-121, 289-298; Anthony J. Woodman, Ronald H. Martin, The Annals of Tacitus, Book 3 (Cambridge 1996) 67-77, 110-118; vgl. ferner Ralf Urban, Tacitus und die Res gestae divi Augusti. Die Auseinandersetzung des Historikers mit der offiziellen 
Bronzetafel bekannt ist, welche im provinzialen Kaiserkult-Heiligtum der Tres Galliae in Condate bei Lugdunum (Lyon) gefunden wurde ${ }^{42}$. Die Verewigung der Rede in Bronze ging daher wohl auf den Wunsch der Provinzialen zurück, die für sie positiven Aussagen des Kaisers für die Nachwelt zu bewahren. Angeregt worden war diese Angelegenheit vermutlich durch eine Gesandtschaft des gallischen Provinziallandtages, die Claudius um die Aufnahme verdienter Notabler aus den eigenen Reihen in den Senatorenstand gebeten hatte und dann den Text seiner Rede nach Gallien zurückbrachte. Ebenfalls epigraphisch überliefert ist die Rede, die Kaiser Nero im Winter 67 (oder 66) bei den Isthmischen Spielen vor den versammelten Griechen der Provinz Achaia hielt, um ihnen die Freiheit zu verkünden. In diesem Falle ist sehr deutlich eine lokale Initiative für die inschriftliche Fassung der Rede auszumachen. Entdeckt wurde die Inschriftenstele in der kleinen böotischen Stadt Akraiphia. Sie enthält das Edikt des Nero, mit dem er die Griechen zusammenrief, seine Ansprache im Wortlaut sowie ein Dekret der Gemeinde, in dem diese eine kultische Verehrung für den Herrscher beschloss ${ }^{43}$. Antragsteller war der lokale Kaiserkultpriester Epameinondas, der in seiner Heimatstadt als Euerget und Förderer des Herrscherkults eine herausragende Position einnahm und bereits früher einer Gesandtschaft zu Kaiser Caligula angehört hatte; er scheint somit auch hier die treibende Kraft gewesen zu sein ${ }^{44}$. Die Ansprache, die Kaiser Hadrian im Sommer 128 im numidischen Lambaesis vor den afrikanischen Truppen hielt, ist ebenfalls inschriftlich überliefert, und zwar eingraviert auf den seitlichen Pfeilern einer Plattform, die sich auf dem Paradeplatz (campus) der legio III Augusta in Lambaesis erhob. Dem Text der Kaiserrede ist (auf einer separaten, zwischen den Pfeilern angebrachten Marmortafel) eine Dedikation beigegeben, aus der hervorgeht, dass die Legion das gesamte Monument dem Kaiser Hadrian widmete, nachdem dieser Lager und Heer inspiziert hatte ${ }^{45}$.

In noch höherem Maße gilt das soeben Ausgeführte für administrative Schreiben, die vom Kaiser entweder an die gesamte Reichsbevölkerung oder - in der Mehrzahl der Fälle - an bestimmte Mitglieder der Provinzialverwaltung, einzelne Gemeinden oder Privatpersonen gerichtet wurden. Hiermit sind im Wesentlichen edicta, mandata, epistulae und subscriptiones gemeint, die nicht nur - oft routinemäßige - Regelungen enthielten, sondern in ihren Formulierungen häufig auch etwas vom Selbstverständnis des Herrschers vermitteln sollten. Die Zahl solcher in Inschriften erhaltenen Dokumente hat sich in den letzten Jahren durch Neufunde merklich erhöht ${ }^{46}$, was den Eindruck

Darstellung, in: Gymnasium 86 (1979) 59-74; Ronald Syme, Tacitus. Some Sources of his Information, in: Ders., Roman Papers, Bd.4 (Oxford 1988) 199-222.

${ }^{42}$ CIL XIII 1668 = ILS 212; dazu zuletzt Werner Rieß, Die Rede des Claudius über das ius honorum der gallischen Notablen. Forschungsstand und Perspektiven, in: REA 105 (2003) 211-249. Zu dem Heiligtum der Tres Galliae vgl. unten Anm. 179.

${ }^{43}$ IG VII $2713=$ Syll. $^{3} 814=$ ILS $8794=$ Oliver, Constitutions Nr. 296.

${ }^{44} \mathrm{Zu}$ Epameinondas s. IG VII 2711/12 sowie James H. Oliver, Epaminondas of Acraephia, in: GRBS 12 (1971) 221-237; Eftychia Stavrianopoulou, Die Bewirtung des Volkes. Öffentliche Speisungen in der römischen Kaiserzeit, in: Olivier Hekster u.a. (Hg.), Ritual Dynamics and Religious Change in the Roman Empire (Leiden, Boston 2009) 159-183.

${ }^{45}$ Michael P. Speidel, Emperor Hadrian's Speeches to the African Army - a New Text (Mainz 2006).

${ }^{46}$ So ist in Alexandreia Troas vor Kurzem eine große marmorne Stele entdeckt worden, auf der drei Briefe des Kaisers Hadrian aufgezeichnet wurden, die dieser alle im Jahr 134 an die Vereinigung der dionysischen Techniten gerichtet hatte und die sehr detaillierte Regelungen für bestimmte Wettkämpfe enthielten, wobei hier auch auf zahlreiche weitere - nicht erhaltene - kaiserliche Schreiben in derselben Angelegenheit verwiesen wird: Georg Petzl, Elmar Schwertheim, Hadrian und die dionysischen Künstler. Drei in Alexandreia Troas neugefundene Briefe des Kaisers an die Künstler-Vereinigung (Bonn 2006). Vgl. ferner Christopher P. Jones, A Letter of Hadrian to Naryha in Eastern Locris, in: JRA 19 (2006) 151-162. Aus Kos stammt ein soeben pub- 
verstärkt, dass Schreiben dieser Art, die sich teilweise mit recht kleinteiligen Angelegenheiten beschäftigten, am Kaiserhof in großen Mengen ausgestellt worden sein müssen ${ }^{47}$. Das wiederum wirft die - hier nicht weiter zu behandelnde - Frage auf, inwieweit der Herrscher tatsächlich selbst an der Abfassung dieser Dokumente beteiligt war (und wir in ihnen somit die eigentümliche Diktion des jeweiligen Princeps lesen können) und welche Rolle hierbei die kaiserlichen Kanzleien spielten, die viele solcher Schreiben im Namen des Kaisers verfassten und ihm diese dann nur noch zur Begutachtung vorlegten - Letzteres dürfte über weite Strecken der Normalfall gewesen $\operatorname{sein}^{48}$. Im Folgenden soll es aber vor allem darum gehen, wie aus solchen Schriftstücken epigraphische Monumente wurden und wer dafür verantwortlich zeichnete.

Die meisten dieser Dokumente enthielten offenbar keine explizite Publikationsanordnung. Sie erreichten ihre Empfänger in der Regel als Schreiben auf Papyrus, und zu ihrer Bekanntmachung scheint es zumeist ausgereicht zu haben, sie der Bevölkerung - etwa im Theater - vorzulesen ${ }^{49}$ und dann an einem öffentlichen Platz für einen bestimmten Zeitraum auszustellen, bevor sie ins Archiv wanderten. Proponiert werden konnte ein solches Schreiben entweder in seiner originalen PapyrusForm oder in einer Abschrift auf geweißten Holztafeln (tabulae dealbatae oder leukömata) ${ }^{50}$. Der Entschluss, ein solches Schriftstück in ein dauerhaftes Material zu übertragen - was recht teuer sein konnte - war kein notwendig hierauf folgender Schritt, sondern hing wesentlich von den lokalen Gegebenheiten ab. Zweck dieser Maßnahme war es in der Regel, wohlwollende Worte des Herrschers einem breiteren Publikum in einer entsprechend aufwändigen Gestaltung zu präsentieren oder eine positive Entscheidung des Princeps bzw. die Bestätigung bestimmter Privilegien für die Nachwelt zu bewahren.

liziertes Dossier mit mehreren Briefen (aus den Jahren 47-48) des Kaisers Claudius (und anderer Personen?), die die herausragende lokale Figur des C. Stertinius Xenophon, des Leibarztes des Claudius (zu diesem s. unten Anm. 66), betrafen: Dimitris Bosnakis, Klaus Hallof, Alte und neue Inschriften aus Kos III, in: Chiron 38 (2008) 205-224 Nr. 25-29.

${ }^{47}$ Insgesamt ist davon auszugehen, dass in der Umgebung des Kaisers oder durch diesen selbst in einem beständigen Rhythmus eine enorme Menge von Einzelfall- oder Generalentscheidungen getroffen wurde, welche wiederum zu einem großen Teil verschriftlicht, d.h. auf Papyrus oder ähnlichem Schreibstoff aufgezeichnet wurden. Nur ein kleinerer Teil dieser Schriftstücke dürfte aber aus den im Folgenden zu beschreibenden Gründen in ein dauerhaftes Material übertragen worden sein; und nur diesen - durch einen Selektionsprozess entstandenen Ausschnitt haben wir als Quellenmaterial vor Augen.

${ }^{48} \mathrm{Zu}$ der Diskussion, wer letztlich den Wortlaut der kaiserlichen Schreiben festlegte, vgl. bezüglich der epistulae Adrian N. Sherwin-White, Trajan's Replies to Pliny. Authorship and Necessity, in: JRS 52 (1962) 114-125 sowie Wynne Williams, Individuality in the Imperial Constitutions. Hadrian and the Antonines, in: JRS 66 (1976) 67-83; ders., Caracalla and the Authorship of Imperial Edicts and Epistles, in: Latomus 38 (1979) 67-89, der die Hauptverantwortung für die Formulierung der kaiserlichen Schriftstücke beim Herrscher selbst sieht; dagegen Naphtali Lewis, Personal Style or Imperial Style?, in: Latomus 54 (1995) 634-641. Zu den subscriptiones vgl. Wynne Williams, Epigraphic Texts of Imperial Subscripts. A Survey, in: ZPE 66 (1986) 181-207; William Turpin, Imperial Subscriptions and the Administration of Justice, in: JRS 81 (1991) 101-118; Tony Honoré, Emperors and Lawyers (London ${ }^{2} 1994$ ); Jean-Louis Mourgues, Les formules rescripsi recognovi et les étapes de la rédaction des souscriptions impériales sous le Haut-Empire romain, in: MEFRA 107 (1995) 255-300. Vgl. ferner die vermittelnde Position von Fergus Millar, L’Empereur romain comme décideur, in: CCG 1 (1990) 207-220.

${ }^{49}$ So wird etwa zu dem Brief des Domitian am Ende der lex Irnitana (s. Julián González, The lex Irnitana. A New Copy of the Flavian Municipal Law, in: JRS 76 [1986] 147-243) vermerkt, er sei am 10. April 91 in Circeii, wo sich der Kaiser gerade aufhielt, ausgegeben (litterae datae) und dann am 11. Oktober desselben Jahres in Irni verlesen (recitatae) worden.

${ }^{50}$ S. oben Anm. 7. 
Man kann dies gut am Beispiel kaiserlicher Briefe (epistulae) demonstrieren, die an hochrangige Persönlichkeiten oder Gemeinden gerichtet waren. Diese Schreiben betrafen oft eher unbedeutende Angelegenheiten, für die die Herrscher bisweilen sehr detaillierte Regelungen trafen. Andere Briefe waren rein routinemäßiger Natur: In ihnen wurden beispielsweise Beschlüsse der lokalen Behörden bezüglich des Kaiserkults bestätigt oder herausragende Bürger der Provinzgemeinden gelobt. In den meisten Fällen wurden solche kaiserlichen Schreiben durch Anfragen von unten angeregt, etwa durch Gesandtschaften von Städten, die dem Herrscher munizipale Dekrete überreichten und von ihm eine Antwort darauf erbaten. Fiel diese positiv aus, konnten die lokalen Behörden entscheiden, eine Aufzeichnung des Texts in Bronze oder Stein vorzunehmen. Gut zu verfolgen ist dieser Vorgang an einem Brief des Vespasian an die Stadt Sabora (Baetica) aus dem Jahr $77^{51}$. Diese hatte den Kaiser darum gebeten, die Siedlung vom Berg in die Ebene verlegen zu dürfen; außerdem ersuchte sie um die Bestätigung finanzieller Vorteile, die sie bereits von Augustus erhalten hatte. Der Kaiser gewährte beides und schrieb am Ende seines Briefes: decretum vestrum accepi VIII kal(endas) August(as) [25.Juli]; legatos dimisi IIII kal(endas) easdem [29. Juli]; diese Gesandten brachten dann offenbar das kaiserliche Schreiben nach Sabora. Nach der Schlussformel valete folgt ein Zusatz, der sich auf die lokalen Verhältnisse bezieht: IIviri C. Cornelius Severus et M. Septimius Severus publica pecunia in aere inciderunt.

Im Gegenzug wurden für den Empfänger negative kaiserliche Mitteilungen zumeist nicht in dauerhafte Materialien übertragen. Es gibt zwar einige wenige Ausnahmen hiervon, aber diese bestätigen dann doch wieder die Regel. So fand sich am Forum der baetischen Gemeinde Munigua eine Bronzetafel mit einem Brief des Kaisers Titus aus dem Jahr 7952: Die Muniguenser hatten in einem Rechtsstreit an den Kaiser appelliert, jedoch den Prozess erneut verloren. Der Kaiser stellte nun fest, dass die Appellation iniusta gewesen war und daher eigentlich hätte bestraft werden müssen; er sah aber aufgrund seiner indulgentia von der Strafe ab und befreite die Muniguenser sogar von den Verzugszinsen, warf ihnen jedoch ihre temeritas vor. Der kaiserliche Gunsterweis scheint den Behörden von Munigua aber so wichtig gewesen zu sein, dass sie sich trotz des wenig freundlichen Tonfalls gerade zu Beginn des Briefes dennoch zu einer Aufzeichnung desselben in Bronze entschlossen.

Auch in Fragen des Kaiserkults fielen die kaiserlichen Antwortschreiben oft nicht rein zustimmend aus, denn es gehörte zu der vom Herrscher in bestimmten Kreisen erwarteten moderatio, ihm angetragene göttliche Ehrungen abzulehnen oder zumindest zu modifizieren. Anschaulich wird dies in einer umfangreichen Inschrift aus der Stadt Gytheion in Lakonien ${ }^{53}$. Sie enthält neben einem Beschluss der Gemeinde über die kultischen Ehren für Augustus, Tiberius und Livia einen Brief des regierenden Kaisers Tiberius an die Oberbeamten der Stadt. Dieser war als Reaktion auf eine Gesandtschaft verfasst worden, die den Kaiser und seine Mutter aufgesucht hatte, um ihnen die vorläufigen Beschlüsse der Bewohner von Gytheion hinsichtlich der Verehrung des Kaiserhauses zu übermitteln. Tiberius belobigte die Gemeinde zunächst vor allem in Bezug auf die kultischen Einrichtungen für Augustus, merkte dann aber an, dass er selbst sich mit maßvolleren und mensch-

${ }^{51} \mathrm{CIL} \mathrm{II}^{2} / 5,871=$ CIL II $1423=$ ILS 6092.

52 AE 1962, 288 = CILA II 4, 1052; dazu Herbert Nesselhauf, Zwei Bronzeurkunden aus Munigua, in: MDAI(M) 1 (1960) 148-154.

${ }^{53}$ SEG 11, 2 (1954) 922/23 = Oliver, Constitutions Nr. 15. Ein weiteres Beispiel bietet ein Schreiben der Kaiser Marc Aurel und Commodus an die Gerusia von Athen, in dem ebenfalls in den Augen der Herrscher zu weit gehende, göttliche Ehrungen (darunter Bildnisse aus Edelmetall) zurückgewiesen werden: Oliver, Constitutions Nr. 196. Vgl. ferner unten Anm. 235. 
licheren Ehren begnügen wolle. Das anfängliche Lob des Kaisers reichte auch hier aus, um den Wortlaut des gesamten Briefes einschließlich der ablehnenden Passagen auf Stein zu verewigen.

Deutlich wird dies ferner bei einigen kaiserlichen Antworten (subscriptiones) auf Bittschriften (libelli), die sozial niedriger stehende Bevölkerungsgruppen an den Kaiser richteten ${ }^{54}$. Solche Bittgesuche auf Papyrus mussten in der Regel persönlich beim Herrscher eingereicht werden, der dann seine Antwort direkt darunter schreiben und diese in Rom aushängen ließ, wovon sich die betroffene Partei wiederum eine Abschrift anfertigen lassen konnte, um diese in die Heimat mitzunehmen. Die kaiserlichen Antworten fielen meist sehr kurz aus und hatten oft einen eher banalen Inhalt. Recht häufig nämlich delegierte der Princeps die gesamte Angelegenheit an untergeordnete Behörden der Provinzialverwaltung, ohne selbst eine Entscheidung zu fällen. Dennoch genügte offenbar bisweilen alleine die Tatsache eines solchermaßen erwirkten Bescheides des Princeps, dessen Wort mehr galt als das jeder anderen Person im Reich, um die Empfänger dazu zu bewegen, den Schriftverkehr mit dem Herrscher in einem dauerhaften Material aufzuzeichnen und in dieser Form der Öffentlichkeit zu präsentieren. Einen schönen Beleg hierfür bietet eine große Inschriftentafel aus der Gemeinde Skaptopara in der Provinz Thracia, die mehrere Schriftstücke enthält ${ }^{55}$ : Zunächst eine Überschrift in Latein, die berichtet, dass es sich um eine beglaubigte Abschrift aus dem Amtsbuch der Bittschriften und Antwortschreiben des Kaisers Gordianus III. handelte, welche in Rom in den Portiken der Trajansthermen angeschlagen wurden, sowie einen Vermerk, wer den libellus eingereicht hatte. Darauf folgt auf Griechisch in mehreren Kolumnen das sehr ausführliche Bittgesuch der Einwohner von Skaptopara (und ein weiteres Schriftstück). Am unteren Rand des Steines wurde schließlich - wiederum auf Latein - die kaiserliche Antwort eingraviert. Diese fiel in der Sache eher ernüchternd aus, denn der Herrscher erklärte sich für nicht direkt zuständig und verwies die Angelegenheit an das Gericht des Provinzstatthalters. Aber das bloße Vorhandensein eines kaiserlichen Bescheides war den Bürgern von Skaptopara offenbar wichtig genug, um ihn zusammen mit dem gesamten Schriftverkehr in Stein aufzuzeichnen und dadurch die "göttlichen“ Worte des Herrschers ${ }^{56}$ für alle sichtbar und erfahrbar zu machen ${ }^{57}$. Anfügen lässt sich an dieser Stelle noch, dass eine solche Dokumentationspraxis nach Ausweis der erhaltenen Inschriften gerade

${ }^{54}$ Vgl. hierzu zusammenfassend Tor Hauken, Petition and Response. An Epigraphic Study of Petitions to Roman Emperors, 181-249 (Bergen 1998).

${ }^{55}$ IGBulg IV 2236; dazu Klaus Hallof, Die Inschrift von Skaptopara. Neue Dokumente und neue Lesungen, in: Chiron 24 (1994) 405-441; Hauken, Petition (wie Anm. 54) 74-139 Nr. 5.

${ }^{56}$ Anführen lassen sich in diesem Zusammenhang auch die Kopien (exempla) einer Mitteilung des Septimius Severus und des Caracalla, von der sich in der Provinz Asia mehrere Abschriften (sowohl in Latein wie auch in Griechisch) auf Stein an verschiedenen Orten erhalten haben. In ihrer Anordnung, die in den Inschriften vermutlich von deren Herstellern - als sacrae litterae bzw. hiera grammata bezeichnet wird, verweisen die Kaiser auf ein (älteres) senatus consultum, das die Senatoren von der Pflicht zur Einquartierung von hospites befreite. Der Empfänger des kaiserlichen Schreibens wird nicht genannt (wahrscheinlich handelte es sich dabei um einen Beamten der Provinzialverwaltung); die inschriftliche Aufzeichnung des Schriftstücks erfolgte somit offensichtlich auf Initiative der direkt Betroffenen, d.h. der in diesem Raum ansässigen Senatoren, die durch den in dauerhaftem Material fixierten Verweis auf die Worte der Herrscher unliebsame Gäste von ihren Gütern fernzuhalten versuchten. Vgl. dazu Thomas Drew-Bear u.a., Sacrae litterae, in: Chiron 7 (1977) 355-383. In der Inschrift, die die coloni des saltus Burunitanus in der Provinz Africa durch ihren magister C. Iulius Pelops errichten ließen, um ihre Position in den Auseinandersetzungen mit dem conductor und Teilen der Provinzialverwaltung durch die Publikation verschiedener Schriftstücke zu dokumentieren (CIL VIII 10570 = 14464 = ILS 6870; Hauken, Petition [wie Anm. 54] 2-28 Nr. 1; vgl. ferner oben Anm. 21), wird die ebenfalls auf dem Stein festgehaltene subscriptio des Kaisers Commodus von den Betroffenen selbst, aber auch von einem kaiserlichen procurator verschiedentlich als sacrum rescriptum, divina subscriptio oder sacra subscriptio bezeichnet. 
im frühen 3. Jahrhundert häufiger wurde und sich in bestimmten Gebieten konzentriert findet, was auf einen gewissen Nachahmungseffekt und auf einen Wandel im epigraphic habit hindeutet, der dazu führte, dass nun auch kleinere Gemeinden damit begannen, einigermaßen positive Antworten des Herrschers in aufwändige epigraphische Monumente umzusetzen ${ }^{58}$.

Im Gegensatz hierzu wurde die explizite kaiserliche Zurückweisung einer Anfrage praktisch niemals vom Empfänger selbst in ein dauerhaftes Material übertragen. Solche negativen Mitteilungen des Herrschers - die nicht selten vorgekommen sein werden - sind uns darum inschriftlich nur in geringer Zahl überliefert. Dass wir dennoch einige von ihnen kennen, verdanken wir dem interessanten Phänomen, dass sie an entfernteren Orten abgeschrieben wurden, wo die Bevölkerung ein Interesse daran hatte, eine kaiserliche Regelung für die Nachwelt zu bewahren, die zwar einer anderen Gemeinde zum Nachteil gereichte, aber vorteilhafte Formulierungen für die eigene Sache enthielt. Ein Beispiel hierfür mag genügen: Zwischen 27 und 20 v. Chr. hatten die Bewohner von Samos bei Augustus durch einen libellus angefragt, ob er ihnen die Freiheit gewähren könne. In seiner subscriptio lehnte der Herrscher das mit dem Hinweis ab, er habe dieses rare Privileg nur den besonders treuen Einwohnern von Aphrodisias verliehen. Die kaiserliche Antwort wurde mit großer Sicherheit in Samos nicht in einem dauerhaften Material publiziert ${ }^{59}$, aber wir kennen sie dennoch, weil nämlich die Bürger von Aphrodisias diese Mitteilung, die ein großes Lob des Herrschers für sie selbst enthielt, für bedeutsam genug erachteten, um sie über 200 Jahre später in die Sammlung der für die Stadtgeschichte wichtigsten Dokumente aufzunehmen, die auf einer Seitenwand des Bühnengebäudes im städtischen Theater eingeschrieben wurden ${ }^{60}$.

Drei wichtige Folgerungen ergeben sich aus diesen Beobachtungen: Zunächst ist anzumerken, dass es auch für andere Parteien als die direkt beteiligten möglich gewesen sein muss, Kopien der kaiserlichen Schreiben in die Hände zu bekommen, obwohl wir oft nicht genau wissen, wie das im Einzelnen vor sich ging ${ }^{61}$. Zum zweiten: Dokumente dieser Art, die auf Papyrus geschrieben waren, blieben offenbar teilweise für viele Jahre in städtischen oder privaten Archiven liegen, bevor sich jemand dazu entschloss, sie in Stein einzugravieren. Letzteres geschah oft in Form von Dossiers, die

${ }^{57}$ Die Einwohner von Skaptopara hatten übrigens in ihrer Eingabe den Herrscher selbst gebeten, er möge befehlen, „dass Dein göttliches Schreiben auf einer Stele aufgezeichnet und öffentlich aufgestellt werden solle" (Z.102-104). Das kaiserliche Antwortschreiben enthielt dann zwar keine solche Anordnung, aber die Publikation auf Stein wurde dennoch ausgeführt und war somit wohl vor Ort schon von Anfang an beabsichtigt. ${ }^{58} \mathrm{Vgl}$. die in diese Richtung zielende, m.E. überzeugende Interpretation der Zeugnisse durch Walter Scheidel, Dokument und Kontext. Aspekte der historischen Interpretation epigraphischer Quellen am Beispiel der ,Krise des dritten Jahrhunderts', in: RSA 21 (1991) 145-164, der sich gegen die Deutung von Peter Herrmann, Hilferufe aus römischen Provinzen. Ein Aspekt der Krise des römischen Reiches im 3. Jahrhundert n. Chr. (Hamburg 1990) wendet; vgl. ferner Christian Witschel, Krise - Rezession - Stagnation? Der Westen des römischen Reiches im 3. Jahrhundert n. Chr. (Frankfurt am Main 1999) 60-62.

${ }^{59}$ Obwohl der Text Eingang in die Neuedition der Inschriften von Samos gefunden hat; s. IG XII 6, 1, 160.

${ }^{60}$ Joyce Reynolds, Aphrodiasias and Rome (London 1982) Dok. $13=$ Oliver, Constitutions Nr. 1.

${ }^{61}$ Vgl. etwa einen Brief des Kaisers Antoninus Pius an die Stadt Berenike, der in einer Zusammenfassung der wichtigsten Punkte auf einem Marmorblock - im Rahmen eines Dossiers von Kaiserbriefen - in Kyrene aufgezeichnet wurde, und zwar offensichtlich deswegen, weil er eine ablehnende Stellungnahme des Kaisers zur Aufnahme von Berenike unter die conventus-Städte der Provinz Creta et Cyrenae wiedergab und dadurch ein Privileg von Kyrene bestätigte. Derselbe Stein enthält einen weiteren Brief des Antoninus Pius aus dem Jahr 153/54 an Ptolemais, der in Kyrene deswegen in vollem Wortlaut eingraviert wurde, weil er die Ablehnung eines eigenen Agon in Ptolemais anstatt des provinzweiten, in Kyrene gefeierten zum Inhalt hatte. Vgl. Joyce Reynolds, Hadrian, Antoninus Pius and the Cyrenaican Cities, in: JRS 68 (1978) 111-121 = Oliver, Constitutions Nr. $122 / 23$. 
mehrere kaiserliche Schriftstücke aus unterschiedlichen Perioden zusammenfassten - im Fall der ,Archivwand' von Aphrodisias reicht die zeitliche Spanne bei den in Stein gravierten Dokumenten von etwa 40 v. Chr. bis in die Regierungszeit des Severus Alexander ${ }^{62}$. Die hier aufgezeichneten Dokumente repräsentierten aber sicherlich nicht alle offiziellen Schreiben, die in Aphrodisias vorhanden waren, sondern spiegelten eine bewusste Selektion durch die lokalen Behörden wider. Neben solchen städtischen Unternehmungen kennen wir auch eine ganze Reihe von Dossiers, die aufgrund der Initiative von Einzelpersonen zusammengestellt und in Stein übertragen wurden, um deren Leistungen zu verewigen. Beispiele für dieses Phänomen sind etwa das sogenannte ,Potamoneion', ein Monument zu Ehren des hervorragenden Bürgers Potamon von Mytilene auf Lesbos ${ }^{63}$; eine Stele mit städtischen Dekreten und einem Brief des Augustus zu Ehren des Menogenes von Sardis ${ }^{64}$; ein Stein mit einer Reihe von Schriftstücken (darunter ein Brief des Kaisers Caligula) mit Hinweisen auf die herausragenden Leistungen des Epameinondas von Akraiphia ${ }^{65}$; ein vor Kurzem publiziertes Dossier von Briefen des Kaisers Claudius aus Kos mit Bezug auf den herausragenden Bürger C. Stertinius Xenophon ${ }^{66}$; und das wohl spektakulärste Monument unter diesen, das Mausoleum des Opramoas von Rhodiapolis in Lykien, auf dem nicht weniger als 70 Dokumente eingeschrieben wurden, darunter zwölf Briefe des Antoninus Pius, die Opramoas priesen ${ }^{67}$. Offensichtlich wurde die Auswahl der aufzuzeichnenden Dokumente in diesen Fällen im Wesentlichen von dem betroffe-

\footnotetext{
${ }^{62}$ Auf der ,Archivwand' im Theater von Aphrodisias wurden zahlreiche Kaiserbriefe und sonstige Schriftstücke, die in einem Zeitraum von der Triumviratszeit bis in das mittlere 3. Jahrhundert entstanden waren, eingeschrieben; dazu Reynolds, Aphrodiasias (wie Anm.60) passim. Die Briefe waren nicht alle an die Aphrodisier gerichtet: Dok. 10 ist ein Privatbrief Octavians an einen Mann namens Stephanos (wohl ein Beauftragter des Marcus Antonius), in dem ein Bürger von Aphrodisias besonders lobend hervorgehoben wird; Dok. 12 ein Brief des Octavian an Ephesos mit der Aufforderung zur Rückgabe gestohlener Güter an Aphrodisias; Dok. 13 die subscriptio an die Samier (s. oben Anm.60). Die Aphrodisier müssen wohl jeweils Abschriften dieser Dokumente, die in gewissem Maße auch sie betrafen, erhalten haben.

${ }^{63}$ Vgl. Guy Labarre, Les cités de Lesbos aux époques hellénistique et impériale (Paris 1996) 109-115. Trotz des fragmentarischen Zustands des Monuments ist erkennbar, dass hier unter anderem - und an prominenter Stelle - Gesandtschaften zu Caesar und Augustus kommemoriert wurden, an denen Potamon teilgenommen hatte, um Privilegien für seine Heimatstadt zu erreichen.

${ }^{64}$ S. unten Anm. 86. Ein ähnliches, sehr fragmentarisch erhaltenes Dossier, das offenbar Schriftstücke zusammenfasste, die mit einer Gesandtschaft der Milesier zu Kaiser Trajan im Winter 99/100 zusammenhingen, ist vor Kurzem vorgelegt worden: Norbert Ehrhardt, Peter Weiß, Trajan, Didyma und Milet. Neue Fragmente von Kaiserbriefen und ihr Kontext, in: Chiron 25 (1995) 315-355. Anzufügen ist ein weiteres vergleichbares Dokument, nämlich ein Block aus Hadrianopolis Stratonikeia mit drei Briefen des Kaisers Hadrian aus dem Jahr 127 (Oliver, Constitutions Nr.79-81). In diesen Briefen wird - neben anderen Dingen - auf die Rolle eines Bürgers namens Claudius Candidus Iulianus verwiesen, der im Frühjahr 127 eine städtische Gesandtschaft zu Hadrian angeführt und die kaiserlichen Briefe nach Stratonikeia zurückgebracht sowie dort dem Archon in der Volksversammlung übergeben hatte. In dem dritten Brief erwähnt Hadrian ein ihm vorgelegtes Dekret der Stadt, in dem Candidus belobigt worden war - die Zusammenstellung und inschriftliche Fixierung des Dossiers ging somit vermutlich auf die Initiative dieses Mannes zurück. Ausgeführt wurde sie aber unter der Obhut von städtischen Aufsehern, wie ein Nachsatz zu dem letzten Brief beweist.

${ }^{65}$ IG VII 2711 = Oliver, Constitutions Nr. 18; zu Epameinondas s. oben Anm. 44.

${ }^{66}$ Bosnakis, Hallof, Inschriften (wie Anm.46); zu Xenophon, seiner Karriere in Rom und seiner Position auf Kos vgl. Kostas Buraselis, Kos between Hellenism and Rome. Studies on the Political, Institutional and Social History of Kos from ca. the Middle Second Century B.C. Until Late Antiquity (Philadelphia 2000) 66-110. ${ }^{67}$ Christina Kokkinia, Die Opramoas-Inschrift von Rhodiapolis. Euergetismus und soziale Elite in Lykien (Bonn 2000).
} 
nen Mann selbst oder seinen Verwandten vorgenommen ${ }^{68}$ - und dies mussten nicht unbedingt die bedeutsamsten kaiserlichen Mitteilungen sein, sondern diejenigen, die einen Bezug zu der jeweils geehrten Person aufwiesen, auch wenn es sich dabei wie im Falle des Opramoas um mehr oder minder routinemäßige Botschaften handelte.

Ein dritter Punkt: Dossiers dieser Art waren augenscheinlich hauptsächlich im östlichen, griechischsprachigen Teil des Imperium Romanum verbreitet ${ }^{69}$. Auch die Praxis, längere Beschlüsse der städtischen Institutionen, die häufig herausragende Bürger mit besonderen Beziehungen zum Herrscher ehrten und die einen wichtigen Bestandteil der soeben angesprochenen Dossiers bildeten, inschriftlich aufzuzeichnen, war nach Ausweis der erhaltenen Inschriften weitgehend auf den Osten des Reiches beschränkt, wo sie eine längere Tradition besa ${ }^{70}$. Für diese ungleiche Verteilung ist vermutlich nicht zuletzt die Wahl des bevorzugten Beschreibstoffes verantwortlich: Im Osten war Stein ein gerne genutztes Material für die Aufzeichnung kaiserlicher Mitteilungen und verwandter Dokumente; diese haben sich daher in einiger Zahl erhalten. Im Westen war es hingegen üblicher, wichtige Schriftstücke, insbesondere diejenigen, die vom Kaiser ausgingen, in Bronze einzugravieren. Bronze aber hatte aufgrund des besonderen Materialwertes erheblich weniger Chancen als Stein, die Zeiten unbeschadet zu überstehen. Das mag ebenfalls ein Grund dafür sein, dass wir weit mehr ausführliche kaiserliche Schriftstücke aus den östlichen Provinzen ${ }^{71}$ als aus dem Westen kennen, auch wenn sich das Bild in den letzten Jahren durch die spektakulären Neufunde von Bronzetafeln in Hispanien nicht unerheblich gewandelt hat ${ }^{72}$. Nichtsdestotrotz bleibt die Tatsache bestehen, dass die Zahl ausführlicher Dokumente im Osten viel höher ist und wir somit für diesen Raum deutlich besser über bestimmte Details etwa des Kaiserkults oder der Kommunikation

${ }^{68}$ Deutlich erkennbar ist dies auch bei der tabula Banasitana, einer in der Provinz Mauretania Tingitana gefundenen Bronzetafel, die Abschriften (exempla) zweier Briefe der Kaiser Marc Aurel und Lucius Verus bzw. Marc Aurel und Commodus sowie einen beglaubigten Auszug aus dem kaiserlichen commentarius civitate Romana donatorum enthält (AE 1971, 534 = IAM II 94; vgl. William Seston, Maurice Euzennat, Un dossier de la chancellerie romaine. La tabula Banasitana. Étude diplomatique, in: CRAI [1971] 468-490). Hierin geht es um die Bürgerrechtsverleihung an führende Angehörige des lokalen Stammes der Zegrenses und an deren Familienmitglieder. Die Anfrage aufGewährung dieses Privilegs war an die Kaiser durch Bittschriften (libelli) der betroffenen Personen herangetragen worden, welche wiederum durch den Statthalter in einem Brief (epistula) unterstützt wurden. Die Kaiser antworteten ihrerseits jeweils brieflich an den Statthalter; aber die Entscheidung, alle diese Dokumente auf einer Bronzetafel einzugravieren und dadurch die Bürgerrechtsverleihung längerfristig festzuhalten, wurde sicherlich durch die hiervon direkt begünstigten Personen getroffen.

${ }^{69}$ Eine der wenigen Ausnahmen im Westen stellt der bekannte, Marbre de Thorigny' (CIL XIII 3162) dar, eine Statuenbasis zu Ehren des T. Sennius Sollemnis, auf deren beiden Seiten exempla von Briefen hochrangiger Funktionäre, die den Geehrten betrafen, eingraviert wurden; vgl. Hans-Georg Pflaum, Le marbre de Thorigny (Paris 1948). S. ferner CIL VI 1585 = ILS 5920.

${ }^{70}$ S. aber unten Anm. 106 zu den decreta Pisana. Zu den relativ wenigen inschriftlich überlieferten Beschlüssen städtischer Behörden aus dem Westen des Reiches, von denen einige auch Ehrungen für das Kaiserhaus betrafen, vgl. zusammenfassend Robert K. Sherk, The Municipal Decrees of the Roman West (Buffalo 1970).

${ }^{71}$ Vgl. dazu das bei Sherk, Documents (wie Anm. 30) und Oliver, Constitutions gesammelte Material.

${ }^{72}$ Es bleibt die Frage, warum gerade in Hispanien und insbesondere in der Baetica so viele Bronzetafen gefunden wurden: Entweder sind hier die Fundumstände günstiger als in anderen Regionen (etwa durch die Abgelegenheit vieler antiker Stätten und die vermehrten Aktivitäten von Hobby-,Archäologen' mit Metalldetektoren in den letzten Jahren), oder aber es gab hier in der Antike tatsächlich eine größere Anzahl solcher epigraphischen Monumente als in anderen Provinzen des Reiches, sei es nun wegen des besonderen (Metall)Reichtums des Gebietes oder aufgrund einer speziellen Ausprägung des epigraphic habit. Vgl. dazu die Diskussion bei Francisco Beltrán Lloris, Inscripciones sobre bronce. ¿Un rasgo característico de la cultura epigráfica de las ciudades hispanas?, in: Atti del XI Congresso Internazionale di Epigrafia Greca e Latina, Roma 1997, Bd. 2 (Rom 1999) $21-37$. 
zwischen Einzelpersonen, Gemeinden und dem Kaiser informiert sind als für den Westen. Das epigraphische Quellenmaterial im Westen ist stärker auf Ehren-, Weih-, und Bauinschriften beschränkt, die mit ihren eher kurzen und formelhaften Wendungen die ausführlichen Angaben der griechischen Inschriften vermissen lassen. Dennoch ist davon auszugehen (und bisweilen auch nachzuweisen), dass die Mechanismen, die bei der Entstehung des kaiserlichen ,Images' und damit auch der auf den Kaiser bezogenen Inschriften am Werk waren, insbesondere der beständige Austausch zwischen Zentrale und Peripherie durch Gesandtschaften zum Kaiser ${ }^{73}$, die Rolle der Statthalter als Vermittler ${ }^{74}$ oder das Wirken herausragender lokaler Persönlichkeiten mit besonde-

${ }^{73}$ Vgl. Gabriele Ziethen, Gesandte vor Kaiser und Senat. Studien zum römischen Gesandtschaftswesen zwischen 30 v. Chr. und 117 n. Chr. (St. Katharinen 1994). In Bezug auf den Westen des Reiches finden sich einige Angaben zu Gesandtschaften in den literarischen Quellen. So können wir sehen, dass der Einrichtung des Kaiserkultes auf provinzialer Ebene (vgl. unten Anm. 176) in Hispanien mehrfach Reisen von Gesandten nach Rom vorausgingen, die im Falle der Provinz Hispania citerior im Jahre 15 n. Chr. positiv beschieden wurden (Tac. ann. 1, 78, 1), während wenig später die Abgesandten der Provinz Baetica bei der Einrichtung eines Tempels für den regierenden Kaiser Tiberius keinen Erfolg hatten - trotz des Verweises auf das Vorbild von Asia (Tac. ann. 4, $37 \mathrm{f}$.). Die sich hier andeutenden Querverbindungen zwischen Ost und West lassen sich durch ein konkretes Beispiel untermauern: Im Jahre 26 v. Chr. beschloss die Stadt Mytilene auf Lesbos umfangreiche Ehrungen für Augustus. Das Dekret enthielt gleichzeitig die implizite Aufforderung, nach noch göttlicheren Ehren für den Kaiser zu suchen. Inschriftliche Kopien des Beschlusses sollten an mehreren Orten errichtet werden, darunter auch in Tarraco, wo sich Augustus zu dieser Zeit aufhielt (IG XII 2, 58 = Labarre, Lesbos [wie Anm. 63] 285-287 Nr. 21). Eine weitere Inschrift aus Mytilene erwähnt tatsächlich eine städtische Gesandtschaft nach Tarraco (IG XII 2, 44; dazu Labarre, Lesbos [wie Anm. 63] 104f., 112). Diese dürfte dem Kaiser das Dekret überreicht und gleichzeitig die Kopie in der Stadt publik gemacht haben. Das war offenbar wiederum ein Anlass für die Bürger von Tarraco, bald darauf selbst einen munizipalen Kult für Augustus einzurichten, als dessen Zentrum ein großer, aus literarischen und numismatischen Quellen bekannter Altar fungierte: Quint. inst. 6, 3, 77; Duncan Fishwick, The Imperial Cult in the Latin West. Studies in the Ruler Cult of the Western Provinces of the Roman Empire, Bd. 1.1 (Leiden 1987) 171-179; ders., Four Temples at Tarraco, in: Alastair Small (Hg.), Subject and Ruler. The Cult of the Ruling Power in Classical Antiquity (Ann Arbor 1996) 165-184.

${ }^{74} \mathrm{Zu}$ der wichtigen Rolle der Provinzgouverneure bei der Erstellung von epigraphischen Monumenten zur Verherrlichung des Kaisers und bei der Verbreitung entsprechender Botschaften in den östlichen Provinzen des Reiches s. oben Anm. 29 und 30. Vergleichbare Phänomene finden wir beispielsweise während der augusteischen Epoche im Nordwesten Hispaniens, wo verschiedene Statthalter Monumente zu Ehren des Princeps errichteten (s. ferner unten Anm. 138). So stellte derselbe Paullus Fabius Maximus, der wenige Jahre zuvor in der Provinz Asia eine Kalenderreform zu Ehren des Augustus vorgeschlagen hatte, zwischen 4 und 1 v. Chr. als Statthalter der Hispania citerior in Lucus Augusti drei Inschriften für den Kaiser auf. Die Funktion dieser Steine ist nicht ganz klar; nicht zuletzt deswegen, weil bei keinem der Anfang der Inschrift zweifelsfrei gesichert ist und somit offen bleibt, ob es sich um Ehren- oder Weiheinschriften oder aber um eine Art von Erinnerungsmonumenten an die Stadtgründung handelte: CIL II 2581 = IRLugo 19; IRLugo 20; AE 1993, $1030=$ HEp 4, $503=$ HEp 7, 399 = HEp 8, 335; dazu Antonio Rodríguez Colmenero, María Covadonga Carreño Gascón, Sobre Paulo Fabio Máximo y la fundación de Lucus Augusti. Nuevos testimonios, in: Fernando Acuña Castroviejo (Hg.), Finis Terrae. Estudios en lembranza do Prof. Dr. A. Balil (Santiago de Compostela 1992) 389-415. In Bracara Augusta (Braga) wurde ein Rundaltar gefunden, der dem Augustus von den Bracaraugustani geweiht wurde, wobei die Dedikation am Geburtstag des Statthalters Fabius Maximus erfolgte: EphEp VIII $280=$ ILS 8895. Am äußersten Rand Galiciens, auf dem Kap Finisterre, hatte bereits L. Sestius Quirinalis, Statthalter der Hispania ulterior zwischen 22 und 19 v. Chr., eine Gruppe von drei - offenbar monumentalen - Altären errichtet, deren Widmung mit Augustus in Verbindung stand und die später nach dem Stifter arae Sestianae benannt wurden. S. Plin. nat. 3, 111; Pomp. Mela 3, 13; Ptolem. 2, 6, 3; dazu Andreas Grüner, Die Altäre des L. Sestius Quirinalis bei Kap Finisterre. Zur geopolitischen Konstruktion des römischen Herrschaftsraums, in: MDAI(M) 46 (2005) 247-266. 
ren Nahbeziehungen zum Herrscher ${ }^{75}$, im Westen nicht deutlich anders strukturiert waren als im Osten, auch wenn wir sie oft nicht im Detail dokumentieren können. Es ist daher von um so gröBerer Bedeutung, die einzelnen Teile des Reiches nicht isoliert zu betrachten, sondern die teilweise immer noch spürbare Trennung zwischen lateinischer und griechischer Epigraphik zu überwinden.

Als Zwischenfazit lässt sich somit festhalten, dass es zahllose kaiserliche Schreiben gegeben haben muss, die sich oft mit eher kleinteiligen oder nur in einem begrenzten regionalen Kontext bedeutsamen Angelegenheiten beschäftigten. Den Inhalt dieser Botschaften hat der Herrscher zumindest mitbestimmt, denn es ist auf jeden Fall davon auszugehen, dass die Formulierungen eines solchen Schreibens nichts enthielten, was seinem Willen und auch seinen generellen Vorstellungen zuwiderlief. Ob allerdings ein solches kaiserliches Schriftstück inschriftlich aufgezeichnet und dadurch Teil eines epigraphischen Monuments wurde, konnte der Kaiser in der Regel kaum von sich aus dekretieren oder auch nur beeinflussen. Hierfür war vielmehr ein Selektionsprozess auf der lokalen Ebene, also bei dem oder den Empfängern, verantwortlich, innerhalb dessen - und oft erst Jahre später - entschieden wurde, welche Botschaften es wert waren, auf kostspielige Weise verewigt zu werden. Auch die Form, die diese inschriftliche Präsentation nahm - etwa als Bronzetafel, die am Forum ausgehängt wurde, oder aber als Teil eines Dossiers mit zahlreichen weiteren Schriftstücken am Grabbau eines lokalen Notablen - wurde in der Regel vor Ort bestimmt, und in den meisten Fällen dürfte der Herrscher hiervon gar nichts gewusst haben. Nur selten ist hingegen explizit belegt, dass der Kaiser selbst bei einem solchen Vorgang die Initiative ergriff. Ein vereinzeltes Zeugnis hierfür ist ein Brief des Kaisers Septimius Severus an die Stadt Aizanoi ${ }^{76}$ : Der Princeps hatte durch eine Gesandtschaft der Aizanites einen Beschluss der Gemeinde erhalten, der von einem Fest sowie Dankopfern für seine Siege und die Erhebung des Caracalla zum Caesar handelte. Da zeitgleich mit der städtischen Gesandtschaft auch eine weitere Siegesnachricht eingetroffen war, nahm der Kaiser diese frohe Botschaft umgehend in seinen Antwortbrief auf und äußerte die Hoffnung, das Schreiben - und damit die Verkündigung seines erneuten Sieges - möge bei den örtlichen Göttern von Aizanoi verwahrt werden. Tatsächlich wurde dort der Brief des Kaisers in die Wand eines der Haupttempel der Stadt eingemeißelt, auch wenn dies der Herrscher so deutlich nicht eingefordert hatte.

Etwas anders stellt sich die Situation bei kaiserlichen Edikten dar, die entweder an bestimmte Gebiete gerichtet waren oder aber reichsweit gelten sollten. Auch diese kaiserlichen Entscheidungen

${ }^{75}$ Besonders auffällig ist die Rolle einiger herausragender Persönlichkeiten mit lokalen Wurzeln und guten Beziehungen zum Herrscher bei der Umgestaltung von Stadtbildern sowie der Einführung des Kaiserkultes während der augusteischen Epoche in den Städten Griechenlands und Kleinasiens. Sie gehörten vielfach der von Caesar oder Augustus mit dem römischen Bürgerrecht ausgezeichneten Elite der C. Iulii an und sind durch zahlreiche epigraphische Zeugnisse in ihren Heimatgemeinden gut dokumentiert; vgl. Louis Robert, Inscriptions d'Aphrodisias, in: AntCl 35 (1966) 413-433. Prominente Vertreter dieser Gruppe waren beispielsweise C. Iulius Eurykles in Sparta (Christian Böhme, Princeps und Polis. Untersuchungen zur Herrschaftsform des Augustus über bedeutende Orte in Griechenland [München 1995] 76-82), der kaiserliche Freigelassene C. Iulius Zoilos in Aphrodisias (zusammenfassend Roland R. R. Smith, The Monument of C. Iulius Zoilos [Mainz 1993] 4-13) sowie C. Iulius Epikrates in Milet (Peter Herrmann, Milet unter Augustus. C. Iulius Epikrates und die Anfänge des Kaiserkults, in: MDAI[I] 44 [1994] 203-236). Vergleichbare Personen gab es aber auch im Westen des Reiches. Gerade in Gallien ist die lokale Aristokratie der C. Iulii ebenfalls recht gut belegt, und zumindest an manchen Orten wie in Saintes ist ihre Rolle bei der Verherrlichung des Kaiserhauses und dem damit verbundenen urbanistischen Ausbau der Städte genauer zu fassen; vgl. hierzu Witschel, Augustus 70-72; sowie allgemein Robert Bedon, Les villes des trois Gaules de César à Neron dans leur contexte historique, territorial et politique (Paris 1999) bes. 211-218, 227f., 235.

${ }^{76}$ IGR IV 566 = Oliver, Constitutions Nr. 213. 
reagierten nicht selten auf an den Herrscher herangetragene Missstände, aber hierbei war seine eigene Initiative wesentlich deutlicher ausgeprägt und insofern auch sein Interesse, solche Anordnungen - gerade diejenigen, die für das gesamte Imperium bestimmt waren - bekannt zu machen. So verfügte ein nur literarisch (bei Flavius Josephus) ${ }^{77}$ überliefertes, angeblich für alle Provinzen gültiges Edikt des Kaisers Claudius über die Juden: „Ich wünsche, dass die Beamten der Städte (poleis) und der Kolonien und der municipia sowohl in Italien als auch außerhalb, sowie (Klientel)Könige und Dynasten durch ihre eigenen Gesandten dafür Sorge tragen, dass dieses mein Edikt aufgeschrieben (engrapsasthai) und dass es dann ausgehängt wird für nicht weniger als 30 Tage (an einem Ort), wo es vom Boden aus gut gelesen werden kann. ${ }^{\text {"78 }}$ Hiermit war aber wohl nicht notwendigerweise eine Fassung in einem dauerhaften Material verbunden, denn für die geforderte dreißigtägige Bekanntmachung dürfte es ausgereicht haben, den Text auf eine Holztafel zu übertragen und diese öffentlich aufzustellen ${ }^{79}$. Ob es dann noch zu einer inschriftlichen Fixierung des entsprechenden Textes kam, hing erneut vornehmlich von lokalen Gegebenheiten ab, und sie scheint nur dann erfolgt zu sein, wenn eine der hiervon direkt betroffenen Parteien ein besonderes Interesse daran hatte. Ein Beispiel hierfür bietet ein erst vor Kurzem bekannt gewordenes Edikt des Augustus aus dem Jahre 15 v. Chr. ${ }^{80}$, das sich auf einer Bronzetafel im nordwestlichen Hispanien, genauer gesagt in der Region El Bierzo (d.h. am westlichen Rand des conventus Asturum) gefunden hat, einem Gebiet, das erst etwa zehn Jahre zuvor unter römische Herrschaft gekommen war. In dem Edikt, das in Narbo (Narbonne) ausgegeben worden war, wo sich der Kaiser im Februar 15 v. Chr. aufhielt, traf Augustus einige detaillierte Regelungen bezüglich einer kleinen indigenen Gemeinde, des castellum Paemeiobriga, welches zur gens der Susarri gehörte, und verlieh ihr das bedeutende Privileg der immunitas. Die ganze Angelegenheit war sicherlich nur von lokalem Interesse und wurde dem Princeps vermutlich entweder von den Paemeiobrigenses selbst oder eher vom zuständigen Statthalter zur Kenntnis gebracht. Augustus scheint im Übrigen im gleichen Kontext auch weitere, ähnliche Angelegenheiten entschieden zu haben, so dass der vorliegende Text vermutlich nur einen Auszug aus einem längeren Schriftstück darstellt, das auch die anderen Beschlüsse des Herrschers enthielt. Dass aber gerade die Paemeiobrigenses sich dazu entschieden, den sie betreffenden Passus

\footnotetext{
${ }^{77}$ Ios. ant. Iud. 19, 287-291 = Oliver, Constitutions App. 5. Die Authentizität dieses Dokuments ist allerdings umstritten.

${ }^{78}$ In ähnlicher Weise wird am Ende eines Edikts des Severus Alexander(?), das sich auf einem Papyrus aus dem Fayum - wie klar ersichtlich ist, handelt es sich um eine lokale Abschrift - erhalten hat, verfügt (Oliver, Constitutions Nr. 275): „Die Beamten jeder Stadt mögen dafür Sorge tragen, dass eine Kopie meines Edikts an einem öffentlichen Platz angebracht wird, und zwar dort, wo sie für die Betrachter/Leser am besten sichtbar ist." ${ }^{79}$ So wissen wir durch die Stadtgesetze der flavischen Zeit aus Hispanien, dass die dortigen Gemeindebeamten dazu verpflichtet waren, die Anordnungen des Statthalters (darunter auch seine edicta, die wiederum nicht selten Anweisungen des Kaisers aufgriffen) in ihrer Stadt für eine bestimmte Zeit öffentlich bekanntzumachen, und zwar offenbar auf Holztafeln oder einem ähnlichen, leicht bewegbaren Material (s. lex Irnitana cap. 85). Eine Anordnung (entweder ein Reskript oder ein Edikt) des Kaisers Vespasian zum reichsweiten Schutz der Ärzte sollte aufgrund seines eigenen Befehls auf einer Holztafel (en leukömati) bekannt gemacht werden - offenbar zunächst in Rom auf dem Kapitol, während sich die erhaltene Abschrift auf einem Stein befindet, der in Pergamon geborgen wurde (Oliver, Constitutions Nr.38).

${ }^{80}$ AE 1999, 915 = AE 2000, 769; dazu Géza Alföldy, Das neue Edikt des Augustus aus El Bierzo in Hispanien, in: ZPE 131 (2000) 177-205; ders., Fasti und Verwaltung der hispanischen Provinzen. Zum heutigen Stand der Forschung, in: Rudolf Haensch, Johannes Heinrichs (Hg.), Herrschen und Verwaltung. Der Alltag der römischen Administration in der römischen Kaiserzeit (Köln u.a. 2007) 328 (jeweils mit weiterer Literatur); ferner Felice Costabile, Orazio Licandro, Tessera Paemeiobrigensis. Un nuovo editto Augusto dalla transduriana provincia e l'imperium proconsulare del princeps (Rom 2000).
} 
in Bronze aufzuzeichnen und in ihrem castrum zu präsentieren (wo die Inschrift auch gefunden wurde), hing sicherlich mit der für sie äußerst vorteilhaften Entscheidung des Augustus sowie seinen lobenden Worten zusammen. Die Paemeiobrigenses werden allerdings die Bronzetafel kaum selbst angefertigt haben, da in einer zu diesem Zeitpunkt noch kaum von der Inschriftenpraxis berührten Region die hierzu nötigen Kenntnisse gefehlt haben dürften. Vermutlich war es auch hier der Statthalter, der aushalf; einige Fehler im Text, die offenbar auf den Abschreibevorgang zurückzuführen sind, machen jedenfalls klar, dass es sich kaum um eine von der kaiserlichen Kanzlei ausgesandte Kopie gehandelt haben kann ${ }^{81}$. Aufgrund dieser Gegebenheiten ist die Zahl der durch Inschriften bekannten kaiserlichen Edikte, vor allem der reichsweit gültigen General-Edikte, tatsächlich vergleichsweise gering ${ }^{82}$.

Letzterer gilt nun gerade nicht für die kleinformatigen Bronzeurkunden (die sogenannten Militärdiplome), die Veteranen vornehmlich der Auxiliartruppen ausgehändigt bekamen, um dauerhaft zu dokumentieren, dass sie vom Herrscher das Bürgerrecht erhalten hatten ${ }^{83}$. Die Zahl dieser Militärdiplome ist in den letzten Jahren durch Neufunde stark angewachsen. Obwohl die erhaltenen Diplome nach wie vor nur einen Bruchteil der einstmals existierenden Dokumente repräsentieren dürften, ist mittlerweile doch davon auszugehen, dass die allermeisten entlassenen Soldaten eine solche Urkunde erhielten und an ihren Alterswohnsitz mitnahmen. Die Militärdiplome waren selbst wiederum beglaubigte Abschriften der kaiserlichen Bürgerrechts-Konstitutionen, die auf großen Bronzetafeln in Rom publik gemacht worden waren, von denen sich aber fast keine Reste erhalten haben ${ }^{84}$. Da letztere direkt aus der kaiserlichen Kanzlei stammten, sind die Militärdiplome unsere beste Quelle für die offizielle Ausprägung der Kaisertitulatur (vgl. unten Kap. 6). Gleichzeitig können sie demonstrieren, welch hoher Aufwand an schriftlicher Kommunikation in der kaiserlichen Verwaltung (und unter Einbeziehung des Princeps selbst) getrieben wurde - bis hin zur massenhaften Anfertigung von Bronzeurkunden im Namen des Herrschers, welche aber offenbar von privaten Unternehmern durchgeführt wurde ${ }^{85}$.

\footnotetext{
${ }^{81}$ Ein weiteres Beispiel für einen solchen Vorgang stellt ein Edikt dar, das Augustus und Agrippa im Jahre 27 v. Chr. als Konsuln (wohl in Umsetzung eines zuvor ergangenen senatus consultum) erlassen hatten und das die Rückgabe geraubter Güter insbesondere an Heiligtümer - offenbar im gesamten Reich - betraf. Gefunden wurde eine Abschrift auf einer Stele in Kyme (Asia), auf der unter dem Edikt ein weiteres Schriftstück aufgezeichnet wurde, nämlich ein Brief des Prokonsuls von Asia an die Magistrate von Kyme, in dem dieser (unter Bezugnahme auf das iussum Augusti Caesaris, also auf den Erlass des Kaisers, der somit in der Provinz bereits bekannt war) auf die Rückgabe des lokalen Heiligtums des Dionysos an den Verein der Thiasitai drängte. Die Aufstellung der Stele - wahrscheinlich vor dem zurückgewonnenen Tempel - mit den beiden Schriftstücken wurde dann offenbar von den Dionysos-Anhängern selbst vorgenommen, nachdem sie ihr Anliegen zu einem erfolgreichen Abschluss gebracht hatten. S. IKyme (IK 5) 17; dazu Adalberto Giovannini, Les pouvoirs d'Auguste de 27 à 23 av. J.-C. Une relecture de l'ordonance de Kymè de l'an 27, in: ZPE 124 (1999) 95-106.

${ }^{82} \mathrm{Zu}$ der relativ kleinen Zahl von erhaltenen, reichsweit gültigen kaiserlichen Edikten der frühen Kaiserzeit vgl. Fergus Millar, The Emperor in the Roman World (London 1977) 252-259. Dies könnte zumindest teilweise eine Folge der geschilderten Aufzeichnungspraxis sein und muss nicht unbedingt dafür sprechen, dass solche auf die Initiative des Herrschers zurückgehenden Generaledikte nur selten erlassen wurden.

${ }^{83} \mathrm{Zu}$ den Militärdiplomen vgl. allgemein Werner Eck, Hartmut Wolff(Hg.), Heer und Integrationspolitik. Die römischen Militärdiplome als historische Quelle (Köln, Wien 1986); Michael A. Speidel, Alfred M. Hirt (Hg.), Militärdiplome. Die Forschungsbeiträge der Berner Gespräche von 2004 (Stuttgart 2007).

${ }^{84}$ Dazu s. oben Anm. 4.

${ }^{85}$ Vgl. zu den administrativen Abläufen zusammenfassend Werner Eck, Die Ausstellung von Bürgerrechtskonstitutionen. Ein Blick in den Arbeitsalltag des römischen Kaisers, in: Anselmo Baroni (Hg.), Amministrare un Impero. Roma e le sue province (Trento 2007) 89-108.
} 
Wie rasch sich generell Botschaften bezüglich des Kaiserhauses verbreiten konnten, die dann in epigraphische Monumente umgesetzt wurden und entsprechende Reaktionen von seiten der Untertanen hervorriefen, soll zum Schluss dieses Abschnitts anhand eines konkreten Beispiels aus dem frühen Prinzipat noch etwas ausführlicher erläutert werden. Augustus hatte bekanntlich seine beiden Enkel Caius und Lucius adoptiert und versucht, sie zu seinen präsumtiven Nachfolgern aufzubauen. Ein wichtiger Akt hierbei war der Empfang der toga virilis durch Caius Caesar im Sommer 5 v. Chr., verbunden mit seiner feierlichen Einführung durch den Kaiser vor Volk und Senat sowie seiner Ernennung zum princeps iuventutis. Nur kurze Zeit später wurde in Sardis in der Provinz Asia ein Volksbeschluss in dieser Angelegenheit gefasst. Darin lesen wir, dass die Menschen in der Stadt durch die Meldung, Caius Caesar habe die toga virilis angelegt, in freudige Stimmung versetzt worden seien und noch am gleichen Tag beschlossen hätten, dass derjenige Tag, „der ihn vom Kind zum Mann machte", heilig sein und zukünftig jährlich als Festtag begangen werden solle, sowie ihm ein agalma im Tempel des Vaters (Augustus) zu weihen. Auch der Tag, an dem die gute Nachricht in Sardis eingetroffen war, sollte feierlich begangen werden. Zudem wollte man möglichst bald eine Gesandtschaft nach Rom senden, um Caius Caesar und Augustus zu gratulieren, ihnen eine Abschrift des Dekrets zu überreichen und mit dem Kaiser über das zu sprechen, was dem asiatischen koinon sowie der Stadt Nutzen bringen könne. Der Tatsache, dass Menogenes als einer der beiden Gesandten ausgewählt wurde, verdankt das Dekret seine inschriftliche Fassung. Es wurde nämlich später zusammen mit dem Antwortschreiben des Augustus an die Magistrate und Boule von Sardis, in dem der Kaiser die Gesandten erwähnte und lobende Worte für die Stadt fand, in das auf einer Stele eingravierte Dossier von insgesamt zwölf Schriftstücken zu Ehren des Menogenes aufgenommen (s. oben $)^{86}$. Andere Gemeinden reagierten ähnlich bzw. gingen sogar noch einen Schritt weiter: Im Heraion von Samos hat sich ein fragmentierter Stein gefunden, der einen Volksbeschluss der Samier überliefert ${ }^{87}$. Auch hier ist von der feierlichen Begehung eines besonderen Tages die Rede und davon, dass die Samier wie alle Menschen durch eine frohe Botschaft - vermutlich die ebenfalls im Jahre 5 v. Chr. erfolgte Übernahme des 12. Konsulats durch Augustus, die das Präludium für die feierliche Einführung des Caius Caesar bildete - in Hochstimmung versetzt worden seien, worauf der Tag zum Festtag erklärt worden sei. Zusätzlich sollte die loyale Haltung der Samier gegenüber dem Kaiser und seiner Familie durch einen Eid bekräftigt werden, dessen Einzelheiten festgelegt wurden. Schließlich sollte eine Gesandtschaft zum Kaiser geschickt werden, um ihm das städtische Dekret zu überreichen und die „Mitfreude“ der Samier zum Ausdruck zu bringen. Zwei Stelen mit Abschriften des Beschlusses sollten im städtischen Tempel der Roma und des Augustus sowie im Heraion aufgestellt werden. Besonders interessant ist hier die Erwähnung eines ,Treueeides' der Einwohner von Samos, der offenbar durch das freudige Ereignis im Kaiserhaus ausgelöst wurde. Ähnliche ,Kaisereide' sind uns gerade aus der frühen Kaiserzeit auch aus anderen Orten des Reiches in einer inschriftlichen Fassung bekannt ${ }^{88}$. Die Frage, die sich hierbei stellt, ist, ob es sich bei solchen

${ }^{86}$ IGR IV 1756 = William H. Buckler, David M. Robinson, Sardis, Bd. 7.1: Greek and Latin Inscriptions (Leiden 1932) 16-27 Nr. 8; der Brief des Augustus auch in Oliver, Constitutions Nr.7.

${ }^{87}$ IG XII 6, 1, 7; dazu mit ausführlichem Kommentar Peter Herrmann, Die Inschriften römischer Zeit aus dem Heraion von Samos, in: MDAI(A) 75 (1960) 70-82 Nr. 1-2.

${ }^{88}$ Vgl. zusammenfassend Peter Herrmann, Der römische Kaisereid. Untersuchungen zu seiner Herkunft und Entwicklung (Göttingen 1968); Joël Le Gall, Le serment à l'Empereur. Une base méconnue de la tyrannie impériale sous le Haut-Empire?, in: CCG 1 (1990) 165-180; Hubert Cancik, Der Kaiser-Eid. Zur Praxis der römischen Herrscherverehrung, in: Ders., Konrad Hitzl (Hg.), Die Praxis der Herrscherverehrung in Rom und seinen Provinzen (Tübingen 2003) 29-45. 
Aktionen um mehr oder minder spontane Aktivitäten einzelner Gemeinden oder um eine von oben angeordnete und koordinierte Maßnahme handelte. Inzwischen ist nämlich aus dem Westen des Reiches ein weiterer inschriftlich aufgezeichneter Kaisereid bekannt geworden, der offensichtlich in denselben chronologischen Kontext (d.h. in die Zeit um oder kurz nach 5 v. Chr.) gehört. Er wurde in der baetischen Gemeinde Conobaria auf einer Bronzetafel eingraviert und enthält eine lateinische Eidesformel, die mit der griechischen allerdings nicht völlig identisch ist ${ }^{89}$. Dennoch hat der Erstherausgeber aus der zeitlichen Koinzidenz gefolgert, solche Eidesleistungen seien nicht spontan, sondern auf Wunsch oder gar Anweisung des Kaisers erfolgt ${ }^{90}$. Mir scheint in dieser Frage eine mittlere Position am ehesten angebracht zu sein: Die meisten Eide wurden wohl nicht völlig spontan ausgesprochen, sondern folgten Vorgaben aus Rom oder Initiativen von Statthaltern. Diese müssen aber keine genauen Anweisungen gewesen sein, denn es reichte wohl in der Regel aus, dass eine Nachricht über ein besonderes, das Kaiserhaus betreffendes Ereignis in den Provinzen eintraf, um dort die entsprechenden Mechanismen der Loyalitätserweisung (eventuell unter Mitwirkung des Statthalters) in Gang zu setzen, in die durchaus lokale Vorstellungen einfließen konnten. Letzteres galt mit Sicherheit auch für die Entscheidung, den performativen Akt der Eidesleistung in das dauerhafte Medium einer Inschrift zu überführen.

Die dynastischen Entwicklungen im Kaiserhaus wurden also in den Städten des Reiches genau registriert, und man reagierte hierauf sehr rasch mit einer Fülle von Ehrungen für die beiden jungen Söhne des Augustus, die uns wiederum vor allem durch epigraphische Zeugnisse bekannt sind und von denen hier nur wenige vorgestellt werden können. In einigen Fällen scheinen hierbei erneut die Provinzialmagistrate eine wichtige Rolle gespielt zu haben. So erfahren wir aus einem Dekret der Stadt Messene, dass ein quaestor pro praetore, der sich bereits wiederholt bei der Feier des Kaisers hervorgetan hatte, nach dem Empfang von Nachrichten über die kriegerischen Erfolge des Caius Caesar an der Ostgrenze des Reiches im Jahre 2 n. Chr. Anweisung an alle Menschen gab, sich zu bekränzen und Opfer darzubringen sowie einen Festtag einzurichten ${ }^{91}$. Mit Sicherheit nicht von oben gesteuert waren aber zahlreiche weitere Ehrungen für die beiden Prinzen, die überall im Reich vorgenommen wurden und sehr unterschiedliche Formen annehmen konnten. Mit Blick auf den Osten fallen hierbei insbesondere die an vielen Orten frühzeitig eingerichteten Kulte auf. Der oben erwähnte Volksbeschluss der Samier etwa zeigt, dass es bereits im Jahre 5 v. Chr. einen Priester des Augustus, des Caius Caesar und des Agrippa in der Stadt gab ${ }^{92}$. Als neos theos wurde Caius Caesar augenscheinlich zu Lebzeiten - auf einer ihm vom Demos von Xanthos gewidmeten Statuenbasis im lykischen Letoon angesprochen, und ebenso auf einem Altar, den ihm das Volk von Halasarna

\footnotetext{
${ }^{89}$ AE 1988, 723 = CILA II 3, 990. Schon Herrmann, Inschriften (wie Anm. 87 ) 81 hatte auf weitere zeitlich benachbarte Eidesleistungen hingewiesen, so den Eid von Gangra in Paphlagonien aus dem Jahr 3 v. Chr. (OGIS II 532 = ILS 8781 = IGR III 137). Auch hier stellt sich aber die Frage, wer die Eidesleistung veranlasst hat - nach Herrmann, Kaisereid (wie Anm. 88) 96-98 geschah dies wohl nicht auf Anweisung von oben, sondern aufgrund einer Initiative des lokalen koinon.

${ }^{90}$ Julián González, The First Oath pro salute Augusti Found in Baetica, in: ZPE 72 (1988) 113-127. Er möchte hieraus ableiten, dass der Eid „was not spontaneous but rather reflected Augustus' wish“, dass auch seine Adoptivsöhne eine solche Treueversicherung erhalten sollten (120); und er betont deswegen stark eine angebliche, mehr oder minder direkte "governmental intervention“ in diesem Vorgang.

${ }^{91}$ SEG 23 (1968) 206; dazu James E. G. Zetzel, New Light on Gaius Caesar's Eastern Campaign, in: GRBS 11

(1970) 259-266.

${ }^{92}$ S. oben Anm. 87.
} 
auf Kos weihte; als neos Ares erscheint er auf einer Statuenbasis in Athen ${ }^{93}$. Besonders zahlreich haben sich Altäre für Caius und Lucius Caesar sowie weitere Familienmitglieder in Mytilene auf Lesbos erhalten ${ }^{94}$, und in der benachbarten Stadt Eresos stiftete ein lokaler Euerget ein temenos und einen naos der beiden Prinzen am prominentesten Platz der Agora ${ }^{95}$. Auch im Westen lassen sich mannigfache Ehrungen ausmachen, bei denen die Rolle der Inschriften deutlich hervortritt. Kurz erläutert sei dies am Beispiel Hispaniens: Ein herausragender Fall ist das in mittelaugusteischer Zeit errichtete Theater von Carthago nova (Cartagena; Hispania citerior) ${ }^{96}$, das den beiden Augustussöhnen gewidmet war, wie die Inschriften zeigen, die vermutlich zwischen 5 und $1 \mathrm{v}$. Chr. auf den Architraven über den beiden Orchestra-Zugängen angebracht wurden ${ }^{97}$. Auf diesen ist kein Stifter genannt, aber aus weiteren epigraphischen Zeugnissen ist klar zu entnehmen, dass sich hier vor allem Mitglieder der städtischen Elite engagierten: So errichtete ein Mann namens L. Iunius Paetus, der augenscheinlich zur munizipalen Aristokratie gehörte, im Theater einen Altar für Caius Caesar $^{98}$. Bruchstücke von Inschriftentafeln, die vermutlich mit Statuensockeln verbunden waren, deuten ferner darauf hin, dass Statuen der beiden Prinzen im Bereich der scaenae frons des Theaters standen ${ }^{99}$. Einer der beiden genannten Stifter, M. Postumius Albinus, ist auf den Münzen der Stadt als quinquennalis in augusteischer Zeit belegt ${ }^{100}$. Angesichts der mittlerweile bekannten epigra-

${ }^{93}$ Xanthos: André Balland, Fouilles de Xanthos, Bd.7: Inscriptions d'époque impériale du Létôon (Paris 1981) 48-50 Nr. 25. Kos: IGR IV 1094. Athen: IG II/III² 3250. In Athen wurde auch Lucius Caesar mit einem auBergewöhnlichen Monument geehrt, nämlich einer Reiterstatue über dem Eingangstor des von Augustus gestifteten Marktes: IG II/III ${ }^{2}$ 3251; dazu Michael C. Hoff, An Equestrian Statue of Lucius Caesar in Athens Reconsidered, in: AA (2001) 583-599.

${ }^{94}$ S. unten Anm. 185. Aus diesen Denkmälern geht deutlich hervor, wie aufmerksam man auf Lesbos die dynastischen Regelungen im Kaiserhaus verfolgte und in entsprechende epigraphische Monumente umsetzte.

${ }^{95}$ S. hierzu das Dekret IG XII Suppl. 124 = Labarre, Lesbos (wie Anm.63) 351-353 Nr.78, in dem von den zahlreichen Stiftungen eines Mannes zugunsten des Kultes der Kaiserfamilie die Rede ist, „so dass es an keinem bedeutenden Platz an seiner eunoia und eusebeia gegenüber dem Gott-Kaiser fehle"; dazu Mika Kajava, Eresian Memories, in: ZPE 139 (2002) 89-107. Zu weiteren Belegen für Kulte des C. und L. Caesar im Osten s. Balland, Xanthos (wie Anm. 93) 50.

${ }^{96}$ Vgl. zusammenfassend Sebastián F. Ramallo Asensio, Elena Ruiz Valderas, El teatro romano de Cartagena (Murcia 1998); Sebastián F. Ramallo Asensio, Inscripciones honoríficas del teatro de Carthago Nova, in: AEA 65 (1992) 49-73; ders., El programa epigrafico y arquitectónico del teatro romano de Cartagena, un ejemplo de monumentalización precoz en Hispania, in: Julián González (Hg.), Ciudades privilegiadas en el occidente romano (Sevilla 1999) 397-410; ders., Los príncipes de la familia julio-claudia y los inicios del culto imperial en Carthago nova, in: Mastia 2 (2003) 189-212.

${ }^{97}$ CarthNova 14 = AE 1992, 1075 (C. Caesar; Architrav über dem westlichen aditus des Theaters); CarthNova 15 = AE 1996, 925 (L. Caesar; Architrav über dem östlichen Zugang).

${ }^{98}$ CarthNova 13 = AE 1992, 1076: C(ai) Caesaris Augustif(ilii)/pontif(icis) co(n)s(ulis) desig(nati)/principis iuventutis / [L(ucius) Iu]nius L(uci)f(ilius) T(iti)n(epos) Paetus [s] ac(rum) [d(e)]d(icavit). Auffällig ist der in der Weihung verwendete Genitiv; die vorgeschlagenen Ergänzungen (donum) C. Caesaris oder (exiussu) C. Caesaris sind m.E. wenig überzeugend. Derselbe Mann stiftete im Theater auch einen Altar für Fortuna (CarthNova 12 = AE 1992, 1077); auf einem weiteren frühkaiserzeitlichen Fragment einer großen Inschrift (vermutlich mit litterae aureae), das eventuell aus dem Theater stammt, liest man ebenfalls den Namen des Paetus (CarthNova 16 = CIL II 3515). Ein L. Iunius, vielleicht der Vater des Stifters, ist als städtischer Münzmeister in (früh)augusteischer Zeit bezeugt.

${ }_{99}$ HEp 10, 382 (zahlreiche Fragmente einer Marmortafel; gefunden im byposcaenium des Theaters): L(ucio) Caesari / Aug(usti) f(ilio) / [M(arci) P]o[s]tumii / [Ma]xi[mus] / e[t A]lbinus. Eine weitere, ähnlich gestaltete Tafel (gefunden im Bereich der porticus post scaenam) mit nur wenigen erhaltenen Buchstabenresten war eventuell C. Caesar gewidmet.

${ }^{100}$ S. RPC I 170/71, 174-178; Ramallo Asensio, Príncipes (wie Anm.96) 196-198; auf dem Revers dieser Münzen ist ein Tempel mit der Inschrift AVGVSTO auf dem Architrav abgebildet. Ein weiteres, fragmentarisch 
phischen Zeugnisse aus dem Theater von Carthago nova, von denen sich bis zu sechs auf Caius und Lucius Caesar beziehen dürften, ergibt sich der Eindruck eines Repräsentationsraumes, der ganz auf die inschriftliche und bildliche Vergegenwärtigung der beiden präsumtiven Nachfolger des Augustus konzentriert war - eine Lösung, die durchaus individuelle Züge aufweist und daher vor Ort konzipiert worden zu sein scheint. In anderen Städten Hispaniens gab es zahlreiche Standbilder für Caius und Lucius Caesar (mit einer entsprechenden Inschrift auf der Basis), die häufig in den Kontext größerer Statuengruppen der Kaiserfamilie eingebunden waren ${ }^{101}$. Besonders auffällig ist eine Gruppe von insgesamt fünf Basen für Reiterstatuen aus Ulia (Montemayor; Baetica), die zwischen 12 und 6 v. Chr. vermutlich von der Stadtgemeinde für Augustus, Agrippa, Lucius Caesar, Tiberius und Agrippa Postumus errichtet wurden - die Gruppe wird sicherlich auch ein Standbild des Caius Caesar enthalten haben ${ }^{102}$. Nicht selten wurde den Prinzen wie in Ulia auch der Stadtpatronat übertragen ${ }^{103}$. Selbst in Regionen, die erst kurz zuvor in das Imperium Romanum eingegliedert worden waren, wurden entsprechende Monumente errichtet, so an mehreren Orten in der Provinz Raetia et vallis Poenina (Martigny, Massongex, Chur, Kempten), wobei dies bisweilen die ersten epigraphischen Denkmäler überhaupt in diesen Gemeinden waren, deren bauliche Ausgestaltung zu dieser Zeit noch sehr rudimentär gewirkt haben muss ${ }^{104}$.

Die in kurzer Zeit aufeinander folgenden Todesfälle des Lucius und Caius Caesar lösten dann eine vielleicht sogar noch größere Anteilnahme unter der Reichsbevölkerung aus, die sich wiederum in der Schaffung zahlreicher epigraphischer und sonstiger Monumente niederschlug ${ }^{105}$. Von diesen sei hier zunächst eines näher beleuchtet, das die unmittelbaren Reaktionen auf die Todesnachrichten widerspiegelt, nämlich die inschriftliche Aufzeichnung zweier diesbezüglicher Dekrete der italischen Gemeinde Pisa auf zwei großen Marmortafeln ${ }^{106}$. Lucius Caesar starb als erster der beiden Prinzen am 20. August 2 n. Chr. in Massilia (Marseille). Der Senat in Rom erließ daraufhin strenge

erhaltenes Statuenpostament, offenbar für eine (kaiserliche?) Reiterstatue (gefunden in Wiederverwendung im Bereich der porticus post scaenam) nennt vermutlich denselben Mann als Stifter: HEp 10, 381.

${ }^{101}$ So auf den Fora von Emporiae (IRC III 19: C. Caesar) und Saguntum (CIL II ${ }^{2} / 14,306=$ CIL II 3828 : C. Caesar; Dat.: wohl 4/3 v. Chr.) in Hispania citerior; oder in Urgavo in der Baetica (CIL II²/7, 71 = CIL II 2109: L. Caesar). Zu Statuengruppen der kaiserlichen Familie vgl. unten Anm. 212.

${ }^{102} \mathrm{CIL} \mathrm{II}^{2} / 5$, 486-90 = CIL II 1525-29. Eine weitere Basis für eine Reiterstatue des Agrippa Postumus (errichtet zwischen 4 und $6 \mathrm{n}$. Chr.), die eventuell zu einer ähnlichen Gruppe gehörte, ist aus Isturgi (Baetica) bekannt: $\mathrm{CIL} \mathrm{II}^{2} / 7,59 \mathrm{a}$. Gerade dieser jüngste Sohn des Agrippa wurde schon vor seiner Adoption durch Augustus im Jahre 4 n. Chr. auch im äußersten Nordwesten Hispaniens in Bracara Augusta von den dortigen Einwohnern geehrt, was erneut zeigt, wie aufmerksam man überall im Reich die Entwicklung der Kaiserfamilie verfolgte: AE 1974, 392 (s. auch CIL II 2422; ebenfalls aus Bracara Augusta; errichtet für C. Caesar von der Gesamtheit der Callaecia). Hierfür sprechen auch die zahlreichen Altäre aus Mytilene auf Lesbos (vgl. unten Anm. 185), auf denen Agrippa Postumus ebenfalls mehrfach (und oft neben seinem verstorbenen Vater Agrippa) genannt wird; s. etwa IG XII 2, 170/71.

${ }^{103}$ Vgl. die Aufstellung bei Claude Eilers, Roman Patrons of Greek Cities (Oxford 2002) 284-286.

${ }^{104}$ S. Witschel, Augustus 96-99.

${ }^{105}$ Allgemein hierzu vgl. Alexander Heinemann, Eine Archäologie des Störfalls. Die toten Söhne des Kaisers in der Öffentlichkeit des frühen Prinzipats, in: Fernande Hölscher, Tonio Hölscher (Hg.), Römische Bilderwelten. Von der Wirklichkeit zum Bild und zurück. Kolloquium Rom 2004 (Heidelberg 2007) 41-110.

${ }^{106} \mathrm{Zu}$ diesen sog. decreta Pisana s. CIL XI 1420/21 = ILS 139/40 = InscrIt VII 1, 6/7 mit dem Kommentar von Alida Marotta d'Agata, Decreta Pisana (CIL, XI, 1420-21). Edizione critica, traduzione e commento (Pisa 1980). Vgl. hierzu zusammenfassend Hartmut Galsterer, Die Trauer der Städte um verstorbene Prinzen in der frühen Kaiserzeit, in: Augusto Fraschetti (Hg.), La commemorazione di Germanico nella documentazione epigrafica. Tabula Hebana e Tabula Siarensis. Convegno internazionale di studi Cassino 1991 (Rom 2000) $173-187$. 
Trauervorschriften, verbunden mit umfangreichen posthumen Ehrungen für den Verstorbenen. Der entsprechende Senatsbeschluss ist uns allerdings nicht im Wortlaut erhalten, sondern nur aus Andeutungen in anderen Dokumenten bekannt ${ }^{107}$; er dürfte aber ähnlich ausgesehen haben wie die senatus consulta für den verstorbenen Germanicus (s. oben) und enthielt wohl wie dieser eine entsprechende Publikationsanordnung. Die Kenntnis hiervon muss sich rasch verbreitet haben, denn schon am 19. September $2 \mathrm{n}$. Chr. traf sich in Pisa der örtliche Stadtrat (und dies offenbar nicht zum ersten Mal) ${ }^{108}$, um seinerseits über Ehrungen für den toten Lucius Caesar, der auch als Patron der Gemeinde gewirkt hatte, zu beraten. Man einigte sich darauf, ein Grundstück zu kaufen und darauf einen Altar zu errichten, auf dem jedes Jahr am Todestag des Prinzen Opfer dargebracht werden sollten. Ferner sollte auf einem großen Cippus neben dem Altar der Beschluss zusammen mit den vorangegangenen Dekreten, die zu Ehren des Lucius Caesar verabschiedet worden waren, eingemeiBelt werden. Mit Letzteren sind unter anderem die Entscheidungen des Senats gemeint, die man also in Pisa bereits kannte. Das wird auch dadurch bewiesen, dass man gleichzeitig festlegte, sich in Fragen des Trauerzeremoniells den Anordnungen des Senats anzuschließen. Schließlich wollte man sobald wie möglich Gesandte nach Rom schicken, um bei Augustus zu erwirken, dass er die Ausführung der Stadtratsbeschlüsse genehmige.

Der ältere der Brüder, Caius Caesar, verstarb dann am 21. Februar 4 n. Chr. im lykischen Limyra. Die Nachricht von seinem Tode erreichte Pisa bereits am 2. April desselben Jahres. Spontan - d.h. diesmal augenscheinlich noch ohne Kenntnis der Senatsbeschlüsse, die zu diesem Zeitpunkt kaum schon verabschiedet gewesen sein können - erließ der Stadtrat erneut Trauervorschriften. Als der Tod des Prinzen in Pisa gemeldet wurde, gab es gerade keine regulär gewählten Beamten in der Stadt. Trotzdem traf man sich sofort zu einer inoffiziellen Versammlung der universi decuriones colonique und traf Anordnungen, die dann später in ein ordentliches Dekret überführt werden sollten, nachdem sie erneut durch Gesandte dem Augustus bekanntgemacht worden waren. Außerdem beschloss man die Errichtung eines aufwändigen Bogenmonuments zu Ehren des verstorbenen Caius Caesar, für das es nicht notwendigerweise ein stadtrömisches Vorbild gab ${ }^{109}$.

${ }^{107}$ So vor allem in den hier behandelten decreta Pisana. Die Beschlüsse des römischen Senats hinsichtlich der verstorbenen Prinzen (u.a. die Aufzeichnung der entsprechenden senatus consulta auf einem cippus aeneus) sind ferner bekannt aus Tab. Siar. frg. b, col. I, Z.4-7.

${ }^{108}$ Die Nachricht vom Tode des L. Caesar wird auf dem Seeweg von Massilia Pisa früher erreicht haben als Rom. Es ist wahrscheinlich, dass daraufhin der Stadtrat - wie später im Falle des Todes von C. Caesar (s. unten) - spontan zusammentrat und erste Ehrungen verabschiedete, denn der erhaltene Stadtratsbeschluss vom 19. September war augenscheinlich nicht der erste seiner Art, sondern erfolgte de augendis honoribus L. Caesaris (so zu Recht Galsterer, Trauer [wie Anm. 106] 180). Dieses zweite Dekret reagierte dann auf die mittlerweile vom Senat vorgenommenen Bestimmungen. Wie sich die Kenntnis von Letzteren in Italien und im Reich verbreitet hatte, ist in diesem Falle nicht genau bekannt, aber wohl analog zu der tabula Siarensis zu rekonstruieren. Unnötig und zu kompliziert erscheint mir daher die Annahme von Wolfgang D. Lebek, Mussolini, Lucius Caesar und die staatlichen Totenopfer am Augustus-Mausoleum, in: Preatti del XI Congresso Internazionale di Epigrafia Greca e Latina (Rom 1997) 385-393, dass der Senat neben dem allgemeinen senatus consultum ein spezielles SC für Pisa (und andere italische Städte?) erlassen habe, das dort dann fast unverändert übernommen worden sei. ${ }^{109}$ Am 2. April wird der Senat in Rom, wo die Nachricht vom Tod des C. Caesar nicht sehr viel früher eingetroffen sein kann, kaum bereits entsprechende Beschlüsse erlassen haben (vgl. Galsterer, Trauer [wie Anm. 106] 182). Die Bewohner von Pisa handelten diesmal also eigenständig, hatten aber natürlich die früheren Anordnungen über L. Caesar vor Augen und wussten außerdem einigermaßen darüber Bescheid, welche honores der Senat in einem solchen Fall beschließen würde. Dazu konnten - wie später für Germanicus - auch Bogenmonumente gehören; aber es ist zu betonen, dass die genaue Ausführung des ianus in Pisa zu dieser Zeit noch kein direktes 
Dieser Fall zeigt erneut, welch große Bedeutung städtischen Institutionen sowohl bei der Ehrung des Kaiserhauses als auch bei der Erstellung entsprechender epigraphischer Monumente zukam (dazu s. auch unten Kap. 3 und 6) und welche Rolle dabei das beständige Wechselspiel zwischen aus Rom kommenden Vorgaben, darauf reagierenden oder eigenständigen lokalen Initiativen sowie deren Rückvermittlung an die Zentrale - etwa durch Gesandtschaften - spielte. Das wird ferner dadurch unterstrichen, dass auch andere Gemeinden eigenständig Denkmäler für die verstorbenen Prinzen entwarfen. Gut zu sehen ist dies in Nordgallien, wo die drei civitates der Senones, Remi und Treveri in diese Richtung tätig wurden. In deren jeweiligen Hauptorten Sens, Reims und Trier wurden nach dem Tod von Caius und Lucius Caesar Denkmäler mit teils monumentalen Inschriften errichtet, die vermutlich die Form großer Grab-arae hatten (zumindest im Falle von Reims ist die Weihung an die Manes gesichert) ${ }^{110}$. Ebenfalls einer lokalen Initiative entsprang ein Monument, das auf der Agora von Thasos errichtet wurde. Erhalten hat sich davon ein großes rechteckiges Fundament, das sich als Sockel eines monumentalen Altares interpretieren lässt. Davor befinden sich zwei Statuenbasen. Ferner berichtet eine Inschrift, dass die Stadt Thasos die Anlage zu Ehren des verstorbenen Lucius Caesar, der hier als hèros bezeichnet wird, erbauen ließ $\beta^{111}$. Wegen der zwei Basen ist eine weitere gleichlautende Inschrift für Caius Caesar anzunehmen. Das individuell gestaltete Monument erscheint als eine Mischung aus Kenotaph und Altar. Hier dürfte eine kultische Verehrung der Verstorbenen stattgefunden haben, die wir uns ähnlich vorstellen können wie die Zeremonien, die man in Pisa nach dem Tode des Lucius Caesar beschlossen hatte. Diese Beispiele zeigen erneut die Vielfalt der - inschriftlich fixierten - Reaktionen, die wichtige Ereignisse innerhalb des Kaiserhauses im gesamten Imperium Romanum auslösen konnten und die kaum von oben gesteuert wurden.

\section{Die großen Monumente zu Ehren des Kaisers und ihre Inschriften}

Bereits im vorangegangenen Abschnitt konnte anhand einiger Beispiele aufgezeigt werden, welche Bedeutung größere Monumente, die mit entsprechend ausgestalteten Inschriften versehen waren, für die Vergegenwärtigung des Kaisers sowie seiner Leistungen und Herrschertugenden besaßen. Dies galt sowohl für die Hauptstadt Rom als auch für Italien und die Provinzen, wie nun noch etwas näher erläutert werden soll. Überliefert sind solche Denkmäler teils in literarischen Quellen, teils aber auch in längeren epigraphischen Dokumenten, und nicht zuletzt durch die zu den Monumenten gehörigen Inschriften selbst.

Eines der wichtigsten Bauprojekte der frühen Kaiserzeit war die große Platzanlage mit dem Tempel des Mars Ultor, die Augustus im Zentrum Roms errichten ließ und deren endgültige

Pendant in Rom hatte - man sollte also die Kreativität der Gemeinden bei der Konzeption solcher Ehrungen nicht unterschätzen.

${ }^{110}$ Reims: CIL XIII 3254 = AE 1979, $411=$ AE 1982, 715; dazu A. Vassileiou, La dédicace d'un monument de Reims élevé en l'honneur de Caius et Lucius Caesar, in: ZPE 47 (1982) 119-130; Robert Neiss, Une dédicace de la cité des Rèmes à C. César et L. César, in: BSocAChamp 75/4 (1982) 3-8. Zu den übrigen Denkmälern s. Witschel, Augustus 74-76.

${ }^{111}$ Guide de Thasos (Paris 1967) 31; zu der Inschrift s. Christiane Dunant, Jean Pouilloux, Recherches sur l'histoire et les cultes de Thasos, Bd. 2 (Paris 1958) 62 Nr. 178. 
Einweihung im Jahre 2 v. Chr. erfolgte ${ }^{112}$. Sie war mit einem reichen Schmuck an Bauornamentik, Reliefbildern und einer großen Zahl von Statuen samt zugehöriger Inschriften versehen, die alle in einem komplizierten Geflecht mehr oder minder expliziter Aussagen auf den Kaiser und dessen Familie sowie auf seine Taten und Leistungen zum Wohle des Imperium Romanum Bezug nahmen. Besonders bedeutsam war dabei eine Galerie der wichtigsten Männer der römischen Geschichte (der principes bzw. summi viri), die die Stadt zur Weltherrschaft geführt hatten. Ihre Taten wurden in den Inschriften, die unter den Statuen angebracht waren, in kurzen Elogien verherrlicht ${ }^{113}$. Diese sollen von Augustus selbst verfasst worden sein ${ }^{114}$. Das ist in diesem direkten Sinn allerdings wohl kaum zutreffend; vielmehr wird man annehmen, dass die Sammlung des umfangreichen Materials für die zahlreichen Kurzbiographien eher einem Mann aus der Umgebung des Kaisers anvertraut worden war, etwa Caius Iulius Hyginus, der als kaiserlicher Freigelassener der palatinischen Bibliothek vorstand und in dieser Funktion dem Kaiser zugearbeitet haben dürfte ${ }^{115}$. Immerhin war Augustus der Bedeutungsgehalt des Monuments so wichtig, dass er durch ein Edikt bekannt gegeben haben soll, wie er die Statuengalerien der Platzanlage verstanden wissen wollte ${ }^{116}$.

Ein wichtiges Thema solcher Denkmäler war die Feier der kaiserlichen Sieghaftigkeit, insbesondere nach größeren militärischen Erfolgen, die der Herrscher immer für sich beanspruchte. Einige herausragende Monumente dieser Art, die mit einer entsprechenden Inschrift versehen waren, wurden ebenfalls vom Kaiser selbst errichtet. Hierzu zählte beispielsweise das tropaeum, das Octavian/ Augustus an der Stelle erbauen ließ, wo er während der Seeschlacht von Actium sein Zelt aufgeschlagen hatte ${ }^{117}$. Dieses besaß die Form einer erhöhten Terrasse mit einem großen, reliefverzierten Altar sowie einer Statuengruppe auf dem Podium. Die Vorderfront der Anlage war in der Tradition von Seesiegdenkmälern mit bronzenen Schiffsschnäbeln geschmückt ${ }^{118}$. Darüber befand sich die riesige, fast 60 Meter lange lateinische Inschrift, die als Weihung an die Götter Mars und Neptun gehalten war pace parta terra [marique $]^{119}$. Sie verkündete, dass der Herrscher nach seinem Sieg in dem Krieg, den er in dieser Region für die res publica geführt hatte, das Lager, aus dem er gegen den Feind ausgezogen war, mit erbeuteten Schiffsteilen geschmückt und geweiht hatte. Solche kurzen Beschreibungen der militärischen Leistungen des Kaisers sind auch in den Inschriften ähnlicher Denkmäler zu finden ${ }^{120}$.

${ }^{112}$ Vgl. Paul Zanker, Forum Augustum (Tübingen 1968); ders., Augustus und die Macht der Bilder (München 1987) 196-217 und zuletzt ausführlich Martin Spannagel, Exemplaria principis. Untersuchungen zur Entstehung und Ausstattung des Augustusforums (Heidelberg 1999). Zur Baustiftung des Augustus s. Suet. Aug. 29, 1f. und 56, 2; Aug. res gest. 21 sowie die sehr stark ergänzte Dedikationsinschrift CIL VI 40311; dazu Alföldy, Studi sull'epigrafia (wie Anm. 9) 17-32.

${ }^{113} \mathrm{Zu}$ den Statuen der summi viri s. zusätzlich Hist. Aug. Alex. Sev. 28, 6; zu den Elogia jetzt CIL VI 8, 3 p. 4839 , 4847-4874 (Nr. 40931-41021a).

${ }^{114}$ So Plin. nat. 22, 13.

${ }^{115} \mathrm{Zu}$ Hyginus s. Suet. gramm. 20; Gell. 1, 14, 1; 6, 1, 2.

${ }^{116}$ Suet. Aug. 31, 5 .

${ }_{117}$ Suet. Aug. 18, 2; Cass. Dio 51, 1, 3.

118 William M. Murray, Photios M. Petsas, Octavian's Campsite Memorial for the Actian War (Philadelphia 1989); Konstantinos L. Zachos, The Tropaeum of the Sea-battle of Actium at Nikopolis. Interim Report, in: JRA $16(2003) 65-92$.

${ }^{119}$ AE 1992, $1534=$ AE 1999, 1448.

${ }^{120}$ Vgl. etwa die Inschrift des großen Denkmals (tropaeum Traiani), das Kaiser Trajan nach seinen Siegen über die Daker in Adamklissi (Moesia inferior) erbaute (CIL III $12467=13733=$ AE 1972, 521 = AE 1996, 1355): Ma[rti] Ultori/Imp(erator) [Cae]sardivi/Nerva[ef(ilius) Ne]rva/[Tr]aianu[s Aug(ustus) Germ(anicus)]/[Dac] i[c]usp[ont(ifex)] ma[x(imus)] / [trib(unicia) potes]t(ate) XIII / [imp(erator) VI co(n)s(ul)] Vp (ater)p(atriae) / 
Häufiger als diese vom Herrscher selbst initiierten Siegesdenkmäler waren aber solche, die zur Verherrlichung der militärischen virtus des Kaisers von anderen Institutionen errichtet wurden, vor allem von Senat und Volk von Rom $(S P Q R)$. Hierzu gehörten neben den Triumphbögen in Rom weitere Bogenmonumente in Italien und in den Provinzen ${ }^{121}$. Ein besonders gutes Beispiel für ein Monument dieser Art ist das von $S P Q R$ gestiftete und im Jahr 7/6 v. Chr. eingeweihte tropaeum Alpium in La Turbie (Alpes maritimae), das an die Eroberung der Alpenregion unter Augustus erinnerte $^{122}$. Hier lässt sich das Zusammenspiel von spektakulärer Plazierung, eindrucksvoller architektonischer Form und monumentaler Inschriftengestaltung besonders gut nachvollziehen: Das Denkmal wurde nicht am Ort eines tatsächlichen Kampfgeschehens erbaut, sondern an einem weithin sichtbaren Platz hoch über dem Meer an der wichtigsten Straßenverbindung zwischen Italien und Gallien. Über einem gewaltigen Podium erhob sich ein großer, säulengeschmückter Rundbau. Die Inschrift war an dem Sockel des Monuments angebracht und wurde von in Relief ausgeführten Victorien und Tropaia gesäumt. Sie hatte enorme Ausmaße (ca. $19 \mathrm{~m}$ Breite und ca. 4,70 m Höhe mit Buchstaben von bis zu 37 cm Höhe) und berichtete zunächst, dass Senat und Volk von Rom das Denkmal dem Augustus geweiht hatten, weil unter seiner Führung alle Alpenvölker unter die Oberhoheit des populus Romanus gebracht worden waren. Hierauf folgte die vollständige Auflistung der über 40 gentes Alpinae devictae, was die Großartigkeit des vom Kaiser errungenen Sieges noch einmal unterstrich ${ }^{123}$. Ähnlich beeindruckend muss der Bogen gewesen sein, den vermutlich ebenfalls Senat und Volk von Rom nach der erfolgreichen Niederschlagung des Bar Kochba-Aufstandes bei Scythopolis (Syria Palaestina) für Kaiser Hadrian errichteten und der eine monumentale, in lateinischer Sprache abgefasste Inschrift trug ${ }^{124}$. Bisweilen wurden auch mehrere Siegesdenkmäler an verschiedenen Orten zur Erinnerung an ein- und dasselbe Ereignis errichtet: Die Eroberung Britanniens unter Kaiser Claudius im Jahre 43 wurde zum einen durch einen Triumphbogen in Rom kommemoriert, den erneut Senat und Volk einige Zeit später erbauen ließen. Die großformatige Inschrift, von der sich Teile erhalten haben, hob hervor, dass Claudius elf britannische Könige in nur wenigen Tagen besiegt und ihre Gebiete und Völkerschaften als erster in die Gewalt des römischen Volkes gebracht hatte ${ }^{125}$. Zum anderen ehrte der Senat den Kaiser durch einen weiteren, nur literarisch überlieferten Bogen am Ausgangsort der Expedition in Nordgallien ${ }^{126}$. Manchmal wurden solche Siegesdenkmäler auch von den Truppen konzipiert, die in die Kämpfe involviert gewesen waren ${ }^{127}$. So wurde in der Nähe von Xanten (Germania inferior) eine Inschriftenplatte

[devicto? exer]citu D[acorum et Sarmata?]rum [---]. Siehe ferner ein nur literarisch überliefertes Siegesdenkmal, das Germanicus nach seinen Siegen in Germanien errichten und mit folgender „stolzer Inschrift“ versehen ließ (Tac. ann. 2, 22, 1): debellatis inter Rhenum Albimque nationibus exercitum Tiberii Caesaris ea monimenta Marti et Iovi et Augusto sacravisse.

${ }^{121}$ Vgl. Sandro De Maria, Gli archi onorari di Roma e dell'Italia romana (Rom 1988).

122 Jules Formigé, Le trophée des Alpes, La Turbie (Paris 1949); Le trophée des Alpes, Nice Historique 108/2 (2005).

${ }^{123}$ Von der Inschrift haben sich vor Ort nur Fragmente erhalten (s. CIL V 7817); sie lässt sich aber aufgrund des Zitats bei Plin. nat. hist. 3, 136-138, der den vollen Wortlaut wiedergibt, in ihrer Gesamtheit rekonstruieren.

${ }^{124}$ AE 1999, 1688; dazu Werner Eck, Gideon Foerster, Ein Triumphbogen für Hadrian im Tal von Beth Shean bei Tel Shalem, in: JRA 12 (1999) 294-313. Die Inschrift war ca. 11 m breit und ca. 2 m hoch; die Buchstabenhöhe beträgt bis zu $41 \mathrm{~cm}$. Ein weiteres aus diesem Anlass errichtetes Siegesmonument für Hadrian, ebenfalls gestiftet von SPQR, stand in Rom: CIL VI $974=40524$.

${ }^{125}$ CIL VI $920=40416=$ ILS 216.

${ }^{126}$ Cass. Dio 60, 22, 1 .

${ }^{127}$ Hierzu auch Eck, Monumente (wie Anm. 15) 483-485; Eck, Foerster, Triumphbogen (wie Anm. 124) 305-307. 
gefunden, die zu dem Sockel eines größeren Monuments gehört haben muss, welches die legio VI Victrix nach der erfolgreichen Niederschlagung des Bataver-Aufstandes für Kaiser Vespasian und seinen Sohn Titus aufstellte ${ }^{128}$.

Ein weiterer wichtiger Anlass für die Errichtung großer, vom Senat oder anderen Institutionen konzipierter Denkmäler zu Ehren des Kaiserhauses, die innerhalb und außerhalb Roms zur Aufstellung kamen, war der (frühzeitige) Tod eines Mitgliedes der domus Augusta, insbesondere eines präsumtiven Nachfolgers. Zwei Beispiele hierfür mögen genügen: Das eine führt noch einmal zurück auf Caius Caesar, der - wie erwähnt (s. oben Kap. 2) - im Februar 4 n. Chr. in Limyra in Lykien verstorben war. An diesem Ort wurde daraufhin ein großes Kenotaph für ihn errichtet. Der Stifter des Monuments ist nicht explizit überliefert, aber Bauausführung und -ornamentik sowie die leider nur sehr fragmentarisch erhaltene lateinische Widmungsinschrift (die mit ca. $30 \mathrm{~m}$ Länge erneut ein monumentales Format aufwies) sprechen eindeutig dafür, hierin ein Denkmal zu sehen, das in Rom konzipiert wurde, vermutlich auf Initiative von SPQR und mit Zustimmung des Augustus. Dafür sprechen zudem die wenigen Reste des höchst qualitätvollen Reliefschmucks, denn dieser präsentierte offenbar die wichtigsten Taten (res gestae) des Prinzen an der östlichen Grenze des Reiches, die in verkürzter Form auch in der Inschrift referiert worden zu sein scheinen ${ }^{129}$. Noch umfangreicher waren die Ehrungen, die der Senat nach dem Tod des Germanicus im Herbst $19 \mathrm{n}$. Chr. beschloss und die wir aus den entsprechenden, inschriftlich überlieferten senatus consulta, insbesondere aus der schon erwähnten tabula Siarensis, kennen ${ }^{130}$. Neben vielen anderen Maßnahmen verfügte der Senat die Errichtung dreier Ehrenbögen, um die bemerkenswerten Taten des verstorbenen Prinzen zu kommemorieren ${ }^{131}$. Diese Bögen sollten an besonders prominenten Orten plaziert werden, die mit der Karriere des Germanicus in Verbindung standen ${ }^{132}$ : Einer in Rom, ein zweiter am Ufer des Rheines in der Nähe des tumulus für seinen Vater Drusus (d.h. in Mainz), und ein dritter auf den Höhen des Mons Amanus in Syrien. Keines dieser Bauwerke hat sich erhalten ${ }^{133}$, aber die detaillierten Beschreibungen in der tabula Siarensis liefern uns zumindest gewisse Anhaltspunkte zu deren Aussehen. Der Bogen in Rom war mit Reliefs geschmückt, die die von Germanicus unterworfenen Völkerschaften zeigten (cum signis devictarum gentium); und er sollte mit einer ausführlichen Inschrift versehen werden, die berichtete, dass SPQR das Denkmal zur Erinnerung an Germanicus erbaut hatten, um dann zur Aufzählung seiner wichtigsten Leistungen für das Reich in West und Ost überzugehen. Der Bogen trug eine Statuengruppe, die Germanicus im Triumphalwagen zeigte, umgeben von den Mitgliedern seiner Familie. Die Angaben zu den Bögen in Syrien und am Rhein sind wesentlich kürzer (und schlechter erhalten), aber wir können recht sicher sein, dass sie ähnlich ausgesehen haben dürften und ebenfalls die wichtigsten Taten des Germanicus in Wort und Bild vorführten.

${ }^{128}$ AE 1979, 413; dazu Christoph B. Rüger, Ein Siegesdenkmal der legio VI victrix, in: BJ 179 (1979) 187-200. ${ }^{129}$ Vgl. dazu Joachim Ganzert, Das Kenotaph für Gaius Caesar in Limyra (Tübingen 1984) mit den epigraphischen Beiträgen von Peter Herz (118-127 und 178-192); die Aufsätze von Ganzert und Jürgen Borchhardt in: Götter, Heroen, Herrscher in Lykien, Ausstellungskatalog Schloss Schallaburg (Wien, München 1990) sowie Jürgen Borchhardt, Der Fries vom Kenotaph für Gaius Caesar in Limyra (Wien 2002) mit zahlreichen, an manchen Punkten zu weit gehenden Spekulationen.

${ }^{130}$ S. oben Anm. 35.

${ }^{131}$ Vgl. Wolfgang D. Lebek, Die drei Ehrenbögen für Germanicus: Tab. Siar. frg. I 9-34; CIL VI 31199a 2-17, in: ZPE 67 (1987) 129-148; ders., Ehrenbogen und Prinzentod: 9 v. Chr.-23 n. Chr., in: ZPE 86 (1991) 47-78.

${ }^{132}$ Zusammengefasst bei Tac. ann. 2, 83, 2: Arcus additi Romae et apud ripam Rheni et in monte Suriae Amano cum inscriptione rerum gestarum ac mortem ob rem publicam obisse ...

${ }^{133}$ Zur Problematik des Bogens in Mainz vgl. Witschel, Augustus 83f. 
Andere Denkmäler betonten die Rolle des Kaisers als Wohltäter des Reiches, der in seiner Sorge (cura) um die Untertanen wichtige Infrastrukturmaßnahmen durchführen ließ. Erst seit wenigen Jahren bekannt ist ein großes, vermutlich von einer Reiterstatue bekröntes Pfeilermonument, das auf einem zentralen Platz der bedeutenden lykischen Hafenstadt Patara gestanden haben muss. Es trug zwei Inschriften: Die eigentliche Widmungsinschrift auf der (schmaleren) Vorderseite war an den Kaiser Claudius (im Dativ) gerichtet, der als „Retter“ gefeiert wurde und dafür, dass durch „seine göttliche Vorsehung“ die Unruhen und räuberischen Umtriebe in der Region beigelegt worden waren sowie die innere Ordnung wiederhergestellt wurde. Stifter des Monuments war laut der Inschrift die Gemeinschaft der Lykier, die als „Römer- und Kaiserfreunde“ bezeichnet werden. Sie hätten das Denkmal aus Dankbarkeit errichtet für etwas, was sie vom Kaiser durch die Vermittlung des Statthalters Q. Veranius erhalten hatten (hier ist der Text schlecht erhalten). Auf der linken Seite folgte eine zweite Inschrift, die nunmehr Claudius im Nominativ anführte, ihn aber in überhöhender Weise als „Herrscher über den gesamten Erdkreis“ "benannte und berichtete, dass auf seine Veranlassung durch den bereits genannten Statthalter Veranius in ganz Lykien Straßen vermessen und ausgebaut worden waren. Das inschriftliche Verzeichnis dieser Straßenverbindungen ist danach angefügt; es zieht sich in Form einer detaillierten Auflistung (mit Angabe der Entfernungen in Stadien) über beide Nebenseiten. Der Sinn dieser Liste (des sogenannten stadiasmus provinciae Lyciae bzw. Patarensis) kann nun kaum darin gelegen haben, dem Betrachter praktische Hinweise für eine Reise durch Lykien zu geben; vielmehr scheint es in erster Linie darauf angekommen zu sein, ihm in möglichst umfangreicher Form die Bautätigkeit des Kaisers vor Augen zu führen und die Erinnerung an diese zu bewahren ${ }^{134}$.

Durch epigraphische Neufunde und -interpretationen der letzten Jahre ist eine weitere Gruppe von Monumenten stärker in das Blickfeld getreten, die an besonders markanten Plätzen errichtet wurden und mit dem Namen des Kaisers oder von Mitgliedern seiner Familie verbunden waren, nämlich Leuchttürme an Hafeneinfahrten oder auf Promontorien. So konnte von Géza Alföldy gezeigt werden, dass das Tiberieum, das Pontius Pilatus als praefectus Iudaeae in Caesarea maritima restaurieren ließ, zusammen mit dem in literarischen Quellen angeführten Drouseion ein ursprünglich von dem Klientelkönig Herodes erbautes Paar von Leuchttürmen bildete, die den Zugang zum Hafen von Caesarea flankierten und nach den beiden Stiefsöhnen des Augustus benannt waren in Anlehnung an stadtrömische Denkmäler, die ebenfalls das Brüderpaar zusammen verewigten ${ }^{135}$. Gleichzeitig wird in der Inschrift betont, dass das Bauwerk zur Unterstützung der Seeleute (nautae) konstruiert worden war. Dieser Aspekt findet sich auch in der monumentalen und mit vergoldeten Bronzebuchstaben versehenen Bauinschrift eines erst vor kurzem entdeckten Leuchtturms in Patara. Diese berichtet davon, dass Kaiser Nero den pharos (zusammen mit einem Pendant) zum

134 SEG 51 (2001) 1832; dazu Fahri Işık u.a., Miliarium Lyciae. Das Wegweisermonument von Patara Vorbericht, in: Lykia 4 (1998/99 [2001]); Christopher P. Jones, The Claudian Monument at Patara, in: ZPE 137 (2001) 161-168; Sencer Şahin, Mustafa Adak, Stadiasmus Patarensis. Itinera romana provinciae Lyciae (Istanbul 2007).

${ }^{135}$ S. AE 1963, 104 in der Neulesung von Géza Alföldy, Pontius Pilatus und das Tiberieum von Caesarea Maritima, in: SCI 18 (1999) 65-108; vgl. ferner ders., Nochmals: Pontius Pilatus und das Tiberieum von Caesarea Maritima, in: SCI 21 (2002) 133-148. Zu beiden Seiten der Hafeneinfahrt standen ferner auf Säulen je drei überlebensgroße Statuen von Mitgliedern der kaiserlichen Familie. Die gesamte Anlage trug darüber hinaus die Bezeichnung „Kaiserhafen“ (Sebastos limēn). 
Schutz der Seefahrenden erbaut hatte ${ }^{136}$. Im äußersten Norden Hispaniens, an der asturischen Küste und in der Nähe der bedeutenden einheimischen Siedlung Noega, ließ der Statthalter Cn. Calpurnius Piso auf dem Cabo Torres bei Gijón ein Monument errichten. Von diesem hat sich die Inschrift auf einem großen Block aus importiertem Marmor erhalten, aus der wir erfahren, dass das Denkmal dem Kaiser Augustus geweiht (sacrum) war ${ }^{137}$. Der Stein wurde im Kontext eines antiken Gebäudes gefunden, welches sich möglicherweise als Leuchtturm identifizieren lässt ${ }^{138}$. In Gallaecia gab es, wie wir aus der literarischen Überlieferung wissen, ein weiteres bekanntes Turm-Monument zu Ehren des Augustus mit einer entsprechenden, vermutlich eindrucksvoll gestalteten Inschriff ${ }^{139}$.

Man sieht an den hier vorgeführten Beispielen, wie mit Hilfe solcher Denkmäler bedeutsame Erinnerungsorte gezielt besetzt wurden, wobei den Inschriften im Verbund mit der bildlichen Austattung der Monumente (Reliefs, Statuen) die Funktion zukam, einerseits genauere Auskunft über die gefeierten Erfolge zu geben und andererseits selbst wiederum den Betrachter durch ihre Monumentalität oder ihren Umfang zu beeindrucken und von der Sieghaftigkeit des durch sie gefeierten Herrschers zu überzeugen. Hervorzuheben ist in diesem Zusammenhang, dass der Kaiser in der Mehrzahl der Fälle zumindest nominell nicht selbst als Urheber dieser Monumente auftrat. Die zugehörigen Inschriften weisen vielmehr andere Institutionen (vor allem $S P Q R$, aber auch die Armee oder die plebs) als Initiatoren aus. Gegen einen in der modernen Forschung weit verbreiteten Trend, solche Formulierungen als reine Fassade hinzustellen, hinter welcher der Kaiser die eigentliche Konzeption der für seine Repräsentation so bedeutsamen Denkmäler vorgenommen habe, scheinen mir die Inschriften in ihrem Wortlaut doch ernster zu nehmen sein ${ }^{140}$. Wir sollten demnach davon ausgehen, dass solche Ehrungen tatsächlich an den Kaiser herangetragen wurden, wobei den Stiftern ein gewisser Gestaltungsspielraum verblieb, um eigene Vorstellungen bezüglich des Herrscherideals in das Design des Denkmals einzubringen. Dies schließt keineswegs aus, dass auch der Herrscher selbst häufiger in den Planungsprozess einbezogen wurde. Zumindest dürfen wir von einer ständigen Kommunikation zwischen Senat und Kaiser in diesen Angelegenheiten

\footnotetext{
${ }^{136}$ Havva İskan-Işık u.a., Der Leuchtturm von Patara und Sex. Marcius Priscus als Statthalter der Provinz Lycia von Nero bis Vespasian, in: ZPE 164 (2008) 91-121.

${ }^{137}$ CIL II $2703=$ AE 1971, 197 = AE 2005, 851; dazu Ronald Syme, A Governor of Tarraconensis, in: Ders., Roman Papers, Bd. 2 (Oxford 1979) 732-741.

${ }^{138}$ So jetzt Carmen Fernández Ochoa u.a., La torre de Augusto en la Campa Torres (Gijón, Asturias). Las antiguas excavaciones y el epígrafe de Calpurnio Pisón, in: AEA 78 (2005) 129-146.

${ }^{139}$ Pomp. Mela 3, 11: sars iuxta turrem Augusti titulo memorabilem. Vgl. ferner oben Anm. 74 zu den in derselben Region errichteten arae Sestianae. Sestius markierte mit der Weihung dieser Altäre das Ende der bekannten und von Augustus für das Imperium Romanum erschlossenen Welt.

${ }^{140}$ Gut zu verfolgen ist die diesbezügliche Diskussion am Beispiel des Trajansbogens von Benevent. Auch dieser war nach Ausweis der Widmungsinschriften (CIL IX 1558 = ILS 296) ein Denkmal, das von SPQR für den Kaiser errichtet wurde. Das hat größere Teile der modernen Forschung jedoch nicht davon abgehalten, in Trajan selbst den eigentlichen Urheber für den reichen Reliefschmuck des Monuments, der den Herrscher in verschiedenen Handlungszusammenhängen vorführte, zu erkennen; vgl. etwa Klaus Fittschen, Das Bildprogramm des Trajansbogens zu Benevent, in: AA (1972) 742-788; Wolfgang Kuhoff, Felicior Augusto melior Traiano. Aspekte der Selbstdarstellung der römischen Kaiser während der Prinzipatszeit (Frankfurt am Main 1993) 233-236 (dazu Christian Witschel, in: Klio 78 [1996] 526-528). Dem ist entgegenzuhalten, dass die Bildzyklen durchaus eigenständige Facetten aufweisen, was darauf schließen lässt, dass die Aussage der Inschriften ernst genommen werden sollte; so schon Franz J. Hassel, Der Trajansbogen von Benevent. Ein Bauwerk des römischen Senats (Mainz 1966) und jetzt noch einmal nachdrücklich Ortwin Dally, Das Bild des Kaisers in der klassischen Archäologie - oder: Gab es einen Paradigmenwechsel nach 1968?, in: JDAI 122 (2007) 223-257, bes. 225-231.
} 
ausgehen, so wie sie beim Zustandekommen einiger senatus consulta, die Ehrungen für Mitglieder des Kaiserhauses betrafen, auch explizit belegt ist ${ }^{141}$. Dennoch ist es wichtig zu betonen, dass der Herrscher selbst bei denjenigen Monumenten und Inschriften, die den Menschen im Imperium Romanum am eindrucksvollsten seine überragende Stellung und seine Leistungen vermittelten, zumeist nicht die alleinige Verfügungsgewalt hinsichtlich der Planung und Ausführung von deren textlicher und bildlicher Gestalt besaß.

Die Wirkung, die diese Denkmäler bei der Bevölkerung entfalteten, ist daran zu erkennen, dass sie auf lokaler Ebene vielfach nachgeahmt wurden. Dieses Phänomen ist gut bezeugt und kann hier nur anhand weniger Einzelfälle vorgeführt werden. Besonders auffällig ist, wie sowohl die architektonische Gestalt des Augustusforums als auch dessen einzelne Bestandteile, inklusive der Tituli, in zahlreichen Gemeinden des Imperium Romanum zitiert wurden. Dies konnte ausschnitthaft geschehen, indem man etwa einige der Elogien des Augustusforums kopierte ${ }^{142}$, oder aber in Form einer Art von Nachbau der gesamten Platzanlage mitsamt ihrer Statuen- und Inschriftenausstattung. Hierfür kennen wir mittlerweile mit dem sogenannten ,Marmorforum' im lusitanischen Augusta Emerita (Mérida) ein herausragendes Beispiel ${ }^{143}$. Diese um die Mitte des 1.Jahrhunderts n. Chr. errichtete Baustruktur erweist sich - soweit noch erkennbar - wenn nicht in der Gesamtarchitektur, so doch in zentralen Elementen der Ausstattung als eine weitgehend getreue Nachbildung des Augustusforums; darunter befand sich auch eine Kopie des Elogiums für Aeneas und der zugehörigen Statuengruppe ${ }^{144}$.

Die großen kaiserlichen Siegesdenkmäler wurden ebenfalls in erheblichem Umfang rezipiert. So errichtete man in den südgallischen Städten während der frühen Kaiserzeit mehrere Bogenmonumente, deren Reliefschmuck die Überwindung der Barbaren vorführte, oder stellte auf den Fora Monumente auf, die wie das tropaeum Alpium die römische Eroberung bestimmter Regionen feierten ${ }^{145}$. Auch der Britanniensieg des Claudius fand entsprechende Resonanz: Im etrurischen Rusellae erfüllte ein flamen Augustalis und Militärtribun im Jahre 45 ein Gelübde, das er

${ }^{141}$ Vgl. oben Anm. 32.

${ }^{142}$ Ausschnitthafte Zitate des Augustusforums in italischen Städten sind aus Arretium und Pompeii bekannt. Zu Arretium s. InscrIt XIII 3, 78-84 = ILS 50, 54, 56-60: Insgesamt sieben Hermenpfeiler(?) mit Elogien, die die stadtrömischen Vorbilder inhaltlich offenbar genau kopierten, jedoch deren Ordination veränderten. $\mathrm{Zu}$ Pompeii s. InscrIt XIII 3, 85/86 = ILS 63/64: Aus einer ursprünglich wohl wesentlich weniger umfangreichen Serie haben sich hier nur die Elogien für Aeneas und Romulus erhalten. Sie gehörten wohl nicht zum sog. Bau der Eumachia am Forum der Stadt, wie man früher vermutet hat, sondern eher zu dem benachbarten ,Heiligtum der Lares Publici. Auf jeden Fall scheint es sich hierbei um ein munizipales Projekt gehandelt zu haben. Auch andere für die augusteische Selbstdarstellung zentrale stadtrömische Monumente wurden in Italien und den Provinzen zitiert, so der clupeus virtutis (s. Aug. res gest. 34), von dem sich eine Kopie in Arelate gefunden hat, die auf dem Forum der Stadt zu sehen war: AE 1952, 165; dazu Witschel, Augustus 51 f.

${ }^{143}$ Vgl. hierzu Walter Trillmich, Gestalt und Ausgestaltung des ,Marmorforums' in Mérida. Kenntnisstand und Perspektiven, in: MDAI(M) 36 (1995) 269-291; José L. de la Barrera Antón, La decoración arquitectónica de los foros de Augusta Emerita (Rom 2000). Rückgriffe auf das Augustusforum gab es in reduzierter Form im Übrigen auch in den beiden anderen hispanischen Provinzhauptstädten Corduba und Tarraco. Vgl. dazu Walter Trillmich, Los tres foros de Augusta Emerita y el caso de Corduba, in: Pilar León (Hg.), Colonia Patricia Corduba. Una reflexión arqueológica (Sevilla 1996) 175-195; ders., Il modello della metropoli, in: Hispania Romana. Da terra di conquista a provincia dell'impero. Ausstellungskatalog Rom (Mailand 1997) 131-141.

${ }^{144}$ AE 1996, 864 = Ramírez Sádaba, Inscripciones (wie Anm. 12) Nr. 76; dazu Walter Trillmich, José L. de la Barrera Antón, Eine Wiederholung der Aeneas-Gruppe vom Forum Augustum samt ihrer Inschrift in Mérida (Spanien), in: MDAI(R) 103 (1996) 119-138.

${ }^{145} \mathrm{Zu}$ den südgallischen Bogenmonumenten, die augenscheinlich von den lokalen Eliten konzipiert wurden, vgl. Annette Küpper-Böhm, Die römischen Bogenmonumente der Gallia Narbonensis in ihrem urbanen Kontext 
[p]ro salute et reditu et victoria Britannica des Claudius abgelegt hatte ${ }^{146}$. Im selben Jahr wurde Claudius - ebenfalls in Erfüllung eines Gelübdes - auch in Antiochia ad Pisidiam (Galatia) pro incolumitate eius et victoria Britannica durch einen weiteren ehemaligen Truppenkommandeur geehrt ${ }^{147}$. In Korinth (Achaia) ernannte man einen eigenen sacerdos victoriae Britannicae ${ }^{148}$; und in Kyzikos (Asia) errichteten die $c$ (ives) R(omani) qui Cyzici [consistunt] et Cyzi[ceni] einen arcus mit einer Inschrift, die diejenige des Bogens in Rom (s. oben) zu zitieren scheint ${ }^{149}$. Gerade die letztgenannten Beispiele können zeigen, dass die Reaktion auf die kaiserlichen Siege keineswegs nur in den direkt betroffenen Regionen erfolgte, sondern auch in weit entfernten Gebieten, wo man dennoch genau registriert zu haben scheint, was in Bezug auf die Ehrung des Herrschers gerade angesagt war ${ }^{150}$.

Besonders ausgeprägt war dieses Phänomen anlässlich der wiederholten Todesfälle im Kaiserhaus in der augusteisch-tiberischen Epoche. Die Nachrichten hierüber lösten überall im Reich die Errichtung von Monumenten zu Ehren der verstorbenen Prinzen aus. Wir haben dies schon in Bezug auf Caius und Lucius Caesar gesehen (s. oben Kap.2), aber die Ausrichtung an den vom Senat und anderen zentralen Institutionen gestifteten Denkmälern ist vielleicht noch besser greifbar in der Zeit nach dem Tod des Germanicus und dem des Drusus minor im Jahre 23 n. Chr., der postum vom Senat ganz ähnliche Ehrungen erhielt wie sein Adoptivbruder ${ }^{151}$. Die Kenntnis von den Ehrenbögen, die man in Rom und anderen Orten für Germanicus und Drusus erbaut hatte, scheint sich rasch verbreitet zu haben, nicht zuletzt durch Abschriften der diesbezüglichen senatus consulta und deren inschriftliche Publikation. An verschiedenen Orten entschloss man sich daraufhin, ähnliche Bauten zu errichten. Diese stellten allerdings in der Regel keine exakten Kopien ihrer Vorbilder dar, sondern variierten diese, indem etwa ein einziger Bogen für mehrere Mitglieder der domus Augusta konzipiert ${ }^{152}$ oder lediglich die bekrönende Statuengruppe in Form eines partiellen Zitats umgesetzt wurde ${ }^{153}$.

(Espelkamp 1996); Witschel, Augustus 57f. Ein gutes Beispiel für die zweite angesprochene Kategorie ist das tropaeum von Saint-Bertrand-de-Comminges (Aquitania): ebd. 73.

${ }^{146}$ AE 1980, 457; s. auch 458.

${ }^{147}$ AE 2001, 1918.

${ }^{148}$ Das Amt ist mehrfach belegt, so in: Allen Brown West, Corinth, Bd.7.2: Latin Inscriptions 1896-1926 (Cambridge, Mass. 1931) 71-74 Nr. 86.

${ }^{149}$ CIL III 7061 = ILS 217: ... vind(ici) lib(ertatis) devi[ctori regum XI] / Britanniae ar[cum posuerunt].

150 Ähnliches lässt sich bei der Verherrlichung von Domitians Germanensiegen beobachten, die auch im fernen Asia aufgegriffen wurde: Michael Dräger, Die Städte der Provinz Asia in der Flavierzeit (69-96 n. Chr.). Studien zur kleinasiatischen Stadt- und Regionalgeschichte (Frankfurt am Main 1993) 122-136.

${ }^{151}$ S. Tac. ann. 4, 9, 2: Memoriae Drusi eadem quae in Germanicum decernuntur, plerisque additis... Es gibt in diesem Fall erneut einige inschriftliche Evidenz zu den entsprechenden senatus consulta, die allerdings nicht so gut erhalten ist wie bei Germanicus: Crawford, Roman Statutes (wie Anm. 35) 544-547 Nr. 38. Vgl. dazu Wolfgang D. Lebek, Die posthumen Ehrungen und der Triumph des Drusus Caesar (CIL VI 31200 B col. I 1-4; Tac. ann. 4, 9, 2), in: ZPE 78 (1989) 83-91.

${ }^{152}$ Außerdem vereinfachte man zumeist die Aussage der Vorbilder, indem man auf den Reliefschmuck und die ausführlichen Elogien verzichtete. So ließ in Spoletium der lokale Stadtrat im Jahre 23 einen ursprünglich wohl für Augustus erbauten Bogen am Eingang zum Forum auf die beiden Prinzen umwidmen: CIL XI 4776/77; dazu De Maria, Archi onorari (wie Anm. 121) 328f. Nr. 109; Henner von Hesberg, Zur Datierung des römischen Ehrenbogens von Spoleto, in: KJ 23 (1990) 109-116. In Saintes errichtete hingegen ein reicher Bürger der Stadt namens Caius Iulius Rufus, der zu der frühzeitig romanisierten, einheimischen Elite (s. oben Anm. 75) gehörte, an der Ausfallstraße nach Lyon einen Bogen für Tiberius, Germanicus und Drusus minor, der wohl mit einer entsprechenden Statuengruppe auf der Attika versehen war. Der Bogen weist eine ungewöhnliche zweitorige Form auf, die als Zeichen für die architektonische Eigenständigkeit des Projektes zu werten ist: CIL XIII 1036 
Die Errichtung des großen Pfeilermonuments in Patara, das die Straßenbautätigkeit des Kaisers Claudius in Lykien feierte, wurde begleitet von der Konzeption weiterer Denkmäler (Statuen und Altäre), die ebenfalls und in teilweise ganz ähnlichen Formulierungen die Leistungen des Herrschers feierten und in den Städten Lykiens sowie am Rande der kurz zuvor ausgebauten Straßen zur Aufstellung kamen ${ }^{154}$. All die hier angeführten Fälle zeigen sehr deutlich, welche Wirkung von den großen Monumenten, die den Herrscher ehrten und seine Taten kommemorierten, ausging, und in welchem Maße sich die Bevölkerung des Reiches an ihnen orientierte. Die hieraus entstehenden Nachahmungen waren jedoch in der Regel keine sklavischen Kopien, und es gibt auch kaum Anzeichen dafür, dass ihre Errichtung von oben gesteuert worden wäre.

\section{Kaiserliche Bauinschriften und Meilensteine}

Wie im vorigen Abschnitt zu sehen war, gab es im gesamten Reich zahlreiche Gebäude und andere Monumente, die dem Kaiser vom Senat, von Stadtgemeinden oder von Einzelpersonen gewidmet wurden, und zwar sowohl im profanen wie auch im kultischen Kontext (zu Letzterem s. unten Kap. 5). Ausgedrückt wurde dies in Bauinschriften, an deren Beginn der Name des Kaisers im Dativ aufgeführt und der Herrscher somit als Empfänger der Widmung prominent herausgestellt wurde ${ }^{155}$. Für unser Thema interessanter sind jedoch diejenigen Bautituli, in denen der Kaiser im Nominativ genannt ${ }^{156}$ und damit - zumindest im Inschriftenformular - als handelnde Figur bei einer Baumaßnahme ausgewiesen wurde ${ }^{157}$. Diese Inschriften waren oft besonders aufwändig

= ILA Santons 7; dazu Louis Maurin, Saintes antique des origines à la fin du VIe siècle après J.-C. (Saintes 1978) 71-81; Emmanuelle Rosso, Présence de la domus impériale julio-claudienne à Saintes. Statuaire et épigraphie, in: Aquitania 17 (2000) 121-149; Witschel, Augustus 71f.

${ }^{153}$ So in Lepcis magna auf der Plattform, die dem Roma und Augustus-Tempel vorgelagert war; s. IRT 334a-b in der Neulesung von Walter Trillmich, Der Germanicus-Bogen in Rom und das Monument für Germanicus und Drusus in Leptis Magna. Archäologisches zur Tabula Siarensis (I 9-21), in: Julián González, Javier Arce (Hg.), Estudios sobre la tabula Siarensis. Actas de las Jornadas celebradas en Sevilla 1986 (Madrid 1988) 51-60.

${ }^{154}$ S. SEG 52 (2002) 1438 (altarartiges Monument an der Straße von Myra nach Limyra); SEG 50 (2000) 1350 (Statuenbasis für Claudius aus Gagai; der Kaiser erscheint hier als epiphanestatos soter theos); dazu Thomas Marksteiner, Michael Wörrle, Ein Altar für Kaiser Claudius auf dem Bonda tepesi zwischen Myra und Limyra, in: Chiron 32 (2002) 545-569 (zu weiteren Statuenbasen für Claudius in Lykien mit ähnlich formulierten Inschriften s. ebd. 562 A. 61); Şahin, Adak, Stadiasmus Patarensis (wie Anm. 134) $42 \mathrm{f}$.

${ }^{155}$ Daneben begegnet der Name des Kaisers am Beginn von Bauinschriften gelegentlich im Ablativ. Er ist in diesen Fällen vorrangig aus Datierungsgründen genannt, aber durch die prominente Platzierung des Herrschers in solchen Inschriften konnten naturgemäß auch diese zur Verherrlichung des Princeps beitragen.

${ }^{156}$ Anzuschließen sind hier Inschriften, die davon berichten, dass eine bestimmte Baumaßnahme „auf Befehl“ (iussu) o.ä. des Kaisers durchgeführt wurde; s. etwa IRT 930 (Lepcis magna/Africa proconsularis) oder IAlexandreia Troas (IK 53) 34 = AE 1975, 806, eine Ehreninschrift aus Alexandreia Troas (Asia) für einen praef(ectus) ... operum quae in colonia iussu Augusti facta sunt; dazu Peter A. Brunt, C. Fabricius Tuscus and an Augustan dilectus, in: ZPE 13 (1974) 161-185. Zu Gebäuden, die unter den auspicia des regierenden Kaisers errichtet wurden, vgl. Géza Alföldy, Traianus Pater und die Bauinschrift des Nymphäums von Milet, in: REA 100 (1998) 367-399.

${ }_{157} \mathrm{Zu}$ den kaiserlichen Bauinschriften im Osten des römischen Reiches vgl. Ramsay MacMullen, Roman Imperial Building in the Provinces, in: HSPh 64 (1959) 207-235; Stephen Mitchell, Imperial Building in the Eastern Roman Provinces, in: HSPh 91 (1987) 333-365; Benjamin Isaac, The Limits of Empire. The Roman Army in the East (Oxford ${ }^{2}$ 1992) 333-371 sowie die Studie von Engelbert Winter, Staatliche Baupolitik und Baufürsorge in den römischen Provinzen des kaiserzeitlichen Kleinasien (Bonn 1996). Die entsprechenden 
gestaltet und hoben durch ihre Monumentalität oder die Verwendung von litterae aureae die Rolle des Kaisers als des größten Bauherren im Imperium Romanum hervor ${ }^{158}$. Sie waren somit ein bedeutsames Mittel der kaiserlichen Repräsentation, indem sie eine der wichtigsten Tugenden des Herrschers, seine Freigebigkeit (verschiedentlich als liberalitas, munificentia oder indulgentia bezeichnet) und Fürsorge (cura) für die Bevölkerung des Reiches, in Rom, Italien und den Provinzen zum Ausdruck brachten, wobei hier einmal mehr der Text der Inschrift, deren Form sowie ihr Kontext - die Architektur, in die der Titulus eingebunden war - in der Aussage zusammenwirkten.

Zwei Probleme verbinden sich mit der historischen Interpretation dieser Zeugnisse. Zum ersten muss danach gefragt werden, inwieweit der Kaiser in die praktische Umsetzung einer in seinem Namen durchgeführten Baumaßnahme involviert war ${ }^{159}$; und insbesondere, ob und in welcher Form er den genauen Wortlaut sowie die Ausgestaltung einer an einem solchen Gebäude angebrachten Inschrift, die seinen Namen im Nominativ anführte, selbst festlegte oder zumindest mitbestimmte. In der Regel geht man davon aus, dass die Texte der kaiserlichen Bauinschriften nicht ohne Weiteres von den Gemeinden, in denen das entsprechende Bauwerk errichtet wurde, oder von den örtlichen Bauaufsehern konzipiert werden konnten; vielmehr sei hierfür eine Rücksprache mit dem Herrscher oder noch eher eine direkte Anweisung von Letzterem erforderlich gewesen ${ }^{160}$. Explizit belegen lässt sich dies allerdings fast nie ${ }^{161}$. In einem Fall erfahren wir immerhin, dass ein

Tituli aus Italien und den Westprovinzen des Imperium Romanum hat jüngst Marietta Horster, Bauinschriften römischer Kaiser. Untersuchungen zur Inschriftenpraxis und Bautätigkeit in den Städten des westlichen Imperium Romanum in der Zeit des Prinzipats (Stuttgart 2001) zusammenfassend behandelt.

${ }_{158}$ Genannt seien hierfür nur zwei Beispiele aus Hispanien und Südgallien, die bezeichnenderweise beide Stadtmauern bzw. -tore betreffen, denn hierbei handelte es sich um bauliche Strukturen, die gerne vom Kaiser gestiftet wurden und an denen sich sein Name in einem aufwändig gestalteten Titulus besonders wirkungsvoll inszenieren ließ (s. ferner oben Anm. 11): Ein erst vor Kurzem entdecktes Zeugnis aus Ilunum (Hispania citerior) berichtet davon, dass Augustus dem municipium die Stadtbefestigung geschenkt hatte (AE 1996, 907a). Die monumentale Bauinschrift mit einer Länge von ca. $8 \mathrm{~m}$ wurde an einer prominenten Stelle in die Blöcke der vorher errichteten Mauer eingemeißelt; die Einweihung wurde vom Provinzstatthalter vorgenommen. Vgl. dazu Lorenzo Abad Casal, La epigrafía del Tolmo de Minateda (Hellín, Albacete) y un nuevo municipio romano del conventus Carthaginiensis, in: AEA 69 (1996) 77-108 sowie Alföldy, Fasti und Verwaltung (wie Anm. 80) $340 f$. mit Abb. 2. In Nemausus (Gallia Narbonensis) stiftete Augustus ebenfalls portas murosq(ue). Die an einem der Stadttore, der sog. Porte d'Auguste, angebrachte Inschrift ist wiederum ca. $8 \mathrm{~m}$ lang und war aus (vergoldeten) Bronzebuchstaben gefertigt, die in der ersten Zeile eine Höhe von $25 \mathrm{~cm}$ erreichten (CIL XII 3151). Zu den Bauinschriften des Augustus in Rom vgl. Alfoldy, Augustus (wie Anm. 9) 293-299.

${ }^{159}$ Zur Problematik der Bauinschriften mit einer Kaisernennung im Nominativ vgl. Mitchell, Imperial Building (wie Anm. 157) 342-344 mit einigen instruktiven Beispielen. Besonders bemerkenswert ist der Fall von Philadelphia in Lydien: Kaiser Caracalla gestand den Bürgern von Philadelphia lediglich eine Neokorie zu, auf der Architravinschrift des daraufhin wohl von der Gemeinde errichteten Tempels erscheint er jedoch selbst (im Nominativ) als Stifter des Baues; s. IGR IV $1619=$ Oliver, Constitutions Nr. 263. Es ist also keineswegs klar, dass die Nennung des Kaisers im Nominativ in jedem Fall bedeutete, dass die Initiative zur Errichtung eines Bauwerkes (direkt) von ihm selbst ausgegangen war. Für Winter, Baupolitik (wie Anm. 157) 72 hingegen drückten diese Inschriften „ein weitestgehendes Engagement des Kaisers“, d.h. seine „aktive Beteiligung ... an einer Baumaßnahme" aus.

${ }^{160}$ So etwa Horster, Bauinschriften (wie Anm. 157) 42-44, die u.a. auf die Tatsache verweist, dass die kaiserlichen Bauinschriften nur selten Fehler enthielten (vgl. dazu aber unten), was auf direkte Anweisungen der kaiserlichen Zentrale bei der Konzeption dieser Tituli schließen lasse.

${ }^{161}$ So wissen wir fast nichts darüber, in welchem Umfang die örtlichen Aufseher bei kaiserlichen Bauprojekten (curatores operum) vom Herrscher detaillierte Anweisungen hinsichtlich der Bauausführung und der Gestaltung der zugehörigen Tituli erhielten. Immerhin berichtet eine Inschrift aus Kibyra (IGR IV 902), der Statthalter Q. Veranius habe als Aufseher über die „kaiserlichen Bauten“ gemäß dem Auftrag des Kaisers Claudius gehandelt. 
Statthalter der Provinz Asia brieflich anordnete, welches Formular die Inschrift an einem Tempel nehmen sollte, der auf Befehl des Augustus restituiert worden war ${ }^{162}$. Allerdings ist auch hier nicht $\mathrm{zu}$ beweisen, dass dies in direkter Absprache mit dem Herrscher erfolgte. In einem weiteren, vergleichbaren Fall erscheint ein solches Vorgehen sogar eher unwahrscheinlich: Hierbei handelt es sich allerdings nicht um eine Bau-, sondern um eine Weiheinschrift, die im Namen des Tiberius im baetischen Tucci dem in dieser Stadt besonders verehrten Gott Hercules Invictus gewidmet wur$\mathrm{de}^{163}$. Verantwortlich hierfür war offenbar ein am Ende der Inschrift genannter Provinzstatthalter, dessen Name später eradiert wurde. Er hat sich bei der Formulierung der Inschrift einige Freiheiten genommen, denn in Abweichung von der zu dieser Zeit gültigen Titulatur des Tiberius wurde dieser nicht als Divi Augusti filius bezeichnet, dafür aber das in Tiberius-Inschriften sonst nur selten vorkommende Nomen Iulius verwendet. Das spricht wohl dagegen, dass der Wortlaut dieser Inschrift vom Kaiser selbst konzipiert worden war ${ }^{164}$.

Weiterhin lassen sich einige Bauinschriften anführen, die nominell vom Princeps selbst herrührten, aber solch gravierende Ungenauigkeiten in der Kaisertitulatur aufwiesen, dass sie kaum direkt von der kaiserlichen Kanzlei angefertigt worden sein können. Im zivilen Bereich kamen solche Fehler zugegebenermaßen eher selten vor, aber es gab sie: So war die Titulatur des Augustus in einer Inschrift in Fano, die von der Stiftung der Stadtmauern der colonia Iulia Fanestris durch den Kaiser berichtete, offensichtlich fehlerhaft, da hier die 26. imperatorische Akklamation des Augustus angeführt ist, obwohl dieser nur einundzwanzig Mal zum imperator ausgerufen worden war ${ }^{165}$. Gerade im militärischen Sektor sind solche fehlerhaften kaiserlichen Bautituli durchaus nicht selten. So wurde in einer Inschrift, die von dem durchgreifenden Umbau des Kleinkastells Ellingen (castellum Sablonetum) am raetischen Limes berichtete und dem Kaiser Commodus gewidmet war, in der Titulatur des Herrschers dessen Siegerbeinamen falsch wiedergegeben, obwohl die Baumaßnahme auf direkte Anordnung (iussu) des Provinzstatthalters erfolgt war ${ }^{166}$. Zumindest

Man wüsste nun zu gerne, was genau in diesen kaiserlichen entolai gestanden hat, aber darüber sagt die Inschrift leider nichts Näheres; und andere Erwähnungen dieser Art sind selten.

${ }^{162}$ IKyme (IK 5) 17 (vgl. oben Anm. 81): ...restituat fa[num e]t in eo inscreibatur: Imp(erator) Caesar Deivei f(ilius) Augustu[s] re[stituit].

${ }^{163} \mathrm{CIL} \mathrm{II}^{2} / 5$, 65 = CIL II 1660 = ILS 161 (Dat.: nach 15 n. Chr.); dazu Géza Alföldy, Epigraphica Hispanica VIII. Eine kaiserliche Widmung in der Stadt Tucci, in: ZPE 59 (1985) 189-199, bes. 193.

${ }^{164}$ Ein ähnliche Situation ist im Falle der Bauinschrift des Leuchtturms von Patara vorstellbar (s. oben Anm. 136): Der Titulus nennt Nero im Nominativ als Initiator der Baumaßnahme; auffällig ist dabei aber, dass die imperatorischen Akklamationen nicht in der üblichen Form angeführt, sondern mit der überhöhenden Formel „Imperator über Land und See“ versehen werden (s. auch oben Anm. 134 zu der vergleichbaren Formulierung im stadiasmus Patarensis). Diese Wortwahl könnte auf den am Ende der Inschrift genannten Statthalter von Lykien, Sex. Marcius Priscus, zurückgehen, über den ferner gesagt wird, er sei der eigentliche Bauausführende gewesen. Dies wird unterstrichen durch den Text einer direkt vor dem Leuchtturm aufgestellten Statuenbasis für Priscus, denn hier wird ausdrücklich berichtet, er werde geehrt, „weil er den Pharos und den Antipharos zur

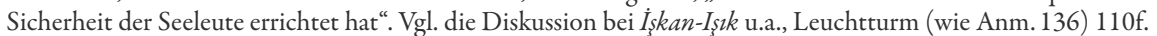
${ }^{165}$ CIL XI 6218 = ILS 104. Die Angabe der 22. tribunicia potestas würde auf das Jahr 9/10 n. Chr. führen. Horster, Bauinschriften (wie Anm. 157) 308-311 Kat. Nr.VI 2,1 vermutet allerdings eine nachträgliche Verwechslung der Bronzebuchstaben bei einer konstantinischen Restaurierung des Bauwerkes; ihrer Meinung nach sei der originale Text in das Jahr $14 \mathrm{n}$. Chr. zu datieren und so zu rekonstruieren: tribunicia potestate $X X X<V>I I$ imp(erator) $X X\{V\} I$. Bei anderen kaiserlichen Inschriften, die im heute sichtbaren Zustand Fehler aufweisen, ist nicht auszuschließen, dass diese in der Antike durch Stucküberzug oder eine farbige Fassung kaschiert wurden.

${ }^{166}$ AE 1983, 730 (Dat.: 182); vgl. den Kommentar von Karlheinz Dietz, Kastellum Sablonetum und der Ausbau des raetischen Limes unter Kaiser Commodus, in: Chiron 13 (1983) 497-536, bes. 503: „Offenbar hatte der 
einige dieser Texte scheinen also, obwohl sie im Namen des Kaisers ausgebracht wurden, vor Ort konzipiert worden zu sein; und sie wurden wohl noch nicht einmal von einer übergeordneten Behörde abgenommen, weil sonst die Fehler aufgefallen sein müssten. Hinzu kommt, dass sich die komplexen Mechanismen und administrativen Abläufe, die bei den kaiserlichen Bauprojekten zur Anwendung kamen und schließlich zur Ausarbeitung eines entsprechenden Titulus führten, aus dem stark verkürzten Formular der meisten Bauinschriften kaum mit hinreichender Genauigkeiten rekonstruieren lassen ${ }^{167}$.

Das zweite wichtige Problemfeld, das hier nur kurz angerissen werden kann, betrifft die Frage, inwieweit in den durch diese Inschriften bekannten Bauprojekten eine zentral koordinierte, zielgerichtete und längerfristig angelegte kaiserliche,Baupolitik' oder gar eine entsprechende,Baupropaganda erkannt werden sollte. Eine solche wurde in der altertumswissenschaftlichen Forschung häufiger postuliert ${ }^{168}$. Dagegen hat Marietta Horster in ihrer vor Kurzem erschienen, umfassenden Studie zu den kaiserlichen Bauinschriften zu Recht eingewandt, dass es kaum Anzeichen hierfür oder für weit ausgreifende ,Bauprogramme gibt, durch die einzelne Städte oder Provinzen vom Herrscher nach genauen Planvorgaben flächendeckend mit bestimmten Gebäudetypen ausgestattet worden wären, um damit klar definierte Ziele, etwa eine reichsweit koordinierte Selbstdarstellung, zu verfolgen ${ }^{169}$. Vielmehr erfolgten die kaiserlichen Baustiftungen fast immer selektiv (wobei die Motivation in vielen Fällen unklar bleibt) und punktuell, so dass sie in den jeweiligen Gemeinden im Vergleich zu der übrigen Bautätigkeit von untergeordneter Bedeutung blieben. Es handelte sich somit in der Regel um Einzelmaßnahmen der Herrscher, die zudem häufig von unten, etwa durch die Statthalter oder die betroffenen Städte selbst, angeregt worden waren oder auf ganz bestimmte, jeweils aktuelle

Konzipient der Inschrift nur vage von der Veränderung der Kaisertitulatur, die eine Umstellung der Reihenfolge der Beinamen mit sich brachte, gehört“, was für eine Konzeption der Inschrift vor Ort sprechen dürfte. Von einem höheren Maß an zentraler Kontrolle auch bei militärischen Bauprojekten geht hingegen Marcus Reuter, $\mathrm{Zu}$ den Befugnissen römischer Provinzstatthalter bei militärischen Bauprojekten, in: Willy Groenman-van Waateringe u.a. (Hg.), Roman Frontier Studies 1995. Proceedings of the XVIth International Congress of Roman Frontier Studies (Oxford 1997) 189-194 aus.

${ }^{167}$ Die Komplexität der einzelnen Vorgänge bei der Verwirklichung eines kaiserlichen Bauprojektes, die von den zumeist lapidaren Bauinschriften weitgehend verschleiert wird, kann die relativ ausführliche epigraphische Dokumentation zu einem Aquädukt in Dyrrachium, einer römischen Kolonie, verdeutlichen. Die Bauinschrift CIL III 709 berichtet, dass Kaiser Severus Alexander ein aquaeductum divi Hadriani parentis sui liberalitate Dyrrachinis factum restaurieren ließ (s. auch AE 1978, 762). Durch die Aufschriften auf einigen ebendort gefundenen Bleirohren (AE 1984, 811-813) wissen wir aber, dass die eigentliche Bauaufsicht bei den Obermagistraten der Stadt lag, während als Beauftragter des Kaisers bzw. des Statthalters offenbar ein gewisser Epagathus, wohl ein kaiserlicher Sklave, fungierte. Die Bleirohre selbst wiederum wurden von einem lokalen officinator, einem Gemeindesklaven, hergestellt.

${ }_{168}$ Vgl. etwa die Arbeiten von Gerhard Waldherr, Kaiserliche Baupolitik in Nordafrika. Studien zu den Bauinschriften der diokletianischen Zeit und ihrer räumlichen Verteilung in den römischen Provinzen Nordafrikas (Frankfurt am Main 1989) und von Winter, Baupolitik (wie Anm. 157) bes. 226-240, für den feststeht, dass bei der baulichen Ausgestaltung der Städte in Kleinasien „der Kaiser und dessen Vertreter in den Provinzen eine maßgebliche Rolle (spielten)“ und dass „das Engagement des römischen Staates im Bauwesen für die Entwicklung provinzialer Verhältnisse von signifikanter Bedeutung war“ (226). Weiterhin nimmt Winter eine gezielte Verteilung der kaiserlichen Bauprojekte an, denn: „Der Kaiser baute dort, wo es gesehen wurde, wo der Propagandawert einer Baumaßnahme am größten war“ (234). Zur Kritik an einem solchen Modell vgl. Heinz Herzig, Gibt es eine Baupolitik in der Schweiz zur römischen Zeit?, in: La politique édilitaire dans les provinces de l'Empire romain. Actes du $1^{\text {er }}$ Colloque roumano-suisse, Deva 1991 (Cluj 1993) 9-13, der zu Recht darauf hinweist, dass sich nur relativ wenige Anhaltspunkte für eine kaiserliche (Bau)Politik ausmachen lassen, die langfristigen Zielvorgaben gefolgt wäre und diese planmäßig in die Tat umgesetzt hätte.

${ }^{169}$ Horster, Bauinschriften (wie Anm. 157) bes. 222-250. 
Bedürfnisse antworteten. Auch ist kaum auszumachen, dass damit propagandistische Ziele verfolgt wurden, die über die von jedem Herrscher erwartete Demonstration der kaiserlichen liberalitas deutlich hinausführten. Dagegen spricht nicht zuletzt die oben angesprochene Vermutung, dass die Inschriften, die die kaiserliche Bautätigkeit kommemorierten, häufiger vor Ort und ohne strenge Kontrolle von oben konzipiert worden sein dürften.

Im weiteren Sinne ebenfalls zu den Bauinschriften zu zählen sind jene epigraphischen Zeugnisse, die an Straßenbaumaßnahmen erinnerten, welche unter der (nominellen) Oberhoheit des Kaisers durchgeführt wurden ${ }^{170}$. Hierzu zählten neben großen Straßenbaumonumenten und längeren Tituli, die den Ausbau der Straßen kommemorierten ${ }^{171}$, vor allem die massenhaft an den Straßenrändern aufgestellten Meilensteine, die in der Regel die Form von beschrifteten Rundsäulen hatten. Am Beginn der Meilenstein-Inschriften wurde fast immer der regierende Kaiser mit einer mehr oder minder ausführlichen Titulatur genannt. In der frühen Kaiserzeit erschien der Name des Kaisers zumeist im Nominativ, oft verbunden mit einem Verb des Bauens (etwa fecit oder munivit), das auf seine Rolle als offizieller Bauherr dieser Straßen verwies. Hieraus hat ein Teil der Forschung geschlossen, der Kaiser selbst habe jeweils das Formular der Inschriften entworfen, und die Anfertigung der Meilensteine sei dann von der Zentrale überwacht worden, um die nötige Einheitlichkeit dieser für den Herrscher wichtigen Form der Selbstdarstellung entlang der wichtigsten Verkehrswege des Reiches zu gewährleisten ${ }^{172}$. Ein solcher Ablauf ist allerdings nirgends explizit belegt; und es gibt einige Argumente, die gegen eine zu starke Zentralisierung der Meilensteinaufstellungen sprechen. So ist nicht klar, inwieweit die Kaiser im Einzelnen tatsächlich in die Straßenbauaktivitäten involviert waren, denn die konkrete Bauausführung oblag den Gemeinden, durch deren Territorium die jeweilige Straße führte. Wer den ,Urtext' für die Meilensteine entwarf, die nach Ende einer Baumaßnahme (zunehmend aber auch unabhängig von einer solchen) oft in größeren Serien errichtet wurden, ist ebenfalls nicht klar; es gibt aber einige Hinweise darauf, dass hierfür nicht selten die Provinzstatthalter verantwortlich waren, was dazu führte, dass sich das Formular von Provinz

\footnotetext{
${ }^{170}$ Zum römischen Straßenbau und zu den damit verbundenen Problemen vgl. allgemein Thomas Pekáry, Untersuchungen zu den römischen Reichsstraßen (Bonn 1968); Heinz E. Herzig, Probleme des römischen Straßenwesens. Untersuchungen zu Geschichte und Recht, ANRW II 1 (1974) 593-648; Michael Rathmann, Untersuchungen zu den Reichsstraßen in den westlichen Provinzen des Imperium Romanum (Mainz 2003); zu den Meilensteinen vgl. Christian Witschel, Meilensteine als historische Quelle? Das Beispiel Aquileia, in: Chiron 32 (2002) 325-393.

${ }^{171} \mathrm{Zu}$ nennen sind hier beispielsweise der stadiasmus Patarensis (s. oben Anm. 134) oder ein größeres Monument mit mehreren Inschriften in Salona, das die Straßenbaumaßnahmen in Dalmatien unter Kaiser Tiberius und dem Statthalter P. Cornelius Dolabella kommemorierte; dazu Manfred G. Schmidt, ,Regional Development under Tiberius and the tabulae Dolabellae, in: Maria G. Angeli Bertinelli, Angela Donati (Hg.), Misurare il tempo, misurare lo spazio. Atti del Colloquio Borghesi 2005 (Faenza 2006) 423-440; Witschel, Augustus $109 f$. ${ }^{172}$ Dass die Beschriftung der Meilensteine ein zentral gesteuerter, also von Rom ausgehender und von dort überwachter Vorgang war, behaupten vor allem Pekáry, Reichsstraßen (wie Anm. 170) 16-22 (bes. 19f.: „Es konnte dem Herrscher keinesfalls gleichgültig sein, in welcher Form er auf diesen zahlreichen und von vielen Leuten gelesenen Inschriften geehrt wurde ... Wollte man aber den Kaiser ehren, musste die Bewilligung dafür bei ihm eingeholt werden"); Thomas Grünewald, Constantinus Maximus Augustus. Herrschaftspropaganda in der zeitgenössischen Überlieferung (Stuttgart 1990) 15, 146f. und Kuhoff, Selbstdarstellung (wie Anm. 140) 150-170. Aufgegriffen wurde dies jüngst etwa von $I_{s} \imath k$ u.a., Miliarium Lyciae (wie Anm. 134) 76f. Vgl. dagegen die überzeugende Argumentation von Ingemar König, Zur Dedikation römischer Meilensteine, in: Chiron 3 (1973) 419-427 und Eberhard Sauer, M. Annius Florianus. Ein Drei-Monate-Kaiser und die ihm zu Ehren aufgestellten Steinmonumente (276 n. Chr.), in: Historia 47 (1998) 174-203, bes. 192-197; zum Folgenden ferner Witschel, Meilensteine (wie Anm. 170) 326-330, 354-356, 366-368.
} 
zu Provinz unterscheiden konnte. Die eigentliche Herstellung der Meilensteine lag dann offenbar zumeist in der Verantwortung der Gemeinden, und zahlreiche Fehler bei der Umsetzung des Textes auf die Steine (insbesondere Ungenauigkeiten in der Wiedergabe der Kaisertitulatur) deuten darauf hin, dass dieser Vorgang nicht allzu strikt überwacht worden sein kann ${ }^{173}$. Die Zuständigkeit provinzialer oder lokaler Behörden für die Konzeption von Meilenstein-Inschriften ist noch deutlicher für die spätere Kaiserzeit fassbar, als das Meilensteinformular einem generellen Wandel unterworfen war: In der Mehrzahl der Fälle wurde der Kaiser nicht mehr als handelnde Person im Nominativ genannt, sondern sein Name erschien nun im Dativ, wodurch der Meilenstein den Charakter eines Ehrenmonuments für den Herrscher annahm. Gleichzeitig verschwand häufig der Bezug auf konkrete Straßenbaumaßnahmen. In manchen Regionen, etwa in Gallien, bürgerte es sich zudem ein, den Auftraggeber eines Meilensteines in dessen Inschrift anzuführen, und an dieser Stelle taucht in der Regel die jeweilige civitas auf. Andere Meilensteintexte wurden weiterhin vom Provinzstatthalter oder von den Provinziallandtagen entworfen und dann seriell verbreitet. Dabei entstanden teilweise recht eigenwillige Kreationen, die nochmals verdeutlichen, dass ein größerer Teil dieser Inschriften nicht in der Zentrale konzipiert, sondern von der Bevölkerung an den Kaiser gerichtet wurde.

\section{Weiheinschriften und das Phänomen des Kaiserkults}

Wie schon gesehen, haben die Kaiser einige Male selbst Weihungen an die Götter errichtet und mit entsprechenden Inschriften versehen ${ }^{174}$. Weitaus häufiger waren aber solche Weiheinschriften, die sich an den Herrscher (der darum in ihnen im Dativ aufgeführt war) richteten und für ihn von anderen Personen oder Gemeinschaften erstellt wurden. Sie waren vornehmlich auf kultisch genutzten Gebäuden und insbesondere auf Altären angebracht, die wiederum verschiedenste Formen annehmen konnten ${ }^{175}$. An der Spitze standen dabei die großen Anlagen des provinzialen Kaiserkults ${ }^{176}$ wie der im Jahre 12 v. Chr. eingerichtete Heiligtumsbezirk der Tres Galliae bei Lyon,

${ }^{173}$ Vgl. hierzu einige Fallstudien: Antonietta Boninu, Armin U. Stylow, Miliari nuovi e vecchi dalla Sardegna, in: Epigraphica 44 (1982) 29-56, bes. 48, 55f. zu Sardinien (hier lassen sogar sich Unterschiede zwischen den im Territorium ein- und derselben Gemeinde zeitgleich errichteten Meilensteine beobachten); Joëlle Napoli, René Rebuffat, Les milliaires ardéchois d'Antonin le Pieux, in: Gallia 49 (1992) 51-79 zur Gallia Narbonensis; ferner König, Meilensteine (wie Anm. 172) 425.

${ }^{174}$ S. oben Anm. 163.

${ }^{175}$ Vgl. etwa Gustav Gamer, Formen römischer Altäre auf der hispanischen Halbinsel (Mainz 1989) und insbesondere Pierre Gros, Les autels des Caesares et leur signification dans l'espace urbain des villes julio-claudiennes, in: Roland Étienne, Marie-Thérèse Le Dinahet (Hg.), L'espace sacrificiel dans les civilisations méditerranéennes de l'antiquité. Actes du Colloque Lyon 1988 (Paris 1991) 179-186.

${ }^{176}$ Zum provinzialen Kaiserkult vgl. Deininger, Provinziallandtage (wie Anm.4) bes. 158-161; Duncan Fishwick, The Imperial Cult in the Latin West. Studies in the Ruler Cult of the Western Provinces of the Roman Empire, Bd.3, 1-4 (Leiden u.a. 2002-05). Allgemein ist zum römischen Kaiserkult auf folgende grundlegende Arbeiten der letzten Jahre zu verweisen: Simon R. F. Price, Rituals and Power. The Roman Imperial Cult in Asia Minor (Cambridge 1984); Duncan Fishwick, The Imperial Cult in the Latin West. Studies in the Ruler Cult of the Western Provinces of the Roman Empire, Bd. 1 und 2 (Leiden 1987-92); Manfred Clauss, Kaiser und Gott. Herrscherkult im römischen Reich (Stuttgart, Leipzig 1999); Ittai Gradel, Emperor Worship and Roman Religion (Oxford 2002); sowie auf die Beiträge in: Alastair Small (Hg.), Subject and Ruler. The Cult of the Ruling Power in Classical Antiquity (Ann Arbor 1996) und in: Hubert Cancik, Konrad Hitzl (Hg.), Die Praxis der Herrscherverehrung in Rom und seinen Provinzen (Tübingen 2003). 
in dessen Mittelpunkt sich ein monumentaler Altar erhob, der der Göttin Roma und dem Augustus geweiht war. Er ist vornehmlich durch literarische und numismatische Zeugnisse bekannt, aus denen hervorgeht, dass das Monument neben der eigentlichen Weiheinschrift ${ }^{177}$ auch ein Verzeichnis der 60 gallischen civitates aufwies ${ }^{178}$, deren Abgesandte sich einmal im Jahr an diesem Ort zu versammeln pflegten ${ }^{179}$. Ebenfalls imposante Formen konnten die auf den öffentlichen Plätzen der Städte errichteten Altäre annehmen, die dem Vollzug des munizipalen Kaiserkults dienten ${ }^{180}$. Nur zwei Beispiele hierfür: Im Jahre 12/13 n. Chr. errichtete die plebs von Narbo (Narbonne) auf dem Forum der Stadt aufgrund eines im Jahr zuvor abgelegten votum einen Altar für das numen des Augustus ${ }^{181}$. Dabei muss es sich um ein größeres Monument gehandelt haben, das auf allen Seiten mit Marmor verkleidet war und in das der erhaltene Block eingelassen war. Dieser trug zwei Inschriften: Auf der Vorderseite die Weiheinschrift, die auch Details zu den Opfern enthielt, die auf dem Altar an bestimmten, mit dem Kaiser in Verbindung stehenden Fest- und Erinnerungstagen dargebracht werden sollten; und auf der rechten Seite eine lex der ara bzw. des Kultes. Im hispanischen Segobriga ist erst vor wenigen Jahren in der Südporticus des Forums ein großer Altar entdeckt worden, dessen fragmentarisch erhaltene Weiheinschrift sich wahrscheinlich ebenfalls auf Augustus ergänzen lässt ${ }^{182}$. Hier ist deutlich zu erkennen, in welchem Maße sich die gesamte Ausstattung des Forums mit Ehreninschriften und -statuen auf dieses Monument hin ausrichtete ${ }^{183}$. Sehr viel zahlreicher waren kleinere (und teilweise transportable) Altäre mit Weihungen an den Kaiser, die auch in privateren Kontexten Verwendung fanden. Auch hierfür mögen zwei Beispiele, dieses $\mathrm{Mal}$ aus dem Osten des Reiches, genügen: In Athen wurden - insbesondere im Umkreis der Agora - zahlreiche einfache Block- und Rundaltäre gefunden, die den Namen des Augustus (im Dativ oder - weitaus häufiger - im Genetiv) trugen und zumeist vom Demos gestiftet worden waren. Sie waren wohl an Straßenrändern aufgestellt und wurden für Opfer genutzt, die etwa zur Feier des kaiserlichen Geburtstags monatlich veranstaltet wurden ${ }^{184}$. In Mytilene auf Lesbos hat sich eine Vielzahl von kleinformatigen Steinen mit Inschriften erhalten, die ebenfalls als

\footnotetext{
177 Zu dieser gehörte eventuell das Inschriftenfragment CIL XIII 1664.

${ }^{178}$ So Strab. 4, 3, 2.

${ }^{179} \mathrm{Vgl}$. Robert Turcan, L'autel de Rome et d'Auguste Ad Confluentem, ANRW II 12.1 (1992) 607-644; Duncan Fishwick, The Imperial Cult of the Latin West. Studies in the Ruler Cult of the Western Provinces of the Roman Empire, Bd.3.3: The Provincial Centres. Provincial Cult (Leiden, Boston 2004) 105-127; Witschel, Augustus $80 \mathrm{f}$.

${ }^{180}$ Vgl. auch das eindrucksvolle Monument im Vorhof des Bouleuterion von Milet, das als Augustus-Altar gedeutet worden ist: Klaus Tuchelt, Bouleuterion und ara Augusti. Bemerkungen zur Rathausanlage von Milet, in: MDAI(I) 25 (1975) 91-140.

${ }^{181}$ CIL XII 4333 = ILS 112: plebs Narbonensium aram Narbone in foro posuit ... . Vgl. Peter Kneißl, Entstehung und Bedeutung der Augustalität. Zur Inschrift der ara Narbonensis (CIL XIII 4333), in: Chiron 10 (1980) 291-328; Michel Gayraud, Narbonne antique des origines à la fin du III' siècle (Paris 1981) 358-366.

${ }^{182}$ AE 2003, 979; dazu Géza Alföldy u.a., Nuevos monumentos epigráficos del foro de Segobriga. Parte primera: Inscripciones votivas, imperiales y de empleados del Estado romano, in: ZPE 143 (2003) 258-260 Nr. 3.

${ }^{183} \mathrm{Vgl}$. Juan Manuel Abascal u.a., Epigrafía, arquitectura y decoración arquitectónica del foro de Segobriga, in: Sebastián F. Ramallo Asensio (Hg.), La decoración arquitectónica en las ciudades romanos de occidente (Murcia 2004) 219-256.

${ }^{184}$ Vgl. Anna Benjamin, Antony E. Raubitschek, Arae Augusti, in: Hesperia 28 (1959) 65-85 (mit Verweisen auf zahlreiche weitere Stücke im griechischen Raum). Zur Feier des kaiserlichen Geburtstags in Athen s. das Dekret IG II/III² 1071 = SEG 17 (1960) 34 = Agora XVI 473f. Nr. 336; sowie zum Vergleich IG XII 2, 58 aus Mytilene.
} 
Altäre anzusprechen sind ${ }^{185}$. Sie sind häufig mehreren Personen zusammen geweiht und nennen in unterschiedlicher Zusammensetzung - neben Pompeius, Caesar und lokalen Persönlichkeiten auch verschiedene Mitglieder des augusteischen Kaiserhauses (Augustus selbst, Agrippa, Caius und Lucius Caesar, Agrippa Postumus), die teilweise als theos angesprochen werden, wodurch vielfältige Kultaktivitäten in der Gemeinde bezeugt sind. Solche mittel- und kleinformatigen Altäre für den Kaiser und seine Familie müssen in den Städten des Imperium Romanum an sehr vielen Orten zu sehen gewesen $\operatorname{sein}^{186}$.

Die Verehrung des lebenden Kaisers als eines "gegenwärtigen Gottes“" (deus praesens oder theos epiphaness ${ }^{187}$ war nach dem Zeugnis der Inschriften ein nicht zu unterschätzender Aspekt des Alltagslebens in der römischen Welt ${ }^{188}$. Die Ansprache des Herrschers konnte in solchen Inschriften unterschiedliche Formen annehmen. Im Westen des Reiches war die direkte Bezeichnung des Kaisers als deus selten, kam aber bereits seit Augustus durchaus vor ${ }^{189}$. Häufiger war die Kombination des Namens Augustus (im Dativ) mit dem Wort sacrum ${ }^{190}$ oder in Verbindung mit einer Weiheformel wie votum solvit libens merito. Nicht selten wurde der Kaiser dabei - mit oder ohne verbinden-

185 S. etwa IG XII 2, 164, 166, 168 (jeweils mit Ansprache der genannten Personen im Dativ). Wichtige Hinweise zu diesen Monumenten verdanke ich der noch unpublizierten Arbeit von Caroline Rödel, Im Osten nichts Neues? Stiftungen und Ehrungen römischer Magistrate im Osten des Römischen Reiches vom Ende des 3. Jahrhunderts v. Chr. bis zum Ende der augusteischen Zeit (Diss. Heidelberg 2008); vgl. ferner Labarre, Lesbos (wie Anm.63) 116-128.

${ }^{186}$ S. etwa die erst kürzlich entdeckten Altäre für Augustus und Germanicus aus dem Theater von Metropolis: Dreyer, Engelmann, Augustus und Germanicus (wie Anm.31) 173-175; oder aber einen kleinen Altar für die Tyche des Autokratōr Kaisar (also wohl des Octavian vor 27 v. Chr.), gestiftet von einem Demarchos in einem Dorf auf dem Territorium der lykischen Stadt Arykanda, der zeigen kann, wie rasch sich die kultische Verehrung des ersten Princeps selbst in den ländlichen Gebieten verbreitete: Michael Wörrle, Ein Weihaltar aus Kilepe/Yeşilköy, in: Fritz Blakolmer u.a. (Hg.), Fremde Zeiten. Festschrift für J. Borchhardt, Bd. 1 (Wien 1996) $153-160$.

${ }^{187}$ Vgl. Manfred Clauss, Deus praesens. Der römische Kaiser als Gott, in: Klio 78 (1996) 400-433.

${ }^{188}$ Dass die Verehrung des lebenden Kaisers als Gottheit für die allermeisten Menschen in den Provinzen und auch in Italien (dazu s. unten Anm. 206) bereits seit Augustus keinerlei Problem darstellte, ja geradezu die Regel war, belegt eine Vielzahl von epigraphischen und anderen Zeugnissen zur Genüge. Lediglich im Bereich des in Rom betriebenen und vom Senat initiierten Staatskultes hatte es sich eingebürgert, eine solche Ehre erst dem verstorbenen Herrscher nach einem aufwändigen Ritual zukommen zu lassen. Von diesem Zeitpunkt an wurden die verstorbenen Kaiser in Ehren- und Weiheinschriften sowohl in Rom wie auch in den Provinzen - auch wenn sie dort schon zuvor kultisch verehrt worden waren - als divi angesprochen; dazu André Chastagnol, Un chapitre négligé de l'épigraphie latine. La titulature des empereurs morts, in: REL 62 (1984) 275-287. Diese beiden Ebenen sind in der modernen Forschung oft nicht genügend auseinandergehalten worden, was jedoch unbedingt notwendig ist, weil sich sonst leicht eine verzerrte Sichtweise auf das Gesamtphänomen des Kaiserkults einstellt, die vernachlässigt, dass aufs Ganze betrachtet die Situation in Rom eine Ausnahme darstellte; vgl. dazu Gradel, Emperor Worship (wie Anm. 176) bes. 102f., 140-144.

${ }^{189}$ Ein Beispiel hierfür bietet die Inschrift AE 1912, 51 = ILS 9495 (Thinissut/Africa proconsularis), die offensichtlich zu Lebzeiten des Augustus errichtet wurde: Augusto deo / cives Romani / qui Thinissut / negotiantur / curatore L(ucio) Fabricio; vgl. Alfoldy, Augustus (wie Anm. 9) $302 \mathrm{f}$.

${ }^{190}$ Zahlreiche Beispiele hiefür sind aus dem gallischen Raum bekannt, so ILGN 88 = AE 1906, 144 (Martigues/ Gallia Narbonensis): Ti(berio) Augusto / sacrum / Sex(tus) Aelanius Pisinus / d(e) s(ua) p(ecunia) d(edit); vgl. hierzu Marcel Le Glay, Le culte d’Auguste dans le villes augustéennes ... et les autres, in: Christian Goudineau, Alain Rebourg (Hg.), Les villes augustéennes de Gaule. Actes du Colloque Autun 1985 (Autun 1991) 117-126; Witschel, Augustus 88f. Wenn nur Augustus alleine genannt ist, kann sich dies auf jeden regierenden Kaiser beziehen; vgl. André Chastagnol, L'expression épigraphique du culte impérial dans les provinces gauloises, in: REA 97 (1995) 593-614. 
des $e t$ - in eine Reihe mit anderen Gottheiten, sowohl römischen ${ }^{191}$ wie einheimischen ${ }^{192}$, gestellt. Weiterhin wurden die Weihungen des Öfteren an das numen oder den Genius des Herrschers gerichtet. In den östlichen, griechischsprachigen Regionen des Imperium Romanum war hingegen die Ansprache des lebenden Herrschers als theos völlig geläufig ${ }^{193}$. Überall häufig waren schließlich Weiheinschriften, in denen die Götter pro salute, pro reditu, pro victoria o.ä. der Herrscher angerufen wurden. Eine solche Formel, in der die Kaiser als Schutzbefohlene der Götter auftreten, lässt auf eine gewisse Abstufung zwischen den als übermenschlich empfundenen Herrschern und den etablierten Gottheiten im Bewusstsein der Zeitgenossen schließen ${ }^{194}$. Auf der anderen Seite gibt es aber genügend Weihungen, die sich - etwa in Erfüllung eines Gelübdes - direkt an den Herrscher richteten, der hierbei in derselben Position erscheint wie in anderen Weiheinschriften die jeweils angesprochene Gottheit ${ }^{195}$. Es erscheint mir daher nicht gerechtfertigt, an diesem Punkt zu genau zu differenzieren und dadurch die kultische Verehrung des Kaisers als religiös zweitrangiges, aus rein politischen Motiven gespeistes Phänomen abzutun, wie es nicht selten immer noch geschieht ${ }^{196}$.

Das hiermit angesprochene Phänomen des Kaiserkultes im Imperium Romanum entfaltete sich bekanntlich auf verschiedenen Ebenen, nämlich der des Staatskultes in Rom, der Provinzialkulte, der zahllosen städtischen Kulte sowie schließlich im individuellen (privaten) Bereich. Alle diese Ebenen werden mehr oder minder stark durch epigraphische Zeugnisse beleuchtet, die über weite Strecken sogar unsere Hauptquelle hierfür bilden. Bei einer einigermaßen günstigen Überlieferungssituation lässt sich beispielsweise aufzeigen, wann und wo es zur Einrichtung eines Kultes für den Herrscher kam und von wem die Initiative hierfür ausging ${ }^{197}$. Allerdings ist an dieser Stelle anzumerken,

${ }^{191}$ S. beispielsweise CIL II ${ }^{2} / 7,69$ = CIL II 2106 (Urgavo/Baetica): Imp(eratori) Caesari Aug(usto) pont(ifici) max(imo) / trib(unicia) pot(estate) XXXIIII co(n)s(uli) XIII / patri patriae Victoriae sacr(um) / L (ucius) Aemilius $L$ (uci) f(ilius) Nigellus aed(ilis) IIvird(e)s(ua) p(ecunia) f(ecit).

192 Dies lässt sich erneut besonders gut in Gallien beobachten; vgl. hierzu Alain Villaret, L'association de l'empereur et des dieux en Aquitaine. Son rôle dans la société et les mentalités, in: Aquitania 16 (1999) 127-151. ${ }^{193}$ Dazu Simon R.F. Price, Gods and Emperors. The Greek Language of the Roman Imperial Cult, in: JHS 104 (1984) 79-95.

${ }^{194}$ Simon R.F. Price, Between Man and God. Sacrifice in the Roman Imperial Cult, in: JRS 70 (1980) 28-43.

${ }^{195}$ Ein gutes Beispiel hierfür sind zwei kleine bronzene Büsten des Augustus und der Livia aus Neuilly-le-Real (Aquitania), die ein Peregriner vermutlich in einem Heiligtum aufgestellt hatte, um ein Gelübde zu erfüllen, wie die Inschriften auf den Sockeln der Bildnisse berichten (CIL XIII 1366 = ILS 8896): Caesari Augusto (bzw. Liviae Augustae) / Atespatus Crixifll(ius) v(otum) s(olvit) l(ibens) m(erito). Einen weiteren interessanten Befund bietet ein indigenes Heiligtum in Châteauneuf in Savoyen, d.h. im Gebiet der Allobroger, das dem lokalen Gott Limetus geweiht war. Hier wurden zahlreiche Graffiti auf Wandresten und Ziegeln aus dem 1. Jahrhundert n. Chr. gefunden, die kurze Weiheformeln der örtlichen Bevölkerung wiedergeben (ILN V 2, 463-500). Neben den einheimischen Gottheiten werden dabei - mit demselben Formular - auch die Göttin Roma und insbesondere der lebende Kaiser angerufen, der zumeist einfach als Imperator, Caesar oder Augustus ohne Nennung des Individualnamens aufgeführt ist. Der Herrscher war hier also vollständig in die lokale Kultpraxis eingebunden. Vgl. Christian Mermet, La sanctuaire gallo-romain de Châteauneuf (Savoie), in: Gallia 50 (1993) 95-138; Bernard Rémy, Religion populaire et culte impérial dans la sanctuaire indigène de Châteauneuf (Savoie), in: RAN 32 (1999) 31-38; Witschel, Augustus 69f.

${ }^{196}$ So etwa durch Duncan Fishwick, Votive Offerings to the Emperor?, in: ZPE 80 (1990) 121-130; der in Hinblick auf die Ansprache von Kaisern und Göttern in solchen Denkmälern zwischen einem „honorific dative“ und einem „votive dative" unterscheiden möchte; dagegen - m.E. zu Recht - Clauss, Herrscherkult (wie Anm. 176) 33-35, 285-289.

${ }^{197}$ Ein Beispiel hierfür bietet die Situation in der Provinz Gallia Narbonensis, wo ein Provinzialkult offenbar erst um oder nach der Mitte des 1. Jahrhunderts n. Chr. eingerichtet wurde, wo es aber nach Ausweis der epigraphischen und archäologischen Quellen in vielen Gemeinden schon in früh- oder mittelaugusteischer Zeit zur Begründung eines munizipalen Kultes für den Herrscher durch die lokalen Eliten kam. Vgl. Émilienne 
dass einige Aspekte des Kaiserkultes in den Inschriften wesentlich besser zu fassen sind als andere. Einigermaßen gut bekannt sind durch entsprechende Bau- und Weiheinschriften die baulichen Strukturen, innerhalb derer der Kult vollzogen wurde. Diese reichten von klassischen Tempeln über Kulträume in anderen Gebäuden und heiligen Bezirken bis hin zu den bereits angesprochenen Altären. Dabei ist eine große Vielfalt in der architektonischen Ausgestaltung der Kulteinrichtungen zu beobachten ${ }^{198}$, die es nicht immer leicht macht, einen bestimmten Bau mit Sicherheit als Kultanlage zu identifizieren, obwohl klar ist, dass der Kaiserkult an zahlreichen Stellen innerhalb einer Stadt oder einer Landschaft vollzogen werden konnte ${ }^{199}$. Ebenfalls recht gut bezeugt ist das Kultpersonal, so die zahlreichen Kaiserkultpriester, die auf provinzialer oder munizipaler Ebene eingesetzt wurden ${ }^{200}$, sowie weitere mit dem Kaiserkult in Verbindung stehende Organisationen wie die mehrheitlich aus Freigelassenen bestehenden Augustalen-Kollegien ${ }^{201}$.

Demougeot, Remarques sur les débuts du culte impérial en Narbonnaise, in: Provence Historique 18 (1968) 3965; Michel Christol, Lépigraphie et les débuts du culte impérial dans les colonies de vétérans en Narbonnaise, in: RAN 32 (1999) 11-20; Witschel, Augustus 61-70. Ausführliche Studien zur jeweiligen regionalen Ausprägung des Kaiserkults, die vornehmlich auf epigraphischer Grundlage erarbeitet worden sind, liegen inzwischen für eine Reihe von Regionen vor; vgl. beispielsweise zu Hispanien Robert Étienne, Le culte impérial dans la péninsule ibérique d'Auguste à Dioclétien (Paris 1958); zu Germanien Uta-Maria Liertz, Kult und Kaiser. Studien zu Kaiserkult und Kaiserverehrung in den germanischen Provinzen und in Gallia Belgica zur römischen Kaiserzeit (Rom 1998); zu Achaia Maria Kantiréa, Les dieux et les dieux augustes. Le culte impérial en Grèce sous les Julio-Claudiens et les Flaviens. Etudes épigraphiques et archéologiques (Athen 2007); zu Kleinasien Jürgen Süß, Kaiserkult und Stadt. Kultstätten für römische Kaiser in Asia und Galatia (Mannheim 1999); Barbara Burrell, Neokoroi. Greek Cities and Roman Emperors (Leiden, Boston 2004); Thomas Witulski, Kaiserkult in Kleinasien, Die Entwicklung der kultisch-religiösen Kaiserverehrung (Göttingen, Fribourg 2007).

${ }^{198}$ Vgl. etwa die Studie von Heidi Hänlein-Schäfer, Veneratio Augusti. Eine Studie zu den Tempeln des ersten römischen Kaisers (Rom 1985).

${ }^{199} \mathrm{Zu}$ den damit verbundenen Fragen vgl. Klaus Tuchelt, Zum Problem ,Kaisareion - Sebasteion'. Eine Frage zu den Anfängen des römischen Kaiserkultes, in: MDAI(I) 31 (1981) 167-186 und Christian Witschel, Zum Problem der Identifizierung von munizipalen Kaiserkultstätten, in: Klio 84 (2002) 114-124.

${ }^{200}$ Besonders zahlreich sind solche Priester beispielsweise aus Asia und Lykien bekannt; vgl. Maria D. Campanile, I sacerdoti del koinon d'Asia (I sec. A.C.-III sec. D.C.). Contributo allo studio della romanizzazione delle élites provinciali nell'Oriente greco (Pisa 1994); Martin Zimmermann, Die archiereis des lykischen Bundes. Prosopographische Überlegungen zu den Bundespriestern, in: Christof Schuler (Hg.), Griechische Epigraphik in Lykien - eine Zwischenbilanz. Akten des Kolloquiums München 2005 (Wien 2007) 111-120. $\mathrm{Zu}$ den provinzialen Oberpriestern im Westen des Reiches vgl. Duncan Fishwick, The Imperial Cult in the Latin West. Studies in the Ruler Cult of the Western Provinces of the Roman Empire, Bd. 3.2: The Provincial Priesthood (Leiden u.a. 2002). Die epigraphischen Belege für munizipale Kaiserkultpriester (flamines, sacerdotes u.ä.) sind systematisch etwa für die afrikanischen und gallischen Provinzen zusammengestellt worden: Maria Silvia Bassignano, Il flaminato nelle province romane dell'Africa (Rom 1974); Jacques Gascou, Magistratures et sacerdoces municipaux dans les cités de Gaule Narbonnaise, in: Michel Christol, Olivier Masson (Hg.), Actes du Xe Congrès International d'Épigraphie grecque et latine, Nîmes 1992 (Paris 1997) 75-140; William van Andringa, Prêtrises et cités dans les Trois Gaules et les Germanies au Haut Empire, in: Monique Dondin-Payre, Marie-Thérèse Raepsaet-Charlier (Hg.), Cités, municipes, colonies. Les processus de municipalisation en Gaule et en Germanie sous le Haut-Empire romain (Paris 1999) 425-446; Bernard Rémy, Loyalisme politique et culte impérial dans les provinces des Alpes occidentales (Alpes Cottiennes, Graies, Maritimes et Poenines) au Haut Empire, in: MEFRA 112 (2000) 881-924.

${ }^{201} \mathrm{Zu}$ den Augustalen und ihren Aufgaben im Kaiserkult vgl. Robert Duthoy, Les augustales, ANRW II 16.2 (1982) 1254-1309; Andrik Abramenko, Die munizipale Mittelschicht im kaiserzeitlichen Italien. Zu einem neuen Verständnis von Sevirat und Augustalität (Frankfurt am Main 1993). Die Vereinshäuser der Augustalen waren, soweit sie sich denn identifizieren lassen, häufig ebenfalls mit Kaiserstatuen und entsprechenden Inschriften ausgestattet; vgl. hierzu Beate Bollmann, Römische Vereinshäuser. Untersuchungen zu den scholae der römischen Berufs-, Kult- und Augustalen-Kollegien in Italien (Mainz 1998). Ein gutes Beispiel ist die 
Ein weiterer, bereits angesprochener Aspekt des Kaiserkults ${ }^{202}$, der insbesondere in den östlichen Provinzen des Reiches mehrfach in Inschriften auftaucht, ist die Kommunikation der Bevölkerung mit dem Kaiser über Fragen der Kulteinrichtung und -ausführung. Es hatte sich nämlich eingebürgert, dass man in Bezug auf umfangreichere kultische Ehrungen das Einverständnis des Herrschers erbat. Das gab diesem wiederum die Möglichkeit, eigene Vorschläge einzubringen und dabei insbesondere seine von der traditionsbewussten Aristokratie eingeforderte Mäßigung (moderatio) zu demonstrieren, indem er scheinbar zu weit gehende Kultpraktiken zurückwies oder modifizierte. Auch solche eher negativen Antworten des Kaisers auf Anfragen, die seinen Kult betrafen, wurden bisweilen von den Empfängern inschriftlich festgehalten, wie wir bereits gesehen haben. Es ist jedoch zu betonen, dass sich aus diesen Belegen keine allgemeine Genehmigungspflicht für die munizipalen Kulte ablesen lässt - vielfach dürften diese eingerichtet worden sein, ohne dass der Kaiser hiervon erfuhr. Gegen eine systematische und zentrale Steuerung des Kaiserkults spricht jedenfalls die überall zu beobachtende Vielfalt und Variabilität der damit verbundenen Strukturen und Institutionen, die augenscheinlich kaum übergreifenden Regelungen unterworfen war.

Andere, nicht minder bedeutsame Elemente des Kaiserkults tauchen hingegen in den Inschriften nur vereinzelt auf. Das betrifft insbesondere den konkreten Ablauf der einzelnen Kulthandlungen ${ }^{203}$. So wissen wir beispielsweise kaum etwas darüber, was die in den Städten des Westens zahlreich belegten flamines und augustales eigentlich im Rahmen des Kults genau taten. Etwas besser ist die Situation in Bezug auf die östlichen Provinzen, denn hier haben sich immerhin einige längere Inschriften erhalten, die ausführliche Vorschriften für die Durchführung der mit dem Kaiserkult verbundenen Rituale enthalten. Dies betrifft etwa die Organisation der zu bestimmten Anlässen veranstalteten Prozessionen, bei denen tragbare Kaiserbildnisse mitgeführt wurden und die teilweise mit Opfern an oder für den Kaiser an verschiedenen Punkten der Stadt verbunden waren ${ }^{204}$. Die Details der eigentlichen Kultpraktiken (Opfer, Gebete, Hymnen an den Kaiser etc.) sind aber auch hier schlecht bekannt, zumal die Inschriften kaum ausführlichere Beschreibungen der tatsächlich vollzogenen Handlungen bieten.

Obwohl also nicht alle Facetten des Kaiserkults durch die zahlreichen Inschriften, die sich in der einen oder anderen Weise auf dieses Phänomen beziehen, gleichermaßen erhellt werden, lassen sich doch einige generelle Aussagen machen. Wichtig scheint mir vor allem, dass sich aus den epigra-

Anlage in Misenum, die nach Aussage einer ebendort gefundenen Statuenbasis als templum Augusti quod est Augustalium bezeichnet wurde (s. AE 1993, 468; ebenso AE 1996, 424b). Die weiteren in situ geborgenen Inschriften und Statuen machen klar, dass der Kult des lebenden Kaisers und der Divi in dem Augustalensitz von Misenum eine große Bedeutung besaß; vgl. Paola Miniero (Hg.), Il sacello degi Augustali di Miseno (Neapel 2000), zu den Inschriften s. AE 1993, 466-479; AE 1994, 426; AE 1996, 424; AE 2000, 344/45; dazu John H. D'Arms, Memory, Money, and Status at Misenum. Three New Inscriptions From the Collegium of the Augustales, in: JRS 90 (2000) 126-144; Fausto Zevi, in: Miniero, Sacello, 47-62.

${ }^{202}$ S. oben Kap. 2, insbesondere Anm. 53.

${ }^{203}$ Vgl. zum Folgenden zusammenfassend Angelos Chaniotis, Der Kaiserkult im Osten des Römischen Reiches im Kontext der zeitgenössischen Ritualpraxis, in: Hubert Cancik, Konrad Hitzl (Hg.), Die Praxis der Herrscherverehrung in Rom und seinen Provinzen (Tübingen 2003) 3-28; ferner Price, Rituals (wie Anm. 176) 188-191, 207-233; Gradel, Emperor Worship (wie Anm. 176) 91-97.

${ }^{204}$ S. dazu etwa die umfangreichen Stifterinschriften des Salutaris in Ephesos und des Demosthenes in Oinoanda: Guy M. Rogers, The Sacred Identity of Ephesos. Foundation Myths of a Roman City (London, New York 1991); Michael Wörrle, Stadt und Fest im kaiserzeitlichen Kleinasien. Studien zu einer agonistischen Stiftung aus Oinoanda (München 1988). Zum Einsatz von tragbaren Kaiserbildnissen vgl. Christian Witschel, Herrscherbildnisse im römischen Kaiserkult. Die Goldbüste des Kaisers Marc Aurel aus Avenches, in: Claus Ambos u.a. (Hg.), Bild und Ritual - visuelle Kulturen in historischer Perspektive (Darmstadt 2010) 55-67. 
phischen Zeugnissen der klare (wenn auch möglicherweise etwas einseitige) Eindruck ergibt, dass sich der Kaiserkult gerade auf der städtischen Ebene weitgehend spontan entwickelte und durch die Initiative der lokalen Eliten vorangetrieben wurde, die auch die Ausgestaltung der mit dem Kult verbundenen Einrichtungen - inklusive der in diesem Zusammenhang errichteten Inschriften - bestimmten. Der Kaiser scheint hierbei nur selten eine aktive, seinen eigenen Kult fördernde Rolle eingenommen zu haben, denn er reagierte in der Regel lediglich auf an ihn herangetragene Anfragen, die die Ausgestaltung des Kultes betrafen. Bisweilen lassen sich zudem allzu apodiktische Angaben in den literarischen Quellen hinsichtlich des Kaiserkults korrigieren, indem man das epigraphische Material heranzieht. So erweckt etwa eine Passage bei Cassius Dio den Eindruck, es habe unter Augustus und seinen Nachfolgern in Italien keine oder nur eine sehr eingeschränkte bzw. indirekte kultische Verehrung des lebenden Herrschers gegeben ${ }^{205}$. Dies kann aber nach Aussage der Inschriften so keineswegs richtig sein, da auch in Italien bereits zu Lebzeiten des Augustus zahlreiche munizipale Kulte für ihn eingerichtet wurden ${ }^{206}$.

\section{Ehreninschriften und die Entwicklung der Kaisertitulatur}

Die Mehrzahl der Inschriften, die auf den Kaiser bezogen waren, gehörte zu Ehrenmonumenten, welche den Herrscher und seine Leistungen für das Reich feierten. Diese wiesen sehr unterschiedliche Formen auf; sie reichten von großen Denkmälern wie Ehrenbögen ${ }^{207}$ (dazu ausführlicher oben Kap.3) bis hin zu den massenhaft errichteten Meilensteinen, die ab dem späteren 2. Jahrhundert ebenfalls zunehmend den Charakter von Ehrungen für den Herrscher annahmen (s. oben Kap.4). Die geläufigsten Denkmäler waren sicherlich die statuarischen Monumente, welche aus einer beschrifteten Basis, einem Statuenkörper sowie dem Porträtkopf des Kaisers bestanden und von denen sich häufig nur noch die Sockel mit der an den Princeps gerichteten Ehreninschrift erhalten haben ${ }^{208}$. Auch diese Statuenbasen können jedoch bereits wertvolle Hinweise auf das einstige Aussehen des Gesamtmonuments geben ${ }^{209}$. Der Standardtypus war augenscheinlich das

${ }^{205}$ Cass. Dio 51, 20, 8 (es ist aber nicht ganz klar, ob sich Dio hier tatsächlich auf die munizipalen Kulte bezieht); vgl. ferner Suet. Aug. 52; Tib. 26, 1.

${ }^{206}$ Vgl. hierzu Ittai Gradel, Mamia's Dedication: Emperor and Genius. The Imperial Cult in Italy and the genius coloniae in Pompeii, in: ARID 20 (1992) 43-58; Gradel, Emperor Worship (wie Anm. 176) 73-108.

${ }^{207}$ Auf solchen Ehrenbögen waren vielfach Bildnisse von Mitgliedern der kaiserlichen Familie zu sehen. Hierzu zählte beispielsweise ein Bauwerk, zu dem die Inschriften gehörten, die ein mittelalterlicher Kopist als in porta Papiae befindlich beschrieb (s. CIL V 6416 = ILS 107). Diese Inschriften überliefern eine Statuengruppe mit insgesamt zehn Mitgliedern der Kaiserfamilie, die im Jahre 7/8 n. Chr. geweiht wurde. Entgegen dem Versuch, dieses Monument in Rom an der Via Appia zu lokalisieren (vgl. Charles B. Rose, The Supposed Augustan Arch at Pavia [Ticinum] and the Einsiedeln 326 Manuscript, in: JRA 3 [1990] 163-168), ist wohl doch davon auszugehen, dass es sich um ein als Ehrenbogen gestaltetes Stadttor mit einem reichen Skulpturenschmuck in Pavia, dem antiken Ticinum, handelte; so Emilio Gabba, L'arco augusteo di Pavia, in: Athenaeum 78 (1990) 515-517; Géza Alföldy, in: CIL VI 8, 2 p. 4301.

$208 \mathrm{Vgl}$. zum Folgenden insbesondere die reiche Materialsammlung von Thomas Pekáry, Das römische Kaiserbildnis in Staat, Kult und Gesellschaft (Berlin 1985).

${ }^{209}$ Eine Pionierstudie zur Typologie römischer Statuenbasen und zur Auswertung der darauf angebrachten Inschriften hat Géza Alföldy, Römische Statuen in Venetia et Histria. Epigraphische Quellen (Heidelberg 1984) vorgelegt. Dieser Ansatz ist in den letzten Jahren zwar mehrfach aufgegriffen, aber nicht immer zufriedenstellend weitergeführt worden: Die jüngst erschienene Monographie von Jakob M. Højte, Roman Imperial Statue Bases. From Augustus to Commodus (Aarhus 2005) bietet zwar eine verdienstvolle Materialsammlung, ist aber 
etwa lebensgroße Standbild des Herrschers. Daneben gab es auch Basen für Kolossalstatuen ${ }^{210}$, Reitermonumente ${ }^{211}$, Darstellungen des Kaisers in der Quadriga sowie Statuengruppen, die mehrere Mitglieder des Kaiserhauses gemeinsam präsentierten ${ }^{212}$. Keiner dieser Monumenttypen war exklusiv dem Herrscher vorbehalten, aber es ist dennoch auffällig, dass die Principes des Öfteren besonders aufwändig gestaltete Ehrungen erhielten, unter denen Bildnisse aus (purem) Edelmetall herausragen ${ }^{213}$. Statuarische Monumente zu Ehren der Kaiser wurden an den verschiedensten Orten errichtet, insbesondere im öffentlichen Raum der Städte, bevorzugt auf den Fora ${ }^{214}$, aber auch in

methodisch problematisch, da die Denkmäler zumeist nicht durch Autopsie erschlossen wurden. Dadurch ist es zu nicht wenigen Fehlzuweisungen bzw. zur Vermischung verschiedener Monumentformen gekommen, so dass die Statistiken von Højte mit großer Vorsicht zu betrachten sind. Vgl. hierzu auch die Rezensionen von Werner Eck, in: Klio 89 (2007) 524-528 und Andreas Kropp, in: CR 58 (2008) 283-285. Was immer noch weitgehend fehlt, ist eine Zusammenschau von epigraphischen und archäologischen Quellen zu Kaiserbildnissen in einer bestimmten Region oder Epoche. Exemplarisch hat die Arbeit von Emmanuelle Rosso, L'image de l'Empereur en Gaule romain. Portraits et inscriptions (Paris 2006) aufgezeigt, welche Fortschritte in diesem Bereich zu erzielen sind.

${ }^{210}$ Brigitte Ruck, Die Großen dieser Welt. Kolossalporträts im antiken Rom (Heidelberg 2007) bes. 129-149, 292-300 zu den Statuenbasen und Inschriften.

${ }^{211}$ Dazu Johannes Bergemann, Römische Reiterstatuen. Ehrendenkmäler im öffentlichen Bereich (Mainz 1990) bes. 120-155 (Katalog der epigraphischen Zeugnisse und Basen für Reiterstatuen).

${ }^{212} \mathrm{Zu}$ den Statuengruppen vgl. Charles B. Rose, Dynastic Commemoration and Imperial Portraiture in the Julio-Claudian Period (Cambridge 1997); Frédéric Hurlet, Les collègues du prince sous Auguste et Tibère (Rom 1997) und vor allem Dietrich Boschung, Gens Augusta. Untersuchungen zur Aufstellung, Wirkung und Bedeutung der Statuengruppen des julisch-claudischen Kaiserhauses (Mainz 2002) bes. 144-158 zu den epigraphischen Quellen; zu Letzteren s. auch Isabelle Cogitore, Séries de dédicaces italiennes à la dynastie julioclaudienne, in: MEFRA 104 (1992) 817-870. Nicht immer stimmen allerdings archäologischer und epigraphischer Befund überein. So wurden in einem kleinen Apsidenraum am Forum von Rusellae (dem sog. Vano Statue) zahlreiche Reste von Inschriften und Skulpturen geborgen, die eine mehrfach erweiterte Bildnisgalerie von Mitgliedern des julisch-claudischen Herrscherhauses bezeugen, sich aber in Bezug auf die durch sie belegten Personen nur teilweise zur Deckung bringen lassen: Stefano Conti, Dinastia giulio-claudia a Roselle. Una serie di dediche imperiali in Etruria, in: AFLS 18 (1997) 101-127; Boschung, Statuengruppen 69-76.

${ }^{213}$ Kaiserbildnisse aus Edelmetall sind nicht selten in Inschriften erwähnt: So errichtete die Provinz Baetica auf dem Augustusforum eine Statue aus 100 Pfund (purem) Gold quod beneficio eius et perpetua cura provincia pacata est: CIL VI 31267 = ILS 103; dazu Alföldy, Augustus (wie Anm.9) 309f. In Augusta Emerita stiftete die Provinz Lusitania ein (tragbares) Bildnis des Kaisers Titus aus fünf Pfund Gold: CIL II $5264=$ ILS $261=$ Ramírez Sádaba, Inscripciones (wie Anm. 12) Nr. 24; dazu Duncan Fishwick, A Gold Bust of Titus at Emerita, in: AJAH 6 (1981) 89-96. Ein Privatmann ehrte in Rom den Kaiser Tiberius mit einem Bildnis(?) aus je fünf Pfund Silber und Gold: CIL VI 904. Zur Wahl des Materials ist zu bemerken, dass Bildnisse aus reinem Gold in der Regel wohl nur an Götter und Herrscher vergeben wurden (vgl. Thomas Pekáry, Goldene Statuen der Kaiserzeit, in: MDAI[R] 75 [1968] 144-148; Pekáry, Kaiserbildnis [wie Anm. 208] 66-80; Büsten aus reinem Silber sind hingegen auch für Privatpersonen bekannt), während vergoldete Statuen auch zur Ehrung von besonders herausragenden Bürgern Verwendung fanden (so Götz Lahusen, Goldene und vergoldete römische Ehrenstatuen und Bildnisse, in: MDAI[R] 85 [1978] 385-395; unterstützt wird dies durch den epigraphischen und archäologischen Befund). Dass auch mit der Vergoldung eine gewisse Überhöhung in Richtung auf die Erhebung in eine übermenschliche Sphäre verbunden war, ist wohl kaum zu bezweifeln. Insbesondere gilt dies für Bildnisse aus reinem Edelmetall, denn sonst hätten die Principes eine solche Ehre nicht relativ regelmäßig und teilweise mit genau dieser Begründung abgelehnt, wenn sie ausdrücklich um Erlaubnis hierfür gefragt wurden (vgl. oben Anm. 53 und unten Anm. 235).

214 Besonders gut lässt sich aufgrund der in situ gefundenen Statuenbasen die Inschriften- und Skulpturenausstattung einiger Fora in Africa rekonstruieren; dazu Gerhard Zimmer (mit epigraphischen Beiträgen von Gabriele Wesch-Klein), Locus datus decreto decurionum. Zur Statuenaufstellung zweier Forumsanlagen im römischen Afrika (München 1989); Christian Witschel, Statuen auf römischen Platzanlagen unter besonderer Berücksichtigung von Timgad (Algerien), in: Klaus Stemmer (Hg.), Standorte. Kontext 
Thermen und Theatern ${ }^{215}$. Dort waren sie jeweils im Kontext weiterer Statuen zu sehen, die Götter oder verdiente Bürger der Gemeinde darstellten, aber man reservierte für sie nicht selten besonders hervorgehobene Plätze oder, Schauseiten'.

Die Inschriften auf den Statuenbasen geben wertvolle Hinweise auf die Stifter von statuarischen Denkmälern zu Ehren der Herrscher. In Rom, wo auf den zentralen Plätzen die Kaiserbildnisse eine absolut dominante Stellung einnahmen, waren hierfür hauptsächlich der Senat, aber auch die plebs und deren Unterabteilungen, die tribus, zahlreiche Vereine und Vereinigungen (collegia), die stadtrömischen Truppen, auswärtige Städte und Provinzen sowie Einzelpersonen aller Art (darunter auch hohe kaiserliche Beamte) verantwortlich. In den Provinzstädten wurden Kaiserstatuen zumeist auf Veranlassung des Stadtrates errichtet und aus städtischen Geldern bezahlt. Es handelte sich hierbei augenscheinlich um kollektive Loyalitätsbekundungen, die im Namen der gesamten Gemeinde ausgesprochen werden sollten und die man deshalb nur recht selten Einzelpersonen überließ. Das bedeutet allerdings nicht, dass es für individuelle Amtsträger oder Privatpersonen irgendwelche grundsätzlichen Beschränkungen gegeben hätte, ebenfalls ein Kaiserbildnis aufzustellen. Auch Menschen aus eher niedereren sozialen Verhältnissen wie Freigelassene durften Statuen dieser Art errichten, wenn sie denn über die nötigen Mittel zur Herstellung eines solchen Monuments verfügten ${ }^{216}$. Bei einem Durchschnittspreis von etwa 5000 Sesterzen für eine lebensgroße Marmorplastik ist allerdings leicht verständlich, dass nur eine relativ kleine Gruppe von Personen für eine Statuenaufstellung infrage $\mathrm{kam}^{217}$.

Nur sehr selten kam es hingegen nach Ausweis der erhaltenen epigraphischen Zeugnisse vor, dass Kaiser Statuen (und entsprechende Inschriften) ihrer selbst errichteten, obwohl dies ein

und Funktion antiker Skulptur. Ausstellungskatalog Berlin (Berlin 1995) 332-358; Claudia Kleinwächter, Platzanlagen nordafrikanischer Städte. Untersuchungen zum sogenannten Polyzentrismus in der Urbanistik der römischen Kaiserzeit (Mainz 2001). Dabei lässt sich teilweise eine Aufteilung der Platzanlagen in bestimmte Zonen, denen augenscheinlich bei der Errichtung von Standbildern eine unterschiedliche Wertigkeit zukam, beobachten. An der wichtigsten Seite eines Forums, dem locus celeberrimus (vgl. oben Anm. 37), fanden wie in Thamugadi oft besonders aufwändige Monumente (etwa Quadriga-Darstellungen) zu Ehren der Kaiser ihren Platz. Ähnlich dicht mit Statuen, darunter kaiserlichen Bildnissen, besetzte Plätze gab es in Hispanien, wo mittlerweile das Forum von Segobriga besonders gut bekannt ist; vgl. Abascal u.a., Foro de Segobriga (wie Anm. 183) sowie Juan Manuel Abascal u.a., La imagen dinástica de los julio-claudios en el foro de Segobriga (Saelices, Cuenca, conventus Carthaginiensis), in: Lucentum 17-18 (1998-99) 183-193. Für Italien lässt sich das Beispiel des Forums und der Basilica von Veleia anführen: Boschung, Statuengruppen (wie Anm. 212) 25-35. ${ }^{215} \mathrm{Zu}$ Statuenaufstellungen in den Thermen vgl. Hubertus Manderscheid, Die Skulpturenausstattung der kaiserzeitlichen Thermenanlagen (Berlin 1981); zu solchen im Theater Michaela Fuchs, Untersuchungen zur Ausstattung römischer Theater in Italien und den Westprovinzen des Imperium Romanum (Mainz 1987).

${ }^{216} \mathrm{Zu}$ der Vielzahl von belegten Stiftern von Kaiserstatuen vgl. allgemein Pekáry, Kaiserbildnis (wie Anm. 208) 4-12. Zur Situation in Rom s. vor allem die zahlreichen epigraphischen Belege in CIL VI (vgl. insbesondere die ausführlichen Angaben in CIL VI 8, 2), von denen im Folgenden nur einige wenige exempli gratia zitiert werden sollen: Zur plebs als Stifterin s. CIL VI 909/10 (= ILS 168/76); 943 (= ILS 6045); zu den tribus ebd. 955 = (ILS 286); zu den collegia bzw. cultores ebd. 956; 967a; 40307; zu den stadtrömischen Truppen ebd. 1023; zu den auswärtigen Städten und Provinzen ebd. 1010 (= ILS 356); 1090; 40313; zu hohen kaiserlichen Beamten ebd. 1088 (= ILS 499). Zu den Verhältnissen in den Provinzstädten vgl. Géza Alföldy, Bildprogramme in den römischen Städten des Conventus Tarraconensis. Das Zeugnis der Statuenpostamente, in: Homenaje a Garcia Bellido, Bd. 4 (Revista de la Universidad Complutense 28, 118, Madrid 1979 [1981]) 177-275; Alfoldy, Römische Statuen (wie Anm. 209) bes. 51-57; Zimmer, Statuenaufstellung (wie Anm.214) passim. In den (nicht ganz seltenen) Fällen, in denen in der Inschrift auf der Basis einer Kaiserstatue gar kein Stifter genannt wird, ist ebenfalls davon auszugehen, dass hierfür die Gemeinde verantwortlich zeichnete.

${ }^{217} \mathrm{Zu}$ den durchschnittlichen Preisen für ein Standbild vgl. János Szilágyi, Zu den Statuenpreisen in der römischen Kaiserzeit, in: Corolla memoriae E. Swoboda dedicata (Graz, Köln 1966) 214-224. 
Standardvorwurf der literarischen Quellen gegenüber den ,schlechten' Kaisern ist ${ }^{218}$. So soll Caligula den Befehl gegeben haben, berühmte Götterbilder in Statuen seiner selbst umzuwandeln bzw. durch solche zu ersetzen ${ }^{219}$. Auch Nero wird nachgesagt, er habe Bildnisse seiner selbst aufstellen lassen, die ihn als Sänger zeigten ${ }^{220}$. Besonders bekannt ist die berühmte Kolossalstatue, die er angeblich mit seinem Porträtkopf im Vestibül der gewaltigen Domus Aurea errichten lassen wollte und die ihn nackt sowie mit einem Steuerruder und dem Strahlenkranz des Sol, also in göttlicher Gestalt, dargestellt haben soll (wobei aber ganz unklar bleibt, ob die Sol-Statue tatsächlich ein Bildnis des Nero trug) ${ }^{221}$. Domitian soll dem Hercules einen neuen Tempel an der Via Appia erbaut und darin eine Statue aufgestellt haben, die ihn in Gestalt des Gottes zeigte ${ }^{222}$. Und auch von Commodus wird berichtet, er habe im Reich Standbilder im Kostüm des Hercules erhalten ${ }^{223}$. Schließlich soll Commodus sogar die berühmte Kolossalstatue vor dem Colosseum in ein Bildnis seiner selbst als Hercules umgewandelt und mit einer ganz außergewöhnlichen Inschrift versehen haben ${ }^{224}$. Inschriftliche Zeugnisse für all diese Behauptungen gibt es nicht - nach meinem Wissen kennen wir praktisch überhaupt keine Basis für ein vom Kaiser in der Öffentlichkeit errichtetes Standbild (mit entsprechender Inschrift), das ihn selbst zeigte ${ }^{225}$. Auch epigraphische Belege für die Ehrung des Kaisers oder von Angehörigen der domus Augusta durch Familienmitglieder sind selten. Immerhin existieren einige wenige Beispiele hierfür, die aber nicht sonderlich spektakulär $\operatorname{sind}^{226}$. Mehrfach finden sich Berichte hierzu ferner in der (allerdings oft unzuverlässigen) Historia Augusta, so in Bezug auf Kaiser Septimius Severus, der zahlreiche Standbilder seiner ersten Ehefrau

\footnotetext{
${ }^{218}$ Vgl. auch Pekáry, Kaiserbildnis (wie Anm. 208) 5 f.

${ }^{219}$ Suet. Cal. 22, 2; s. auch Claud. 9, 1 zu Standbildern von Familienmitgliedern. Von Caligula wird sogar behauptet, er habe selbst Statuen angefertigt: Cass. Dio 59, 4, 4.

${ }^{220}$ S. Suet. Nero 25, 2: statuas suas citharoedico habitu (posuit).

${ }^{221}$ Suet. Nero 31, 1: vestibulum ..., in quo colossus CXX pedum staret ipsius effigie; s. ferner Hist. Aug. Hadr. 19, 12f. Zur Diskussion um diese Statue vgl. Marianne Bergmann, Der Koloß Neros, die Domus Aurea und der Mentalitätswandel im Rom der frühen Kaiserzeit (Mainz 1994) und Roland R.R. Smith, Nero and the Sun-god: Divine Accessoires and Political Symbols in Roman Imperial Images, in: JRA 13 (2000) 532-542, bes. $537 \mathrm{f}$.

${ }^{222}$ Mart. 9, 64; 9, 65; 9, 101.

${ }^{223}$ Hist. Aug. Comm. 9, 2: accepit statuas in Herculis habitu.

${ }^{224}$ Cass. Dio 73 (72), 22, 3; Herodian. 1, 15, 9; Hist. Aug. Comm. 17, 9f. Auch hier verbleiben aber erhebliche Zweifel; vgl. Olivier Hekster, Commodus. An Emperor at the Crossroads (Amsterdam 2002) 122-124.

${ }^{225}$ Jedenfalls ist es im epigraphischen Material nur sehr selten bezeugt, dass die Kaiser selbst in der Öffentlichkeit Monumente errichteten, die (auch) Statuen ihrer selbst oder von Angehörigen der domus Augusta enthielten. Vgl. aber ein offenbar mit Statuen geschmücktes Denkmal der claudischen Familie (monumentum Claudianum) an der Via Flaminia, das von Tiberius im Jahre 22 n. Chr. geweiht und von Claudius wohl zwischen 41 und 43 restauriert wurde: CIL VI 40420-40430; dazu Francesca De Caprariis, Un momumento dinastico tiberiano nel campo Marzio settentrionale, in: BCAR 95 (1993) 93-114.

${ }^{226}$ Anzuführen ist hier eine Inschrift (offenbar zu einer Statuenbasis gehörig) aus Avennio, die der Iulia Drusilla von ihrem Onkel, dem späteren Kaiser Claudius (hier lediglich als [T]i[b]erius aufgeführt) gewidmet wurde, und zwar nach ihrem Tod im Jahre 38 und der damit verbundenen Konsekration: parenti num(inis) honore delato [pos(uit)]; s. CIL XII 1026 = ILS 195 = AE 1998, 888; dazu Jacques Gascou, Claude et Drusilla d'après une inscription d'Avignon, in: ZPE 121 (1998) 291-296. Ansonsten ist festzuhalten, dass epigraphische Belege für die Ehrung des Kaisers durch Familienmitglieder selten sind; s. etwa SEG 20 (1964) 157 = IKourion 85 (Kaiser Hadrian ehrt seinen Vater, den theos Traianus) oder CIL III 4366 = ILS $319=$ RIU I 251 (Ehrung Hadrians durch L. Aelius Caesar, der sich alsf(ilius) bezeichnet). Ein weiteres Beispiel für eine solche Ehrung im Familienkreis stellt wohl die berühmte Augustus-Statue von Primaporta dar, die auf der Gartenterrasse in einer Villa der Livia gefunden wurde.
} 
Paccia Marciana und anderer Verwandter errichtet haben soll ${ }^{227}$. Der epigraphische Befund insbesondere in seiner Heimatstadt Lepcis magna zeigt allerdings erneut ein abweichendes Bild, denn es wird klar, dass hier zwar tatsächlich umfangreiche Bildnis-Galerien von Mitgliedern des severischen Herrscherhauses zur Aufstellung kamen, diese aber ausschließlich von der Gemeinde, anderen Vereinigungen oder Privatpersonen gestiftet wurden ${ }^{228}$; und dasselbe gilt für die Situation in anderen Städten des Reiches ${ }^{229}$. Festzuhalten bleibt somit, dass die überwältigende Mehrheit von Kaiserstatuen und der damit verbundenen Ehreninschriften nicht vom Kaiser selbst, sondern von anderen Institutionen und Personen in Auftrag gegeben wurde.

Die erhaltenen Basen von Kaiserstatuen geben ferner wertvolle Aufschlüsse über die Anlässe, zu denen solche Standbilder aufgestellt wurden. Wir können dabei erkennen, dass Kaiserbilder zu jeder Zeit errichtet werden konnten, ohne dass ein Bezug auf bestimmte, das Kaiserhaus betreffende Ereignisse vorliegen musste. In der Regel waren augenscheinlich eher die lokalen Verhältnisse oder die individuellen Bedürfnisse der Stifter - nicht zuletzt der Wunsch nach inschriftlicher Repräsentation - hierfür ausschlaggebend ${ }^{230}$. Die kaiserlichen Ehreninschriften verteilen sich in der Regel chronologisch über die gesamte Regierungszeit eines bestimmten Kaisers, häufig mit einem mehr oder minder stark ausgeprägten, leicht erklärbaren Schwerpunkt zu Beginn der Herrschaft. Auffällig ist dabei aber, dass die Basen mit den zugehörigen Statuen zumeist nicht direkt nach dem Herrschaftsantritt errichtet wurden, sondern eher im zweiten oder dritten Regierungsjahr eines Kaisers. Das spricht gegen eine zentrale Steuerung dieser Bildnisaufstellungen. Vielmehr ist davon auszugehen, dass Gemeinden oder Einzelpersonen hierüber aus eigenem Antrieb entschieden und sich dafür zunächst geeignete Vorlagen für die Gestaltung der Inschrift und insbesondere des Porträts besorgen mussten, was die zeitliche Verzögerung erklärt ${ }^{231}$.

Es bleibt die Frage nach einer möglichen Genehmigungspflicht für die Errichtung von Kaiserstatuen und der damit verbundenen Ehreninschriften. Ein solches Verfahren hätte es dem Herrscher ermöglicht, direkten Einfluss auf seine Darstellungen im gesamten Reich zu nehmen. Ein Teil der modernen Forschung hat tatsächlich vermutet, dass auf Grundlage eines (postulierten) kai-

\footnotetext{
${ }^{227}$ Hist. Aug. Sept. Sev. 3, 2: cui postea in imperio statuas conlocavit; 14, 4: patri, matri, avo et uxori priori per se statuas conlocavit.

${ }^{228}$ S. IRT $387-444$.

${ }^{229}$ Vgl. beispielsweise zu den Statuen der Paccia Marciana IRT 410/11; CIL VIII $19494=$ ILS 440. Immerhin hat Septimius Severus in Rom nach Ausweis einer Inschriftentafel (CIL VI $954=31214=$ ILS 418) eine Statue seines atavus, des Divus Nerva, errichtet.

${ }^{230} \mathrm{Zu}$ den Zeitpunkten, an denen Kaiserstatuen errichtet wurden, vgl. Pekáry, Kaiserbildnis (wie Anm. 208) 22-28 und Højte, Statue Bases (wie Anm. 209) 143-166.

${ }^{231}$ Eine Untersuchung zur julisch-claudischen Zeit hat ähnliche Ergebnisse erbracht: Meriwether Stuart, Wie wurden Kaiserporträts im römischen Reich verbreitet?, in: Helga von Heintze (Hg.), Römische Porträts (Darmstadt 1974) 232-265. Vgl. weiterhin zu den Bildnissen Hadrians die Auflistung der epigraphischen Belege bei Cécile Evers, Les portraits d'Hadrien. Typologie et ateliers (Brüssel 1994) 27-53: Auch hier gibt es nur wenige Zeugnisse aus dem Jahr 117, deutlich mehr dann aus 118, aber diese hohe Zahl setzt sich kontinuierlich bis 122 fort. Starke Ausschläge nach oben gibt es noch einmal in den Jahren 129 und 131/32. Manche Städte scheinen gar jährlich ein Kaiserbildnis aufgestellt zu haben, wie dies etwa im kretischen Lyttos für das frühe 2. Jahrhundert belegt ist: Angelos Chaniotis, Giorgos Rethemiotakis, Neue Inschriften aus dem kaiserzeitlichen Lyttos (Kreta), in: Tyche 7 (1992) 27-38, bes. 31-33. Nochmals bestätigt hat sich dieses Bild bei einer Sammlung der Statuenbasen für L. Aelius Caesar, den designierten Nachfolger Hadrians, der aber schon vor diesem verstarb: Jakob M. Højte, The Epigraphic Evidence Concerning Portrait Statues of Hadrian's Heir L. Aelius Caesar, in: ZPE 127 (1999) 217-238, bes. 229: ,there is no sign of active involvement in promoting the new heir by the imperial administration".
} 
serlichen ,Bildnisrechtes" jede statuarische Ehrung des Herrschers bei der Zentrale - unter Angabe aller Details - beantragt werden musste ${ }^{232}$. Dafür gibt es aber keine expliziten Hinweise, denn ein reichsweit zur Anwendung kommendes, regelmäßig durchgeführtes Genehmigungsverfahren ist aus den literarischen Quellen, den juristischen Texten sowie vor allem aus den Tausenden von Inschriften auf den erhaltenen Statuenbasen der Kaiserzeit nicht abzuleiten. Die hierfür in der Regel angeführten Zeugnisse sind vielmehr differenziert zu betrachten. Sie betreffen zum einen die Situation in der Hauptstadt Rom, wo die Herrscher bisweilen regulierend in die Statuenaufstellung auf öffentlichen Plätzen eingriffen und Bestimmungen zur Errichtung ihrer eigenen Bildnisse erließen, wenn es um besonders heikle Kontexte, etwa Tempel, ging ${ }^{233}$. Zum anderen scheint es sich bei besonders aufwändigen, etwa den kultischen Bereich betreffenden Ehrungen für den Kaiser in den Provinzstädten eingebürgert zu haben, dass man zur eigenen Absicherung beim Herrscher nachfragte, $\mathrm{ob}$ ihm dies genehm sei ${ }^{234}$. Hierfür kennen wir eine Reihe von Beispielen aus literarischen und epigraphischen Quellen ${ }^{235}$. Diese Einzelfälle sollten aber nicht verallgemeinert und als Belege für eine generelle Genehmigungspflicht gewertet werden ${ }^{236}$. Es dürfte nämlich ausgeschlossen sein,

232 Die Existenz eines kaiserlichen ,Bildnisrechtes' ist vor allem von Jean P. Rollin, Untersuchungen zu Rechtsfragen römischer Bildnisse (Bonn 1979) 94-116 postuliert worden. Ebenso wie er geht auch Hans $G$. Niemeyer, Studien zur statuarischen Darstellung der römischen Kaiser (Berlin 1968) 26f. davon aus, dass jede Kaiserstatue in Rom genehmigt werden musste und dass der Kaiser auf diese Weise alle seine Darstellungen im gesamten Reich bis in die Einzelheiten festlegen konnte; vgl. dazu ebd. 111: „(es) muss eine zwingende Zuständigkeit der Kaiser zur Genehmigung ihrer einzelnen öffentlichen Bildnisse angenommen werden“. Die Anträge auf Errichtung eines kaiserlichen Standbildes in der Öffentlichkeit hätten regelmäßig Angaben zum in Aussicht genommenen Material, zur Form des Denkmals und zu sonstigen Merkmalen der Ausführung enthalten. In den Quellen ist all dies aber kaum nachzuvollziehen.

${ }^{233}$ So soll Tiberius angeordnet haben, dass man ihm in diesem Falle Statuen und Büsten nur mit seiner ausdrücklichen Erlaubnis widmen dürfe (Suet. Tib. 26, 1: probibuit ... statuas atque imagines nisi permittente se poni; ähnlich Cassius Dio 57, 9, 1f.), und zwar unter der Bedingung, dass diese nicht zwischen den Götterbildern im Innersten des Tempels zur Aufstellung kämen, sondern lediglich unter den Gegenständen, die das Heiligtum schmückten.

${ }^{234}$ Hierbei lässt sich in den literarischen Quellen ein bestimmtes Stereotyp ausmachen: Während principes boni überhöhende Ehrungen, etwa Statuen aus Edelmetall, regelmäßig ablehnten, nahmen sie ,schlechte' Kaiser angeblich gerne an, so Caligula nach Phil. leg. 346 oder Domitian nach Plin. paneg. 52, 3 und Cass. Dio 67, 8, 1. Allerdings kann das selbst bei diesen Kaisern kein durchgängiges Verhaltensmuster gewesen sein, wie andere Zeugnisse beweisen; s. IG VII 2711 = Oliver, Constitutions Nr. 18 zu Caligula oder Tac. ann. 13, 10, 1 zu Nero. ${ }^{235}$ S. etwa Plin. ep. 10, 8f. Bei solchen Anfragen war den Herrschern dann auch die Möglichkeit gegeben, regulierend in die Produktion von Darstellungen ihrer selbst einzugreifen und gewisse Anweisungen bezüglich ihres Aussehens zu geben, vor allem um ihrer Meinung nach zu weit gehende Ehrungen abzulehnen; s. dazu die in Anm. 53 zitierten Belege sowie IEph $25=$ Oliver, Constitutions Nr. 170. Die überlieferte Kommunikation der Untertanen mit dem Kaiser bezüglich einer Statuenaufstellung folgte jeweils einem ähnlichen Muster (vgl. zusätzlich noch IGR IV 1756 = Oliver, Constitutions Nr.7; OGIS II $475=$ IGR IV 561 = Oliver, Constitutions Nr. 35 sowie Suet. Vesp. 23, 3; Cass. Dio 65 [66], 14, 5): Ein provinziales koinon, eine Gemeinde oder auch eine Einzelperson beschloss herausragende, oft kultische Ehrungen für den Herrscher. Das entsprechende Dekret wurde dann durch Gesandte nach Rom geschickt und dem Kaiser vorgelegt. Dieser antwortete darauf mit einem Brief, korrigierte gegebenenfalls die Vorschläge und belobigte die Stifter, die deswegen das gesamte Dossier in ihrer Heimatstadt inschriftlich aufzeichnen ließen (vgl. oben Kap.2). Nur dadurch wissen wir in der Regel überhaupt von diesen Vorgängen, und es ist nicht ganz ausgeschlossen, dass sie häufiger vorkamen, als es uns die relativ wenigen diesbezüglichen Zeugnisse glauben lassen.

${ }^{236}$ Eine solche Vorstellung findet sich aber noch in der jüngsten archäologischen Literatur, so bei Rose, Commemoration (wie Anm.212) 8f., 51f. und bei Boschung, Statuengruppen (wie Anm.212) 172-174, die allerdings beide nicht daran glauben, dass die Kaiser auch die Details der provinzialen Statuensetzungen beeinflussten. 
dass ein vergleichbarer Aufwand bei jedem normalen Standbild betrieben wurde, das in irgendeiner Provinzstadt zur Aufstellung kam - weder gibt es hierfür, wie gesehen, Hinweise in den Quellen, noch würde es zu dem Bild passen, das wir von den administrativen Strukturen im römischen Reich gewonnen haben ${ }^{237}$.

Wie bereits erwähnt wurde, ist nur eine sehr geringe Zahl von Ehreninschriften für Mitglieder des Kaiserhauses vom Herrscher selbst konzipiert und dann in ein epigraphisches (und statuarisches) Monument umgesetzt worden. Die allermeisten dieser Tituli sind dem Princeps vielmehr von anderer Seite gewidmet worden. Dennoch weisen die Tausenden von Ehreninschriften, die sich für die Kaiser des 1. und 2.Jahrhunderts erhalten haben, in der Regel keine rein individuell oder gar willkürlich anmutenden Formulierungen auf. Vielmehr erscheinen sie - zumindest auf den ersten Blick - eher einheitlich. Das liegt daran, dass sich in der Ansprache des Herrschers seit dem Beginn des Prinzipats ein standardisiertes Formular durchgesetzt hatte, welches die kaiserliche Kanzlei verwendete, wenn Schriftstücke im Namen des Herrschers zu erstellen waren, und das auch fast alle Stifter von kaiserlichen Ehreninschriften - aufgrund einer nie in Frage gestellten Konvention - übernahmen. Wir sprechen hier von der ,offiziellen' Kaisertitulatur, der für die öffentliche Wahrnehmung des Kaisers augenscheinlich eine hohe Bedeutung zukam ${ }^{238}$. An der Ausformulierung dieser Titulatur war der Princeps mehr oder minder direkt beteiligt; sie bildete somit das wichtigste Instrument, mit dem er die Form beeinflussen konnte, in der sein Name in den Tituli erschien. Dabei handelte es sich um ein eher konservatives Element der Kommunikation mit bzw. über den Herrscher ${ }^{239}$, denn die wichtigsten Bestandteile der Titulatur waren bereits unter Augustus etabliert worden und wurden in der Folgezeit nur noch wenig verändert ${ }^{240}$. Gewisse

${ }^{237}$ Vgl. in diesem Sinne auch Pekáry, Kaiserbildnis (wie Anm. 208) 144 und Horst Blanck, in: Gnomon 55 (1983) 534-536. Gelegentlich wird eine Bestätigung von Ehrungen für den Kaiser o.ä. durch den curator rei publicae oder den Statthalter erwähnt (so in CIL III 6885; dazu Wilhelm Liebenam, Städteverwaltung im römischen Kaiserreiche [Leipzig 1900] 381f. mit einer m.E. unrichtigen Einschätzung); aber hierbei handelt es sich zumeist um Sonderfälle, in denen etwa finanzielle Fragen berührt wurden. Sie können auf keinen Fall generalisiert und im Sinne eines allgemeingültigen, die ganze Kaiserzeit hindurch bestehenden kaiserlichen Bildnisrechtes interpretiert werden. Für die Zeit vor dem 4. Jahrhundert gibt es jedenfalls keine sicheren Belege dafür, dass die öffentliche Aufstellung von Kaiserstatuen in den Provinzstädten von einer regelmäßig einzuholenden Zustimmung abhängig gewesen wäre; so nochmals nachdrücklich Thomas Pekáry, „Bildnisrecht“, in: Boreas 13 (1990) 51f.

${ }^{238} \mathrm{Als}$ heuristisches Instrument hat sich die Unterscheidung in ,offizielle‘ und ,inoffizielle Titulaturelemente m.E. durchaus bewährt. ,Offiziell' war demnach diejenige Titulatur, die vom Kaiser selbst bzw. von seiner Kanzlei in am Hof ausgestellten Schriftstücken verwendet wurde. Am besten zu fassen ist sie in den kaiserlichen Konstitutionen zur Bürgerrechtsverleihung an Veteranen, von denen sich in den Militärdiplomen eine hohe Zahl beglaubigter Abschriften erhalten hat; dazu s. oben Anm. 85.

${ }^{239}$ Zur offiziellen Kaisertitulatur vgl. allgemein Kienast, Kaisertabelle (wie Anm. 16) 19-58; ferner Dora Alba Musca, Le denominazioni del principe nei documenti epigrafici romani (Bari 1979); Andreina Magioncalda, Lo sviluppo della titolatura imperiale da Augusto a Giustiniano attraverso le testimonianze epigrafiche (Turin 1991). Zur späteren Entwicklung im 3. und 4.Jahrhundert vgl. Michael Peachin, Roman Imperial Titulature and Chronology, A.D. 235-284 (Amsterdam 1990); André Chastagnol, Le formulaire de l'epigraphie latine officielle dans l'antiquité tardive, in: Angela Donati (Hg.), La terza età dell'epigrafia (Faenza 1988) 11-65.

${ }^{240}$ Die wichtigsten Elemente dieser Titulatur waren zum einen die an die tria nomina eines römischen Bürgers erinnernden, bereits für den ersten Princeps - aufbauend auf spätrepublikanischen Vorläufern - gebrauchten Namensbestandteile Imperator, Caesar und Augustus, die sich in der frühen Kaiserzeit zu regelmäßig gebrauchten Titeln verfestigten; vgl. hierzu Ronald Syme, Imperator Caesar. A Study in Nomenclature, in: Historia 7 (1958) 172-188; Jürgen Deininger, Von der Republik zur Monarchie. Die Ursprünge der Herrschertitulatur des Prinzipats, ANRW I 1 (1972) 982-997. Hinzu traten die Aufzählung der vom Kaiser bekleideten Konsulate 
Erweiterungen der offiziellen Titulatur, die schrittweise eingeführt wurden, betrafen etwa die zunehmende Bedeutung von kaiserlichen Siegerbeinamen (welche vom Senat verliehen wurden) ab dem späten 1.Jahrhundert n. Chr. und insbesondere unter Trajan ${ }^{241}$. Radikale Neuerungen, welche die Herrscher gleichsam von oben durch eine stark veränderte Konzeption ihrer offiziellen Titulatur durchzusetzen versuchten, waren hingegen selten. Zumindest ist das der Eindruck, der sich aus den Inschriften selbst ergibt. Die literarischen Quellen hingegen behaupten nicht selten, dass sich vor allem die sogenannten ,schlechten' Herrscher zahlreiche ihre Leistungen oder ihre Person überhöhende Beinamen oder Titulaturelemente zugelegt hätten, aber dies lässt sich nur in den seltensten Fällen am epigraphischen Befund verifizieren ${ }^{242}$. So fällt beispielsweise die von Caligula oder $\mathrm{Ner}^{243}$ benutzte Titulatur keineswegs aus dem Rahmen. Und der für Domitian postulierte Gebrauch der von der augusteischen Prinzipatsidee stark abweichenden Formulierung dominus et deus, die selbst in offiziellen Dokumenten Verwendung gefunden haben soll, ist in den Inschriften ebenfalls nicht nachweisbar ${ }^{244}$. Einzig Commodus hat mit den neuen Beinamen felix

und der imperatorischen Akklamationen, die Nennung der tribunicia potestas (ab 23 v. Chr.), des Oberpontifikats (ab 12 v. Chr.) und schließlich des Ehrennamens pater patriae (ab 2 v. Chr.).

${ }^{241} \mathrm{Zu}$ den Siegerbeinamen vgl. Peter Kneißl, Die Siegestitulatur der römischen Kaiser. Untersuchungen zu den Siegerbeinamen des ersten und zweiten Jahrhunderts (Göttingen 1969).

${ }^{242}$ Vgl. zum Folgenden Christian Witschel, Verrückte Kaiser? Zur Selbststilisierung und Außenwahrnehmung nonkonformer Herrscherfiguren in der römischen Kaiserzeit, in: Christian Ronning (Hg.), Einblicke in die Antike. Orte - Praktiken - Strukturen (München 2006) 87-129, bes. 108-122. S. ferner unten Anm. $270 \mathrm{zu}$ Caligula - mit der ebendort formulierten Einschränkung, dass möglicherweise gerade diejenigen Inschriften, die besonders außergewöhnliche Beinamen für die Herrscher enthielten, aufgrund der posthum verhängten Gedächtnisstrafen vernichtet worden sein könnten.

${ }^{243}$ Die Neuausrichtung der kaiserlichen Selbststilisierung durch Nero spiegelt sich jedenfalls in seiner Titulatur und auch in den (erhaltenen) Inschriften aus dem Westteil des Reiches kaum wider. So ist die von ihm so stark betonte Nahbeziehung zu Sol und Apollo in den lateinischen Tituli kaum nachzuweisen. Eine seltene Ausnahme hiervon führt in das direkte Umfeld des Herrschers: Der kaiserliche Sklave und Hofangestellte Eumolpus stiftete einen Altar für Sol und Luna (CIL VI $3719=31033$ = ILS 1774). Auf der Vorderseite befindet sich eine Reliefbüste des Sonnengottes, dessen Bildnis Züge des Nero aufweist. Diese Art der weitgehenden Verschmelzung von Kaiser und Gottheit war jedoch ungewöhnlich; vgl. dazu die ausführliche Diskussion bei Marianne Bergmann, Die Strahlen der Herrscher. Theomorphes Herrscherbild und politische Symbolik im Hellenismus und in der römischen Kaiserzeit (Mainz 1998) 194-201. Deutlicher lassen sich Bezüge dieser Art im griechischen Osten ausmachen, so in einer Inschrift aus Akraiphia (s. oben Anm. 43). Sie feiert den Kaiser mit folgenden Wendungen: „Herr der gesamten Welt, größter Imperator ..., die neue Sonne (neos Hëlios), die den Griechen erstrahlt" sowie „Zeus der Befreier (Eleutherios) und Philhellene“. Zu Nero als Helios s. ferner IGR III 345 (Sagalassos) sowie AE 1961, 22 = SEG 18 (1962) 566 (Prostranna); außerdem eine (verlorene) Reliefplatte aus dem Sebasteion von Aphrodisias, auf der Nero laut der Inschrift (SEG 31 [1984] 919) neben Helios dargestellt war. Interessant ist schließlich die - bei den bekannten Vorlieben des Kaisers naheliegende Benennung des Nero als neos Apollön in einigen Inschriften des Ostens; so in IG II/III 3278 und in AE 1971, 435 (beide Athen).

${ }^{244}$ Behauptet wird die (offizielle) Verwendung der Anrede dominus et deus für Domitian von Suet. Dom. 13, 1f.; Dion. Chrys. or. 45, 1; Cass. Dio 57, 4, 7; Eutr. 7, 23, 2 (dominum se et deum primus appellari iussit) und Aur. Vict. Caes. 11, 2 (se dominum deumque dici coegerit). Die angebliche Einführung der Bezeichnung dominus et deus als zumindest halboffizielle Titulatur datieren die spätantiken Chroniken in das Jahr 85/86; sie folgen dabei aber recht unkritisch der von Sueton vorgegeben Zweiteilung der Regierungszeit Domitians in eine gute und in eine tyrannische Phase. In den epigraphischen Zeugnissen findet sich diese Formel jedoch fast nie; vgl. Werner Eck, in: Gnomon 53 (1981) 347 sowie insbesondere die Zusammenstellung des Materials bei Alain Martin, La titulature épigraphique de Domitien (Frankfurt am Main 1987). Die einzige mögliche Ausnahme ist eine bei Mart. epig. 5, 8 erwähnte Verordnung des Kaisers über die Sitzplätze im Theater (s. auch Suet. Dom. 8, 3), denn hier ist von einem edictum domini deique nostri die Rede. Es ist aber m.E. sehr fraglich, ob dies die 
invictus Hercules Romanus und pacator orbis, die er im Sommer 192 in seine offizielle Titulatur einfügen ließ, wirkliches Neuland betreten ${ }^{245}$. Selbst diese außergewöhnliche Selbststilisierung, die im Übrigen nur wenige Monate bis zum Tod des Kaisers am letzten Tag des Jahres 192 Bestand hatte, ist aber von der Bevölkerung des Reiches rezipiert und bei der Erstellung eigener epigraphischer Monumente für den Herrscher umgesetzt worden ${ }^{246}$.

Das letztgenannte Beispiel kann noch einmal zeigen, in welch hohem Maße sich die Stifter von Ehrenmonumenten für den Kaiser bei der Konzeption der entsprechenden Tituli ${ }^{247}$ an den Vorgaben ausrichteten, die ihnen in Form der an den meisten Orten gut bekannten kaiserlichen Titulatur zur Verfügung standen. Die bereits angesprochene hohe Standardisierung bei der Ansprache des Herrschers ist vor allem durch diesen Nachahmungseffekt zu erklären. Dieser kann allerdings keineswegs auf eine zentrale Steuerung der kaiserlichen Ehrungen zurückgeführt werden. Das ist schon daran zu erkennen, dass offenbar kein Zwang bestand, alle Elemente der offiziellen Kaisertitulatur in einer Inschrift in toto anzuführen, denn häufiger begnügten sich die Auftraggeber mit einer Auswahl einzelner Titel oder gar mit der schlichten Ansprache des Herrschers als Augustus $^{248}$. Dass auch die Ausführung von epigraphischen Monumenten zu Ehren des Herrschers kaum flächendeckend kontrolliert worden sein $\operatorname{kann}^{249}$, zeigen die zahlreichen Fehler ${ }^{250}$, die sich

amtliche Überschrift war; eher handelt es sich um eine dichterische Umschreibung, die zu der panegyrischen Sprache Martials passen würde. Zu den beiden einzigen inschriftlichen Belegen für Domitian als dominus s. CIL X 444 = InscrIt III 1, 7 = ILS 3546 und CIL VI 23454. Beide Inschriften sind jedoch von kaiserlichen Freigelassenen bzw. Sklaven gestiftet worden, für die eine solche Anrede normal war; dazu Martin, Titulature, 194-196. Hinzu kommt eventuell ein heute nicht mehr auffindbarer Meilenstein aus der Baetica, dessen Inschrift laut den frühen Gewährsmännern mit $D$ (ominus) n(oster) begonnen haben soll, was von den modernen Editoren aber aufgrund allgemeiner Erwägungen - vielleicht zu Unrecht - getilgt worden ist (s. CIL II 4722). Weitere gesicherte Fälle sind nicht bekannt; Martin, Titulature, 207 gelangt daher zu folgendem Fazit: „Domitien innove peu en matière de dénominations impériales ... Domitien, par sa titulature, s’inscrit dans une continuité impériale“.

${ }^{245}$ S. Cass. Dio 73 (72), 15, 3-5 mit den Anmerkungen von Pieter J. Sijpesteijn, Commodus' Titulature in Cassius Dio LXXII 15, 5, in: Mnemosyne 41 (1988) 123f.; ferner Christian Witschel, Kaiser, Gladiator, Gott Zur Selbstdarstellung des Commodus, in: SCI 23 (2004) 255-272.

${ }^{246}$ S. CIL XIV 3449 = ILS 400; IAM II 363 und insbesondere AE 2002, 1501; dazu Michael P. Speidel, Commodus the God-Emperor and the Army, in: JRS 83 (1993) 109-114.

${ }^{247}$ Dasselbe gilt im Übrigen für die Gestaltung des Kaiserporträts; vgl. dazu den Beitrag von Ralf von den Hoff, in diesem Band.

${ }^{248}$ Dazu Alföldy, Repräsentation (wie Anm.9) 7f.

${ }^{249}$ Dies gilt auch für die Durchführung von Gedächtnisstrafen gegen bestimmte Kaiser (vgl. oben Anm.6), die keineswegs überall gleichermaßen streng gehandhabt wurde, was wiederum darauf hinweist, dass es hierbei wohl keine zentrale Steuerung oder flächendeckende Kontrolle gab. So wurde nach dem Tod des Domitian vom Senat angeordnet, dass der Name des Domitian überall aus den Inschriften zu tilgen sei (s. Suet. Dom. 23, 2: senatus adeo laetatus est, ut ... eradendos ubique titulos abolendamque omnem memoriam decerneret; vgl. ferner Lact. mort. pers. 3, 2-4). Von den erhaltenen Tituli Domitians weisen jedoch nur ca. 40 Prozent eine deutlich erkennbare Eradierung seines Namens auf, wobei dies vor allem die öffentlich aufgestellten Inschriften betraf; vgl. Martin, Titulature (wie Anm. 244) 197-204. Eine Steuerung solcher Aktionen war immer nur partiell möglich, da die Zentralverwaltung hierbei auf die Mitarbeit der lokalen Behörden angewiesen war; so auch Kajava, Erasure of Inscriptions (wie Anm. 6) 203 (mit weiteren Beispielen): „The central administration in Rome must have realized that carrying out consistently the penalty of epigraphic erasure would have not only been nonsense but impossible“; sowie 204: „Individual provincial cities could act independently in such matters“.

${ }^{250}$ Selbst in Rom waren die Kaiserinschriften nicht immer ganz korrekt ausgeführt, auch wenn sich hier dieZahl der gröberen Fehler stark in Grenzen hielt; vgl. hierzu den Überblick von Hans Krummrey, Irreguläre Schreibungen in stadtrömischen Kaiserinschriften von Augustus bis Commodus, in: Ulrike Peter (Hg.), Stephanos nomismatikos. Festschrift E. Schönert-Geiss (Berlin 1998) 369-398. Häufiger waren Verschreibungen in den Provinzen, 
gerade in diejenigen Elemente der Kaisertitulatur eingeschlichen haben, die wie etwa die Zählung der imperatorischen Akklamationen variabel waren und darum eine besonders gute Kenntnis der aktuellen Ausprägung der offiziellen Titulatur voraussetzten ${ }^{251}$. Es gibt aber noch wesentlich deutlichere Hinweise darauf, dass man im Imperium Romanum bei der Konzeption einer Kaiserinschrift zwar gehalten war (auch wenn dies kaum überprüft wurde), sich in der Ansprache des Herrschers an dem Formular der vom Kaiser verwendeten Titulatur zu orientieren, dies aber durchaus Spielraum für eigene Gestaltungsmöglichkeiten ließ. So konnte man dem Herrscher einen Titel zugestehen, den dieser selbst gar nicht führte. Tiberius etwa hat das von Augustus etablierte praenomen imperatoris abgelehnt; nicht alle Menschen, die im Reich Inschriften für ihn errichteten, sind ihm

und zwar auch bei prominenten Monumenten, so auf einem Ehrenbogen, den die Stadt Volubilis in der Provinz Mauretania Tingitana zu Ehren des Kaisers Caracalla, der die Gemeinde offenbar besonders begünstigt hatte, ganz am Ende von dessen Regierungszeit (d.h. zwischen Dezember 216 und April 217) errichten ließ; s. IAM II 390/91. Hier ist für Caracalla eine vierte imperatorische Akklamation angegeben, obwohl er offiziell bis zu seinem Lebensende nur imp. III war (seit 213). Zwei Erklärungsmöglichkeiten bieten sich an: Entweder handelte es sich tatsächlich um einen unbewussten Fehler, wie er offenbar auch auf einigen Meilensteinen vorliegt, die Caracalla zwischen 214 und 216 ebenfalls als imp. IIII führten. Oder der Stadtrat von Volubilis wollte besonders aktuell sein, indem er dem Herrscher, der zu dieser Zeit gegen die Parther kämpfte, eine vierte Ausrufung zum siegreichen Feldherren zugestand, obwohl eine solche noch gar nicht erfolgt war (und dann eben auch nicht mehr stattfand). Damit wäre der Fall mit der zeitgleichen Inschrift für Caracalla aus Tarraco zu vergleichen; dazu ausführlicher unten Anm. 255. Auch im griechischen Osten kamen Fehler bei der Wiedergabe der Kaisertitulatur nicht selten vor; vgl. Chaniotis, Rethemiotakis, Lyttos (wie Anm. 231) 34.

${ }^{251}$ Nicht einfach zu klären ist die Frage, wie die Reichsbewohner Kenntnis von den Neuerungen in der offiziellen Kaisertitulatur erhielten - insbesondere in den Fällen, in denen es sich nicht um routinemäßige Veränderungen wie die Zählung der tribunicia potestas handelte. Auch hierbei scheint in einigen Situationen den Provinzgouverneuren eine wichtige Vermittlerrolle zugekommen zu sein. Besonders gut lässt sich der Einfluss der Statthalter auf die Ausformung der Kaisertitulatur in Ägypten anhand der Papyri verfolgen; vgl. hierzu etwa Fritz Mitthof, Vom hierōtatos Kaisar zum epiphanestatos Kaisar. Die Ehrenprädikate in der Titulatur der Thronfolger des 3.Jahrhundert n. Chr. nach den Papyri, in: ZPE 99 (1993) 97-111. Mitthof denkt darüber hinaus auch an direkte Anordnungen aus der Reichszentrale, für die es jedoch keine sicheren Hinweise gibt (103f.). Unklar ist ferner, ob der Postverkehr zwischen dem Kaiser, der Provinzialverwaltung sowie den lokalen Behörden in einem regelmäßigen Rhythmus erfolgte und somit eine Kontinuität der Nachrichtenübermittlung gewährleistet war. Dies erscheint zwar durchaus vorstellbar; dennoch bemerkt Eck, Administrative Infrastruktur (wie Anm.34) 79 m.E. zu Recht einschränkend: „Ein völlig einheitliches, rationales System der Überbringung von Nachrichten wurde offensichtlich in den ersten Jahrhunderten nicht entwickelt; damit fehlt aber auch ein wesentliches Element, das es erlauben würde, die kaiserzeitliche Verwaltung in erster Linie unter den Gesichtspunkten von bürokratischer Effektivität und Rationalität zu sehen.“ Ähnlich äußert sich Anne Kolb, Transport und Nachrichtentransfer im Römischen Reich (Berlin 2000) bes. 306: „[es] ist davon auszugehen, dass kein geregeltes System der administrativen Nachrichtenübermittlung im Imperium Romanum existierte“. Demnach war man wohl auf lokaler Ebene doch häufig darauf angewiesen, selbst Informationen einzuholen (etwa durch Gesandte in Rom; dazu oben Anm.34), wobei es je nach Region oft mehrere Monate dauern konnte, bis die Nachrichten vor Ort eintrafen; vgl. dazu auch Richard Duncan-Jones, Communication-Speed and Contact by Sea in the Roman Empire, in: Ders., Structure and Scale in the Roman Economy (Cambridge 1990) 7-29. Anderseits zeigen etwa Kaiserinschriften aus dem mittleren 3. Jahrhundert, als sich teilweise sehr kurzlebige Herrscher in rascher Folge ablösten, dass man in vielen Städten so aktuell wie möglich zu reagieren versuchte. So hat sich beispielsweise für die beiden älteren Gordiane, die zu Beginn des Jahres 238 für weniger als einen Monat als Augusti fungierten, eine ganze Reihe von Inschriften aus verschiedenen Teilen des Reiches erhalten, und zwar nicht nur auf schnell herzustellenden Meilensteinen, sondern auch auf Statuenbasen, die mit einem entsprechenden Bildnis verbunden gewesen sein müssen; vgl. Xavier Loriot, Un milliaire de Gordien II découvert près de Césarée de Palestine et l'extension aux provinces de l'insurrection de 238 après J.-C., in: REA 80 (1978) 71-84, bes. 81-84 (Katalog der Zeugnisse). 
darin jedoch gefolgt ${ }^{252}$. Auffällig ist auch, dass in einigen Fällen ehrende Beinnamen des Herrschers in Inschriften, die weit entfernt von Rom errichtet wurden, bereits Verwendung fanden, bevor sie dem Kaiser offiziell (d.h. in der Regel durch den Senat) verliehen wurden; das gilt beispielsweise im Falle des Augustus für die Verwendung der Bezeichnung pater patriae vor 2 v. Chr. ${ }^{253}$ oder im Falle Traians für den Beinamen Optimus vor dessen offizieller Verleihung (vermutlich) im Spätherbst des Jahres $113^{254}$. Ein besonders gutes Beispiel für eine solche lokal initiierte Vorwegnahme eines kaiserlichen Titulaturelements kennen wir aus Tarraco (Tarragona): Dort wusste man sicherlich von dem

252 Tiberius lehnte es ab, das praenomen imperatoris und den Ehrentitel pater patriae zu führen: praenomen quoque imperatoris cognomenque patris patriae ... recusavit (Suet. Tib. 26, 2; s. ferner Tac. ann. 1, 72, 1; 2, 87; Cass. Dio 57, 8, 1). Dennoch kennen wir einige Inschriften, die für ihn das praenomen imperatoris, das man von der Titulatur des ersten Kaisers Augustus her gewohnt war, aufführen; s. beispielsweise CIL VIII 10023 = $21915=$ ILS 151; CIL II 4905 = ILS 152; IRT 335; ILAfr 558. Daneben gibt es einige Inschriften, die den Titel Imperator zwar nicht zu Beginn der Titulatur nennen, aber an einer ungewöhnlichen Stelle, nämlich direkt hinter Caesar bzw. Augustus, womit wohl ein Kompromiss zwischen den Vorstellungen des Kaisers und dem Wunsch des Stifters, den Herrscher angemessen zu ehren, erreicht werden sollte; s. etwa CIL III $6703=$ IGLS I 164; CIL XIII 11513 = AE 1958, 79; CIL II²/5, 747 = CIL II 2037 = ILS 155. Weitere Belege finden sich bei Robin Seager, Tiberius (London 1972) 142 A. 2. Viele dieser Inschriften entstammen allerdings der Anfangszeit von Tiberius' Regierung, als vermutlich noch erhebliche Unsicherheit über die neue Titulatur herrschte. Interessant ist in diesem Zusammenhang auch eine Inschrift aus Paphos auf Zypern, auf der ein Treueeid der Bewohner für Tiberius festgehalten wurde. Vor bzw. hinter dem Namen des Kaisers wurde dabei jeweils eine größere Lücke freigelassen; offenbar, um hier eventuell später das Wort autokratōr einfügen zu können. Man wusste hier also augenscheinlich von dem Wunsch des Kaisers, erwartete aber eine nachfolgende Änderung seiner Haltung; dazu Terence B. Mitford, A Cypriot Oath of Allegiance to Tiberius, in: JRS 50 (1960) 75-79 = IPaphos 151. Bei der Aufstellung von zwei Statuen für Tiberius in derselben Gemeinde zeigte man diese Zurückhaltung im Übrigen nicht, denn beide Male findet sich in der Inschrift auf den Basen der Titel autokratōr (IGR III 941/42 = IPaphos 147/48). Auf ähnliche Weise versuchte man, die Vorstellung vom pater patriae doch in den Inschriften für Tiberius unterzubringen, ohne den vom Kaiser zurückgewiesenen Titel explizit zu gebrauchen. So wurde Tiberius etwa als conservator patriae gefeiert, womit ein ähnlicher Sinngehalt erreicht war; s. CIL XI 3872 = ILS 159 (principi optumo ac iustissimo conservatoripatriae); AE 1965, 113; CIL II²/5, 748 = CIL II 2038. Ein weiteres Zeugnis für die (inoffizielle) Verwendung sowohl von autokratōr als auch von patēr tès patridos für Tiberius stellt die sog. lex sacra von Gytheion dar (s. oben Anm. 53). In dem zum selben Dossier gehörigen Brief des Tiberius ist die Kaisertitulatur hingegen korrekt wiedergegeben.

${ }^{253}$ S. etwa CIL XII 136 = ILS 6755; CIL II²/7, 70 = CIL II 2107 = ILS 96; CIL III 6803 = ILS 101; AE 1952, 166; dazu Witschel, Augustus 51f. Diese Inschriften zeigen, dass die Ehrenbezeichnung pater bzw. parens patriae dem Augustus in den Provinzen vereinzelt schon vor Februar 2 v. Chr. angetragen wurde; Ähnliches berichtet im Übrigen Cass. Dio 55, 10, 10. Auf einer Serie von südgallischen Meilensteinen, die vor 2 v. Chr. errichtet worden waren, wurde hingegen der Beiname pater patriae nachträglich am Beginn der Inschrift hinzugefügt; so in CIL XVII/2, 82 = CIL XII $5497=$ ILN IV $150=$ ILS 100.

${ }^{254} \mathrm{Zu}$ der neuen Datierung der offiziellen Verleihung des Beinamens Optimus an Trajan im Spätherbst 113 oder zu Beginn des Jahres 114 vgl. RMD IV p.619f. App. IV. In einigen Militärdiplomen, die im Frühjahr 114 ausgegeben wurden, ist die Bezeichnung optimus nachträglich über Z. 1 hinzugefügt worden: RMD IV 225/26. Trajan war aber bereits zuvor in Inschriften nicht selten als optimus princeps o.ä. angesprochen worden; so etwa in CIL II ${ }^{2} / 5,846$ = CIL II 2010 (optumo maxsumoque principi); CIL VI 959 = ILS 292 ([opt]ime de re publica [merit]o domi fori[sque]); CIL VII $10117=22125 \mathrm{a}=$ ILS 293 (Optimus [Au]g(ustus)); ferner Plin. paneg. 2, 7; dazu Martin Fell, Optimus princeps? Anspruch und Wirklichkeit der imperialen Programmatik Traians (München 1992) 40-42, 52-61, 73f. Interessanterweise kam es im provinzialen Kontext bisweilen auch zu einer Vorwegnahme der Siegesbeinamen Trajans, bevor diese ihm offiziell vom Senat verliehen wurden, etwa im Falle von Parthicus (offiziell ab dem 20.2. 116 nach den FastOst; s. jedoch auch Cass. Dio 68, 23, 2; 28, 2). Zwei Inschriften aus der Baetica sprechen den Kaiser bereits im Jahre 114, als der Krieg gegen die Parther gerade begonnen hatte, als Parthicus an: CIL II / 5, 295 = CIL II 2097 = ILS 297 und AE 1987, 499 (errichtet wurde hier eine statua triumphalis des Kaisers) mit dem Kommentar von Julián González, Trajano: Part(h)icus, trib. pot. XIIX, imp. X, in: AEA 60 (1987) 237-250 (der m.E. jedoch nicht völlig überzeugend argumentiert). 
Partherfeldzug, den Kaiser Caracalla im Sommer 216 begonnen hatte. Da man in der Hauptstadt der Provinz Hispania citerior bei der Verehrung des Kaisers nicht zurückstehen wollte und wohl auch gehört hatte, dass dieser seinen angeblichen Parthersieg - mit Zustimmung des Senats - bereits feiern ließ, errichtete man auf Beschluss des Stadtrats Ende 216 oder Anfang 217 ein bedeutendes Monument für den Herrscher, vermutlich eine Reiterstatue, deren Basis mit einer eindrucksvollen Inschrift versehen wurde. Im Frühjahr des Jahres 217 schienen sich dann die Anzeichen dafür zu verdichten, dass Caracalla vom Senat auch offiziell den Siegerbeinamen Parthicus verliehen bekommen würde, und dies schon zum zweiten Mal, denn er führte den Titel bereits seit 211. Um nun besonders aktuell zu sein und der plakativ zur Schau gestellten Siegesideologie Caracallas entgegenzukommen, änderte man in Tarragona - ohne eine definitive Bestätigung der neuen Titulatur aus Rom erhalten zu haben - die gerade fertiggestellte Inschrift entsprechend ab, indem man - handwerklich durchaus geschickt - aus dem PARTH (für Parthico) ein PART II (für Parthico iterum) machte. Das war auch insofern innovativ, als die Iterierung von Siegerbeinamen im frühen 3. Jahrhundert eine weitgehende Neuheit war, die sich noch kaum verbreitet hatte und erst Jahrzehnte später in die offizielle Praxis übernommen wurde. In diesem Fall erfüllte sich die Erwartung der städtischen Behörden von Tarragona jedoch nicht, denn Caracalla wurde bereits im April 217 ermordet, ohne zuvor nochmals mit einem Siegertitel geehrt worden zu sein ${ }^{255}$. Dieser Fall demonstriert sehr klar, welcher Freiraum bei der Konzeption von Kaiserinschriften auf lokaler Ebene herrschte. Dies ermöglichte es den Stiftern solcher Tituli wiederum, hierin auch eigene Vorstellungen über die Ausprägung der kaiserlichen Macht einzubringen ${ }^{256}$.

${ }^{255}$ S. RIT 83 mit der verbesserten Lesung und dem ausführlichen Kommentar von Armin U. Stylow, Änderungen in Kaiserinschriften. Zwei Beispiele aus Hispanien, in: Chiron 19 (1989) 387-399 (= AE 1989, 483). Zur Propagierung von Caracallas victoria Parthica, die vom Senat nach entsprechender Benachrichtigung durch den Kaiser anerkannt wurde, s. Cass. Dio 79 (78), 1, 4f.; Herodian. 4, 11, 9. Nach dem Zeugnis der Hist. Aug. Carac. 6, 5 soll sich unter den vom Senat zuerkannten Ehrungen auch der Siegestitel Parthicus befunden haben; dabei handelt es sich aber offenbar um ein Missverständnis, obwohl nicht völlig sicher ausgeschlossen werden kann, dass der Senat kurz vor der Ermordung Caracallas doch noch einen neuen Ehrenbeinamen für diesen beschlossen hatte. Dass aber weder die Korrektur in der Inschrift aus Tarraco noch die allmähliche Durchsetzung der iterierten Siegestitel, die keineswegs einheitlich verlief, aufgrund einer Anordnung aus der Zentrale erfolgte, betont Stylow (398f.) zu Recht.

256 Ähnliche Vorwegnahmen finden sich auch in Bezug auf die Titulatur des Commodus: So lässt sich die unter Commodus überhaupt erstmals verstärkt auftretende Ansprache des Herrschers als dominus noster (vgl. unten Anm. 264) bereits zu Beginn seiner Alleinherrschaft nachweisen; s. AE 1986, 532 mit dem Kommentar von Karlheinz Dietz, Die älteste Weihinschrift aus dem Regensburger Legionslager, in: BVBl 49 (1984) 79-85, bes. $82 \mathrm{f}$. Ebenso frühzeitig erfolgte die Verwendung des Beinamens Invictus schon im Jahre 189 (s. AE 1957, 50), obwohl diese Bezeichnung erst 192 offizieller Bestandteil der Kaisertitulatur wurde. Auf einem in seiner Echtheit allerdings umstrittenen Medaillon aus Asia wurde Commodus bereits vor der Mitte des Jahres 191 Hëlios und Hercules Romanus genannt: Hekster, Commodus (wie Anm. 224) 170f. Schließlich wurden die von Commodus ebenfalls im Sommer 192 etablierten, neuen Monatsnamen offensichtlich vereinzelt schon vor ihrer regulären Einführung gebraucht: Ist dies bei einer Inschrift aus Lanuvium (CIL XIV 2113 = ILS 5193) von 187(?) wegen der möglicherweise verderbten Lesung unsicher und bei einem Graffito in Ostia (AE 1924, 64) nicht genauer zu datieren, so haben wir hierfür doch einen klaren Beleg aus Dakien, der in das Jahr 190 führt (s. AE 1992, 1484). Vgl. zusammenfassend Witschel, Selbstdarstellung des Commodus (wie Anm. 245) 261-265. Interessant ist auch die weitere Entwicklung der Titulatur nach der Ermordung des Commodus: Die übersteigerten Elemente des Jahres 192 wurden sofort zurückgenommen (so schon in der Grabinschrift des Commodus: CIL VI 992 = ILS 401), und das Andenken des Kaisers verfiel zunächst der damnatio, bevor er unter Septimius Severus rehabilitiert wurde. Dennoch lebten zumindest einzelne Elemente der extravaganten Titulatur des Commodus auch in der Folgezeit fort. So wurde Invictus nach Commodus zum regelmäßigen Bestandteil der (offiziellen) Kaisertitulatur. Bei pacator orbis erfolgte dies zwar nicht, aber die Bezeichnung wurde schon unter den Severern 
Noch sehr viel offenkundiger wird all dies, wenn wir den Blick über die offizielle Titulatur hinauslenken. Viele Kaiserinschriften begnügten sich nämlich keineswegs mit der mehr oder minder getreuen Umsetzung der aus Rom kommenden Vorgaben, sondern fügten diesen weitere Beinamen oder rühmende Adjektive (oft im Superlativ) für den Herrscher und seine Leistungen hinzu. Diese Epitheta, die zumeist einen panegyrischen Charakter hatten, werden als, inoffizielle 'Titulaturelemente bezeichnet ${ }^{257}$. Bei ihrer Formulierung und Auswahl war nach allem, was wir wissen, der Stifter einer Kaiserinschrift keinerlei Restriktionen unterworfen, sondern konnte seinen eigenen Vorstellungen über den aus seiner Sicht idealen Herrscher freien Lauf lassen. So können wir in diesem Bereich bisweilen völlig singuläre Wortschöpfungen beobachten ${ }^{258}$. Häufiger waren aber Beinamen, die eine weitere Verbreitung fanden, wobei sich nicht selten gewisse regionale oder chronologische Verdichtungen ausmachen lassen. So wurden etwa im Osten des Reiches bei der Ansprache des Kaisers sehr oft die Bezeichnungen euergetès, ktistēes und sōtēr gebraucht. Diese waren bereits für hellenistische Herrscher verwendet worden, knüpften dabei aber in der Regel an die Vergabe spezifischer Wohltaten an. Ab dem 2. Jahrhundert v. Chr. wurden sie auf die im Osten agierenden römischen Magistrate übertragen und lösten sich bei den großen Persönlichkeiten der späten Republik wie Pompeius oder Caesar zunehmend vom Bezug auf konkrete Ereignisse, um dann für Augustus universell eingesetzt und auf dessen Leistungen zugunsten des gesamten Reiches bezogen zu werden. Für diese Epitheta finden sich keine echten Äquivalente im Westen, so wie auch die Ansprache des lebenden Herrschers als theos im Osten sehr viel geläufiger war als die entsprechende Anrede als deus im Westen ${ }^{259}$.

nicht selten gebraucht. Exsuperantissimus blieb rarer, ist aber in inoffizieller Anrede belegt für Caracalla (CIL XIV 2073) und Gallienus (CIL XIV 5334).

${ }^{257}$ Vgl. dazu Leo Berlinger, Beiträge zur inoffiziellen Titulatur der römischen Kaiser. Eine Untersuchung ihres ideengeschichtlichen Gehaltes und ihrer Entwicklung (Breslau 1935); Regula Frei-Stolba, Inoffizielle Kaisertitulaturen im 1. und 2. Jahrhundert n. Chr., in: MH 26 (1969) 18-39; Andreas Alfoldi, Die monarchische Repräsentation im römischen Kaiserreiche (Darmstadt 1970) 204-213.

${ }^{258}$ Nur drei Beispiele hierfür: In einer Inschrift des Jahres 143 aus Ostia (AE 1940, 62; dazu Guido Calza, Un documento del culto imperiale in una nuova iscrizione ostiense, in: Epigraphica 1 [1939] 28-36), die aus der statio eines dortigen collegium stammt und ein Verzeichnis der von den Vereinsmitgliedern gestifteten Kaiserporträts und anderer Geschenke enthält (vgl. Peter Herz, Kaiserbilder aus Ostia, in: BCAR 87 [1980-81] 145-157), werden drei Bildnisse des Verissimus Caesar (also des späteren Kaisers Marc Aurel) erwähnt. Dieser kaiserliche Beiname scheint im epigraphischen Material nur hier belegt zu sein (er soll jedoch schon zuvor in Hofkreisen verwendet worden sein: Cass. Dio 69, 21, 2; Hist. Aug. Marc. 1, 10; 4, 1). Vgl. ferner Brian K. Harvey, Two Bases of Marcus Aurelius Caesar and the Roman Imperial Succession, in: Historia 53 (2004) 46-60. Ganz außergewöhnlich sind die Formulierungen, die das corpus piscatorum et urinatorum in Rom gewählt hat, um in einer längeren Inschrift auf einer Marmortafel, die in einem als Vereinslokal genutzten Nymphenheiligtum aufgestellt war, den Kaiser Caracalla und dessen Geburtag zu feiern; s. CIL VI $1080=31236=40638$; dazu ausführlich Géza Alfoldy, Nox Dea fit lux! Caracallas Geburtstag, in: Giorgio Bonamente, Marc Mayer (Hg.), Historiae Augustae Colloquium Barcinonense (Bari 1996) 9-36. Der Kaiser wird hier u.a. als deus (vgl. oben Anm. 189), [T]onitrator Augustus (das Epitheton ist ansonsten lediglich für Iuppiter bezeugt: CIL III 2766a $=8374=$ ILS 3045) und [dominus] maximus angesprochen, und es wird von ihm gesagt, er sei sideribu[s in terram delapsus], was sich nur in literarischen Quellen parallelisieren lässt. Auf einem Meilenstein des frühen 4. Jahrhunderts schließlich findet sich für Kaiser Maxentius die singuläre Bezeichnung als sacrosanctus dominus noster: AE 1990, 224; dazu Cecilia Roncaioli Lamberti, L'appellativo sacrosanctus su un nuovo miliario massenziano della Valeria, in: Epigraphica 52 (1990) 77-84. Der (uns unbekannte) Verfasser der Inschrift wollte also offenbar den Kaiser mit einer besonders ausgefallenen Formulierung ehren. Eine Anweisung von oben ist hierfür ganz unwahrscheinlich. Insofern ist m.E. nicht nachzuvollziehen, warum Roncaioli Lamberti (81) hierin ein Indiz für eine „articolata programmazione centrale“ sehen kann.

${ }^{259}$ Vgl. oben Anm. 193. 
Interessanter als diese eher traditionellen Bezeichnungen, die sich durch ihre weite Verwendung in gewissem Sinne abgeschliffen hatten, sind aber wohl solche, die im Laufe der Zeit neu entwickelt wurden und dann eine mehr als nur lokale Verbreitung fanden. An diesem Punkt stellt sich die Frage, wer diese Epitheta entworfen haben könnte - geschah dies gleichsam spontan und auf Betreiben einzelner Personen, die den Kaiser mit neuartigen Formulierungen preisen wollten; oder wurde es in irgendeiner Form von oben koordiniert oder gar vom Kaiser selbst vorgegeben? Letzteres hat man in der modernen Forschung des Öfteren vermutet, um die bisweilen rasche Verbreitung bestimmter inoffizieller Titulaturelemente über weite Entfernungen hinweg erklären zu können ${ }^{260}$. Dieses Phänomen ist in der Tat erstaunlich, muss aber m.E. nicht notwendigerweise mit einem zentralen Entwurf und dessen gezielter Weiterleitung erklärt werden. Vielmehr ist ebenso gut vorstellbar (wenn auch nicht beweisbar), dass man vor Ort auf bestimmte zeitgenössisches Vorstellungen reagierte, indem man neue Lobpreisungen für den Kaiser formulierte, und diese dann sehr rasch von anderen Personen oder Gemeinden nachgeahmt wurden, welche - gerade in Gebieten mit einer besonders ausgeprägten Städterivalität wie in Kleinasien - dahinter nicht zurückstehen wollten und zudem im selben ,Klima' der Herrscherverehrung agierten ${ }^{261}$.

Von großem Interesse ist es ferner zu beobachten, wie längerfristig einzelne Bestandteile der inoffiziellen Ansprache des Herrschers Eingang in die offizielle Kaisertitulatur fanden. Als Beispiel hierfür kann die Anrede des Princeps als dominus dienen ${ }^{262}$ : In Hofkreisen war sie in der direkten Kommunikation mit dem Herrscher offenbar schon seit der frühen Kaiserzeit nicht ungewöhn-

${ }^{260}$ Vgl. hierzu zuletzt Christof Schuler, Augustus, Gott und Herr über Land und Meer. Eine neue Inschrift aus Tyberissos im Kontext der späthellenistischen Herrscherverehrung, in: Chiron 37 (2007) 383-403 anhand der in einer lykischen Inschrift für Augustus verwendeten Bezeichnung epoptēs gēs kai thalassēs. Diese - im epigraphischen Material selten anzutreffende - Formel ist erstmals in zwei Inschriften aus verschiedenen Orten Kleinasiens für Pompeius bezeugt. Schuler meint deshalb, die Wendung sei am ehesten von Pompeius selbst oder in dessen unmittelbarem Umkreis, etwa durch griechische Intellektuelle wie Theophanes von Mytilene, entwickelt worden (393-397). Ähnliches ist für das Aufkommen der Formel super omnes retro principes ... vermutet worden. Sie ist im epigraphischen Material des lateinischsprachigen Reichsteiles - nachdem der Topos bei den Schriftstellern schon früher begegnet - ab dem späteren 2. Jahrhundert belegt, mit einer besonderen Häufung unter Caracalla; vgl. Andrea Scheithauer, Super omnes retro principes ... Zur inoffiziellen Titulatur römischer Kaiser, in: ZPE 72 (1988) 155-180. Scheithauer sieht hierin ein Indiz dafür, dass die Formulierung möglicherweise gezielt von der kaiserlichen Propaganda lanciert wurde, was mir aber nicht beweisbar erscheint. Möglich ist eben auch die Alternative, die Scheithauer (167) erwägt: „Andererseits könnte sich aber die Tatsache, dass Caracalla nach Getas Tod massiv auf den Vergleich mit den Vorgängern zurückgriff, auch auf die Dedikanten ausgewirkt haben, indem sie die Nachahmung des kaiserlichen Vorbildes und schließlich eine einheitliche Denkweise auslöste, die sich allmählich in weiten Teilen des Reiches durchsetzte.“

${ }^{261}$ Vgl. hierzu die m.E. überzeugenden Anmerkungen von Rödel, Stiftungen (wie Anm. 185) 162-164 zu dem Modell von Schuler, Augustus (wie Anm. 260). Zum Austausch zwischen verschiedenen Städten des Reiches über die Ehrungen zugunsten des Herrschers s. oben Anm. 73.

${ }^{262}$ Eine etwas andere Entwicklung lässt sich für den griechischsprachigen Raum ausmachen, denn im Osten des Reiches war die Anrede des Kaisers als kyrios (und auch als theos kai kyrios) schon recht frühzeitig anzutreffen (ohne dass dies notwendigerweise als ein Unterwerfungsgestus gedeutet werden muss), so - zunächst allerdings noch vereinzelt - in den ägyptischen Papyri. Um 300 wurde dann in Ägypten die inzwischen zur Floskel erstarrte Bezeichnung kyrios allmählich (d.h. ohne eine zentrale Anordnung) durch despotēs ersetzt, da dies den Respekt der Untertanen vor dem Herrscher offenbar besser zum Ausdruck brachte; vgl. dazu Dieter Hagedorn, Klaas A. Worp, Von kyrios zu despotēs. Eine Bemerkung zur Kaisertitulatur im 3./4. Jahrhundert, in: ZPE 39 (1980) 165-177; aber auch die differenzierenden Bemerkungen von Eleanor Dickey, Kyrie, despota, domine. Greek Politeness in the Roman Empire, in: JHS 121 (2001) 1-11. 
lich $^{263}$, was unter einem Kaiser wie Domitian zugenommen haben dürfte, der jedoch - wie gesehen - trotz der gegenteiligen Behauptungen der literarischen Quellen nicht versucht zu haben scheint, den Gebrauch dieser Bezeichnung auch in öffentlich präsentierten Dokumenten durchzusetzen. Nach seiner Ermordung setzte sich die Verwendung der Bezeichnung am Hof fort, aber erst gegen Ende des 2.Jahrhunderts tauchte sie - zumeist in Form der Anrede d(omino) n(ostro) - auch in Inschriften auf, die an den Kaiser gerichtet wurden ${ }^{264}$. Die hierin zum Ausdruck kommende Untergebenheit eines Großteils der Bevölkerung, die dem (vornehmlich) senatorischen Ideal des civilis princeps entgegenstand, wurde durch die wenig später entwickelte, ebenfalls an den Herrscher herangetragene Devotionsformel devotus numini maiestatique eius verstärkt ${ }^{265}$. Ab dem späteren 3. Jahrhundert ist dann dominus noster auch als offizielle Bezeichnung des Herrschers anzutreffen ${ }^{266}$. Man sieht hieran noch einmal sehr gut, wie stark die Vorstellungen, die die Menschen im gesamten Reich in Bezug auf den für sie zumeist fernen Herrscher ausbildeten und die sie unter anderem in epigraphische Monumente umsetzten, auf dessen Repräsentation zurückwirkten.

${ }^{263}$ Dass die Anrede des Herrschers als dominus in Hofkreisen frühzeitig aufkam, ist daraus ersichtlich, dass schon Tiberius diese Bezeichnung vehement zurückgewiesen haben soll; so Suet. Tib. 27: dominus appellatus a quodem denuntiavit, ne se amplius contumeliae causa nominaret (ebenso Tac. ann. 2, 87). Auch Cass. Dio 57, 8, 1 berichtet, Tiberius habe es abgelehnt, von freien Bürgern despotēs genannt zu werden, denn er sei Herr lediglich für seine Sklaven. Ähnliches wird von Augustus überliefert: domini appellationem ut maledictum et obprobium semper exhorruit (Suet. Aug. 53, 1). Offiziell wurde nach der Regierungszeit Domitians die Bezeichnung dominus für den Herrscher weiterhin deutlich abgelehnt. Dass er nie wieder den Kaiser dominus et deus nennen wolle, betont etwa Plinius d.J. gleich zu Beginn seiner Lobrede auf Trajan (paneg. 2, 3). Zur durchgängigen Praxis des Plinius, Trajan in seiner Korrespondenz dennoch mit dem als Anrede inzwischen weit verbreiteten domine anzusprechen, s. nur Plin. ep. 10, 2, 1; 3a, 1 usw. Generell ist zu beachten, dass im Umkreis des Hofes überhöhende Anreden für den Herrscher schon früh üblich gewesen zu sein scheinen, wie man etwa an den Widmungen der Werke römischer Schriftsteller an den Kaiser ablesen kann; so Vitr. praef. 1 (zur divina mens des Herrschers); Val. Max. 1 praef., wo Tiberius in eine göttliche Sphäre erhoben wird; das Rezeptbuch des Arztes Scribonius Largus, der Claudius mehrfach als deus noster Caesar anspricht (so praef. 60: tradendo scripta mea ... deo nostro Caesari); oder Plin. nat. hist. praef. 11 mit ähnlichen Wendungen für Titus.

${ }^{264}$ Die Bezeichnung des Kaisers als d(ominus) $n$ (oster) ist in mehrfacher Ausführung in den Inschriften erstmals für Commodus belegt (vgl. oben Anm. 256). Einige wenige Zeugnisse aus der Zeit zuvor führen zumeist in die unmittelbare Umgebung des Herrschers; vgl. Willy Hüttl, Antoninus Pius, Bd. 1 (Prag 1936) 64-69 zu Vorläufern in antoninischer Zeit. In der severischen Epoche wurde diese Anrede dann recht regelmäßig in den Tituli gebraucht; vgl. Attilio Mastino, Le titolature di Caracalla e Geta attraverso le iscrizioni (Bologna 1981) $58 \mathrm{f}$.

${ }^{265}$ Dazu Hans G. Gundel, Devotus numini maiestatique eius. Zur Devotionsformel in Weihinschriften der römischen Kaiserzeit, in: Epigraphica 15 (1953) 128-150. Der früheste Beleg hierfür sind stadtrömische Inschriften aus der Zeit um 210; s. etwa CIL VI 1058 (= ILS 2157); 40621; 40623. Die Wendung numini eius devotissimus ist hingegen schon für das Jahr 197 bezeugt: AE 1967, 237.

${ }^{266} \mathrm{Ab}$ der tetrarchischen Epoche war die Bezeichnung dominus noster ein fester Bestandteil der Kaisertitulatur; dazu Chastagnol, Formulaire (wie Anm. 239) 12-14. Dass sie nun teilweise auch offiziell verwendet wurde, zeigen die Münzlegenden; dazu Jean-Pierre Callu, DN. La genèse d'une titulature monétaire, in: BSFN 40 (1985) 616-619. Interessant ist im Übrigen, dass nach späterer Überlieferung noch Severus Alexander die Anrede dominus abgelehnt haben soll (Hist. Aug. Alex. Sev. 4, 1: dominum se appellari vetuit), womit er sich jedoch nach Ausweis der Inschriften nicht mehr durchsetzen konnte. 


\section{Schluss: Der Kaiser und die Inschriften}

Aus dieser kurzen Vorstellung des Materials ergeben sich einige wichtige Schlussfolgerungen: Für die Mehrzahl der Inschriften, die den Kaiser nannten, ist nicht davon auszugehen, dass der Herrscher in irgendeiner direkten Form Einfluss auf ihre Konzeption nehmen oder die Art ihrer Ausführung festlegen konnte. Das gilt mit Sicherheit für die große Masse der überall im Reich für den Kaiser errichteten Ehren- und Weiheinschriften, von deren schierer Existenz der Princeps kaum je detaillierte Kenntnis gehabt haben dürfte (s. oben Kap.5-6). Es trifft m.E. aber auch für einen nicht geringen Teil der im Namen des Herrschers angefertigten Inschriften zu, etwa der Bautituli oder Meilensteine, in denen der Herrscher als scheinbar handelnde Figur im Nominativ erschien. Denn auch bei diesen epigraphischen Zeugnissen scheint die genaue Formulierung des Textes und die Gestaltung des Monuments - vor allem außerhalb Roms - häufig in der Verantwortung provinzialer und lokaler Institutionen gelegen zu haben, und es kann zumindest in einzelnen Fällen wahrscheinlich gemacht werden, dass dabei nicht immer eine Rücksprache mit der Zentrale erfolgen musste. Das ist allerdings zugegebenermaßen in der epigraphischen Forschung umstritten, da andere Wissenschaftler - wenn auch zumeist ohne klare Evidenz - eine wesentlich stärkere Einflussnahme des Herrschers selbst oder zumindest des Kaiserhofes auf die Formulierung und Anfertigung von Bau- und Meilensteininschriften postulieren (s. oben Kap.4). Am ehesten ist ein direkter Zugriff des Princeps bei den umfangreichen kaiserlichen Mitteilungen und administrativen Dokumenten anzunehmen, aber auch hierbei war es, wie gesehen (s. oben Kap.2), in der Regel seiner Kontrolle entzogen, wie, wo und wann die entsprechenden Texte in ein auf Dauerhaftigkeit ausgerichtetes epigraphisches Monument umgestaltet wurden. Und selbst bei den besonders bedeutungsvollen Denkmälern zur Feier des Herrschers in der Metropole Rom lag die Initiative oft nicht beim Kaiser selbst, sondern bei anderen Gruppierungen wie Senatus Populusque Romanus oder der plebs. So zumindest besagt es der Wortlaut der an diesen Monumenten angebrachten Inschriften, und dieser sollte m.E. durchaus ernst genommen werden, auch wenn es gerade in der Hauptstadt natürlich möglich war, dass der Kaiser gleichsam hinter den Kulissen auf die Gesamtplanung und vielleicht auch die Detailgestaltung dieser Ehrungen Einfluss nahm (s. oben Kap. 3).

Insofern sind Kaiserinschriften nur in relativ begrenztem Maße eine Quelle für eigenmächtiges kaiserliches Handeln; sie eignen sich hingegen wesentlich besser für die Erforschung von Kommunikations- und Rezeptionsprozessen, die sich im Wechselspiel zwischen der kaiserlichen Zentrale, der provinzialen Administration und der Bevölkerung des Imperium Romanum vollzogen. Auch auf diesem Feld ist jedoch bei der Interpretation epigraphischer Zeugnisse eine gewisse methodische Vorsicht angebracht, bei der insbesondere die folgenden Punkte im Auge behalten werden sollten: Zunächst einmal ist festzuhalten, dass das Bild, das sich aus den epigraphisch festgehaltenen Texten in Bezug auf den Kaiser ergibt und das uns zumindest in Ausschnitten bekannt ist, grundsätzlich positiv gefärbt war, da im Medium der Inschriften zu Lebzeiten eines Herrschers keine Kritik an diesem geäußert werden konnte ${ }^{267}$. Spottverse auf den Princeps, wie sie nach Ausweis

\footnotetext{
${ }^{267}$ Möglich war explizit geäußerte Kritik in den Inschriften eigentlich nur im Rückblick auf bereits verstorbene Herrscher, vor allem solche, die der sog. damnatio memoriae verfallen waren. Vgl. dazu etwa die claudische Bauinschrift CIL VI 1252 = ILS 205 aus Rom: Ti(berius) Claudius Drusif(ilius) Caesar Augustus Germanicus / pontifex maxim(imus) trib(unicia) potest(ate) V imp(erator) XI p(ater) p(atriae) co(n)s(ul) desig(natus) IIII I arcus ductus aquae Virginis disturbatos per C(aium) Caesarem / a fundamentis novos fecit ac restituit. Vgl. Edwin S. Ramage, Denigration of Predeccesor Under Claudius, Galba, and Vespasian, in: Historia 32 (1983) 200-214.
} 
der literarischen Quellen in Form von Flugschriften und Graffiti zumindest in Rom recht weit verbreitet waren ${ }^{268}$, oder die oft mit kritischen Untertönen verbundenen Spitznamen der Kaiser, die ebenfalls in ziemlich großer Zahl im Umlauf gewesen sein sollen ${ }^{269}$, finden sich in den erhaltenen Tituli praktisch nie - Inschriften fallen somit auf diesem Gebiet als Korrektiv zu den möglichen Übertreibungen der literarischen Quellen, insbesondere in Bezug auf die in der senatorischen Überlieferung als principes mali erscheinenden $\operatorname{Herrscher}^{270}$, weitgehend aus.

${ }^{268} \mathrm{Zu}$ Schmähschriften, Spottgedichten und Graffiti, die sich gegen den Herrscher und dessen Auftreten richteten, s. etwa Suet. Aug. 70; Tib. 59; Claud. 38, 3; Nero 39, 2; Otho 3, 2; Dom. 14, 2; von einem allgemeinen (d.h. offenbar unter allen Kaisern verbreiteten) Phänomen spricht auch Cass. Dio 65 (66), 11, 1. Dass die Verbreitung von Pamphleten dieser Art vor allem in Krisenzeiten wie Hungersnöten in der Stadt Rom stark zunahm, berichtet Cass. Dio 55, 27, 1-4 zum Jahr 6 n. Chr. Schon Augustus war gegen famosi libelli bzw. biblia - vor allem die anonymen - vorgegangen (s. Tac. ann. 1, 72, 3; Cass. Dio 56, 27, 1; aber auch Suet. Aug. 55); ebenso Domitian (Suet. Dom. 8, 3); dazu Giancarlo Muciaccia, In tema di repressione delle opere infamanti (Dio 55, 27), in: Studi in onore di A. Biscardi, Bd. 5 (Mailand 1984) 61-78. In materieller Form haben sich solche Schriften nur selten erhalten; vgl. zu einigen Graffiti Paolo Cugusi, Spunti di polemica politica in alcuni graffiti di Pompei e di Terracina, in: ZPE 61 (1985) 23-29.

${ }^{269} \mathrm{Zu}$ den kaiserlichen Spitznamen vgl. Christer Bruun, Roman Emperors in Popular Jargon. Searching for Contemporary Nicknames, in: Lukas De Blois u.a. (Hg.), The Representation and Perception of Roman Imperial Power (Amsterdam 2003) 69-98, der 88f. auf die sehr geringe Evidenz für solche Namen (die von inoffiziellen Titulaturelementen zu unterscheiden sind; dazu oben Kap.6) in den Inschriften verweist.

${ }^{270}$ Immerhin bieten die Inschriften ein gewisses Gegengewicht zu den Behauptungen der literarischen Quellen in Bezug auf die principes mali. So sollen Letzteren - oft auf deren eigenes Betreiben - zahlreiche Titel zuerkannt worden sein, die die etablierten Normen überstiegen, aber dennoch angeblich sogar in offiziellen Schriftstücken Verwendung fanden (vgl. auch oben Kap. 6 mit Anm. 244). Ein gutes Beispiel hierfür stellt der Kaiser Caligula dar: Er soll mehrfach Britannicus genannt worden (Cass. Dio 59, 25, 5a) und siebenmal zum imperator ausgerufen worden sein (Cass. Dio 59, 22, 2), obwohl er weder Britannien unterworfen noch eine einzige Schlacht gewonnen hatte. Bei Suet. Cal. 22, 1 werden weitere ehrende Beinamen erwähnt, die Caligula angenommen habe, nachdem sie ihm offenbar von anderen Personen angeboten worden waren: compluribus cognominibus adsumptis - nam et pius et castrorum flius et pater exercituum et optimus maximus Caesar vocabatur ... . Schließlich wird berichtet, Caligula sei am Ende seines Lebens offiziell als theos und Iuppiter angesprochen worden; und diese Bezeichnungen wären auch in Dokumenten verwendet worden (Cass. Dio 59, 28, 8). Keine dieser Behauptungen lässt sich bei einer Musterung der erhaltenen Inschriften des Caligula verifizieren. Einige Male wird zwar Caligula im Osten des Reiches als theos bezeichnet (so in IDidyma 148 aus Didyma oder in AE 1995, 1459 = SEG 45 [1995] 1645 aus Sardis; in SIG 799 erscheint Caligula als megistos kai epiphanestatos theos; s. ferner den in SIG $^{3} 797=$ IGR IV 25 überlieferten Treueeid der Einwohner von Assos aus dem Jahre 37). Diese Inschriften gehören aber alle, wie leicht zu erkennen ist, in den Kontext des Kaiserkultes, wo zumindest in den östlichen Reichsteilen eine solche Benennung durchaus nichts Ungewöhnliches war; vgl. dazu oben Anm. 193. In einer weiteren Inschrift aus Kyzikos wird Caligula, wohl zu Beginn seiner Regierungszeit, ho neos Hëlios Gaios Kaisar Sebastos Germanikos genannt (SIG $\left.{ }^{3} 798\right)$. Diese Benennung ist insofern interessant, als die Sol-Identifikation für Caligula selbst (anders als später für Nero) keine Rolle gespielt zu haben scheint. In den Provinzen wurde sie jedoch - offenbar ohne Einfluss aus Rom - mehrfach vorgenommen, wie auch lokale Münzprägungen zeigen, die Caligula (zum ersten Mal bei einem lebenden Kaiser) mit der Strahlenkrone vorführten: Bergmann, Herrscherbild (wie Anm.243) 127-129. Wenn also in Bezug auf Caligula in den Inschriften Bezeichnungen auftauchen, die eher außergewöhnlich wirken, so scheinen sie von unten an ihn herangetragen worden zu sein, ohne dass jeweils klar würde, inwieweit der Kaiser hiervon überhaupt gewusst hat. Allerdings ist noch anzumerken, dass gerade bei den principes mali davon auszugehen ist, dass ein größerer Teil der sie betreffenden Inschriften aufgrund einer postum verhängten Gedächtnisstrafe vernichtet wurde (dazu s. oben Anm. 6). Darunter könnten sich insbesondere diejenigen Tituli befunden haben, die anstößige Titulaturelemente enthielten. Das wiederum würde bedeuten, dass uns die erhaltenen Inschriften dieser Kaiser ein schiefes Bild in Bezug auf die von ihnen verwendeten oder für sie gebrauchten Bezeichnungen vermitteln. 
Die sich in den Inschriften widerspiegelnden Kommunikationsprozesse zwischen Herrscher und Untertanen sind vermutlich ebenfalls einseitig dargestellt, da auch hier Konfliktsituationen weitgehend ausgeblendet wurden - nicht zuletzt dadurch, dass negative kaiserliche Mitteilungen von den Empfängern nur sehr selten inschriftlich aufgezeichnet wurden (s. oben Kap. 2). Beim Vorliegen einer (literarischen) Parallelüberlieferung ergibt sich aber nicht selten ein abweichendes Bild, in dem die durchaus vorhandenen Spannungen sehr viel deutlicher hervortreten. Ein Beispiel hierfür bietet die Situation in Athen (Achaia) während der augusteischen Zeit. Wenn wir nur auf die epigraphische (und archäologische) Überlieferung blicken, bietet sich ein Bild, wie wir es auch aus vielen anderen Städten im Imperium Romanum kennen: Es gab einige Stiftungen des Kaiserhauses, auf die die Stadt mit mannigfachen Ehrungen für Augustus selbst, vor allem aber für Mitglieder seiner Familie wie Agrippa, Caius und Lucius Caesar antwortete ${ }^{271}$. Besonders hervorzuheben ist dabei die frühzeitige Einführung des Kaiserkultes, der in Athen offenbar an mehreren Orten ausgeübt wur$\mathrm{de}^{272}$. Unter diesen fällt ein Rundtempel für Roma und Augustus auf, der an einem besonders prominenten Platz, nämlich vor der Ostseite des Parthenon auf der Akropolis, stand und dessen Inschrift sich erhalten hat ${ }^{273}$. Weiterhin zeugen zahlreiche kleinere Altäre von der offenbar weit verbreiteten kultischen Verehrung des Augustus ${ }^{274}$. Schließlich lassen die epigraphischen Zeugnisse erkennen, dass bei der Kommunikation zwischen Herrscher und Untertanen wie üblich einige herausragende Figuren der lokalen Oberschicht, die nicht zuletzt Gesandtschaften nach Rom unternahmen, eine wichtige Rolle spielten ${ }^{275}$. Dieses harmonische Bild stellt sich allerdings ein wenig anders dar, wenn auch die literarische Überlieferung einbezogen wird, denn in dieser ist mehrfach von erheblichen Spannungen zwischen Augustus und der Bevölkerung von Athen die Rede. Diese rührten zunächst offenbar daher, dass Athen einer der bevorzugten Aufenthalte des Marcus Antonius gewesen war; aber sie traten später (etwa bei dem Besuch des Augustus in der Stadt im Winter 22/21 v. Chr.) erneut auf und setzten sich, wenn wir den Angaben einiger spätantiker Autoren trauen dürfen, sogar bis in die spätaugusteische Zeit fort ${ }^{276}$. Von solchen Störungen der Kommunikation erfahren wir

\footnotetext{
${ }^{271}$ Vgl. allgemein Michael C. Hoff, Augustus, Apollo, and Athens, in: MH 49 (1992) 223-232; Susan Walker, Athens under Augustus, in: Michael C. Hoff, Susan I. Rotroff (Hg.), The Romanization of Athens. Kongreßbericht Lincoln 1996 (Oxford 1997) 67-80. Zu den Ehrungen für C. und L. Caesar in Athen s. oben Anm. 93. Mit Blick auf die Initiatoren dieser Maßnahmen ist zu betonen, dass es sich dabei nicht um ein vom Kaiser gesteuertes Programm handelte, sondern die kaiserlichen Stiftungen nur punktuelle Akzente setzten, während der Großteil der den Herrscher verherrlichenden Monumente von der Stadtgemeinde bzw. von Mitgliedern der lokalen Elite konzipiert wurde; so zu Recht Ortwin Dally, Athen in der frühen Kaiserzeit - ein Werk des Kaisers Augustus?, in: Stavros Vlizos (Hg.), Athens during the Roman Period. Recent Discoveries, New Evidence (Athen 2008) 43-53.

${ }^{272} \mathrm{Vgl}$. Michael C. Hoff, The Politics and Architecture of the Athenian Imperial Cult, in: Alastair Small (Hg.), Subject and Ruler. The Cult of the Ruling Power in Classical Antiquity (Ann Arbor 1996) 185-200; Antony J.S. Spawforth, The Early Reception of the Imperial Cult in Athens. Problems and Ambiguities, in: Michael C. Hoff, Susan I. Rotroff (Hg.), The Romanization of Athens. Kongreßbericht Lincoln 1996 (Oxford 1997) 183-201 (mit etwas abweichender, m.E. nicht völlig überzeugender Wertung).

${ }^{273}$ IG II/III 3173 (gestiftet vom Demos); dazu Paola Baldassari, Augusto soter. Ipotesi sul monopteros dell'Acropoli ateniesi, in: Ostraka 4 (1995) 69-84.

${ }^{274}$ S. oben Anm. 184.

${ }^{275}$ S. etwa die Inschrift des Eingangstores zur Römischen Agora: IG II/III 3175.

${ }^{276}$ S. insbesondere Cass. Dio 54, 7, 2f.; dazu und zu weiteren Belegen vgl. Michael C. Hoff, Civil Disobedience and Unrest in Augustan Athens, in: Hesperia 58 (1989) 267-276; ferner Dietmar Kienast, Antonius, Augustus, die Kaiser und Athen, in: Klassisches Altertum, Spätantike und frühes Christentum. Festschrift A. Lippold (Würzburg 1993) 191-222.
} 
aus den Inschriften naturgemäß nichts, die uns somit zumindest in diesem Fall ein ziemlich einseitiges Bild der antiken Realität vermitteln.

Bisweilen ist in Fällen, in denen die Aussagen der literarischen und der epigraphischen Quellen bei der Schilderung kaiserlichen Handelns oder der Reaktionen hierauf in unterschiedliche Richtungen weisen, nicht sicher zu entscheiden, welchem Überlieferungsstrang der Vorzug zu geben ist, da beide aus jeweils ganz bestimmter und eingeschränkter Perspektive berichten und darum ein- und denselben Vorgang unterschiedlich akzentuieren konnten. So stellen bei einigen Bauprojekten, die mit dem Kaiserkult verbunden waren, die literarischen Quellen eine angeblich direkte Initiative des Kaisers hierfür heraus, während die Inschriften eher die Rolle provinzialer oder munizipaler Institutionen betonen. Hadrian etwa werden in seiner Biographie zahlreiche Tempelbauten in Kleinasien zugeschrieben, die er auf seinen Reisen durch die Region erbaut und dadurch seinen eigenen Kult befördert haben soll ${ }^{277}$. Einen Beleg hierfür hat man in einem monumentalen, ursprünglich dem Zeus geweihten Tempel in Kyzikos erblicken wollen, der - nach der Aussage späterer literarischer Quellen, insbesondere des Johannes Malalas ${ }^{278}$ - tatsächlich von Hadrian selbst nach einer Erdbebenzerstörung wiedererrichtet und seinem Kult gewidmet worden sein soll. Zugleich ist jedoch ein Bauepigramm überliefert, aus dem hervorgeht, dass ein Architekt namens Arist(o)netos das Gebäude von den Fundamenten errichtete, und zwar auf Kosten „von ganz Asien“, womit mit Sicherheit der Landtag der Provinz Asia gemeint ist ${ }^{279}$. Hier fallen die Widersprüche zwischen den einzelnen Quellengattungen klar ins Auge: Die späten literarischen Quellen machen Hadrian selbst, die Inschrift hingegen das koinon zum Initiator des Projekts. Hierfür ließe sich immerhin als mögliche Erklärung anführen, dass sich eventuell beide Seiten an den Baukosten beteiligten, wobei dann immer noch die Frage offen bliebe, wer den ursprünglichen Anstoß zu den Baumaßnahmen gegeben hatte. Vermutlich hatten dies - wie in solchen Fällen üblich - die Provinzialen getan, während sich Hadrians Beitrag im Wesentlichen auf einen Zuschuss zur Finanzierung des Riesenbaues beschränkt haben dürfte. Dagegen steht freilich die Aussage des Malalas. Bei ihm ist jedoch fraglich, wieviel er über die Vorgänge zur Zeit Hadrians noch wusste. Es könnte sehr wohl sein, dass er den Bau mit der Widmungsinschrift an Hadrian (im Dativ) kannte, dann aber aus eigener Vorstellungskraft hinzufügte, der Kaiser sei selbst für diesen Bau verantwortlich gewesen ${ }^{280}$.

${ }^{277}$ Hist. Aug. Hadr. 13, 6: eodemque modo per Asiam iter faciens templa sui nominis consecravit.

${ }^{278}$ Joh. Mal. 11, 16 (ed. Thurn, p. 210); dazu Alexander Schenk Grafv. Stauffenberg, Die römische Kaisergeschichte bei Malalas. Griechischer Text der Bücher IX-XII und Untersuchungen (Stuttgart 1931) 299f.; s. ferner Chron. Pasch. I p. 475 [Bonn] und Sokr. HE III 23, 59. Eine Angabe zur Finanzierungsart findet sich in einem Scholion zu Lukian aus dem 6.Jahrhundert (danach habe Hadrian lediglich einen wesentlich älteren Tempel vollendet). Die einzige einigermaßen zeitgenössische Quelle ist die or. 27 des Aelius Aristides, gehalten 166 bei der Wiedereinweihung des Tempels nach einer weiteren Erdbebenzerstörung im Jahre 161. Allerdings bietet leider gerade dieser Text für unsere Fragestellung nicht allzu viele Informationen. Immerhin erfahren wir aus $\$ 22$, dass auch bei der Restaurierung in antoninischer Zeit wieder der Name des Kaisers Hadrian an dem Bau angebracht wurde.

${ }^{279} \mathrm{Zu}$ dem von Cyriacus von Ancona überlieferten Bauepigramm s. IGR IV 140. Da Cyriacus leider nicht genau angibt, wo er diese Inschrift gesehen hat, kann nicht endgültig gesichert werden, dass sich diese tatsächlich auf den großen Tempel bezieht.

${ }^{280}$ Zur Diskussion um den Tempel in Kyzikos vgl. Price, Rituals (wie Anm. 176) 153-155, 251 Nr. 17 (mit der älteren Literatur); Armin Schulz, Engelbert Winter, Historisch-archäologische Untersuchungen zum Hadrianstempel in Kyzikos, in: Elmar Schwertheim (Hg.), Mysische Studien (Bonn 1990) 33-82; Andrea Barattolo, The Temple of Hadrian-Zeus at Cyzicus, in: MDAI(I) 45 (1995) 57-108. 
Einen von der Quellenproblematik her vergleichbaren Fall kennen wir aus Milet. Er betrifft den Kaiser Caligula, der tatsächlich in relativ starkem - in der frühen Kaiserzeit jedenfalls ganz ungewöhnlichem - Maße versucht zu haben scheint, den Kult seiner eigenen Person zu fördern. Trotzdem ist dies in jedem einzelnen Fall zu überprüfen, denn bei genauerem Hinsehen ergeben sich oft Widersprüche zwischen den entsprechenden Zeugnissen. So berichtet Cassius Dio, Caligula habe befohlen, für ihn in Milet ein Heiligtum einzurichten; weiterhin lässt der Historiker durchscheinen, Caligula habe die Stadt gerade deswegen gewählt, weil er vorgehabt habe, sich den in der Nähe gelegenen Tempel des Apollo, d.h. das berühmte Heiligtum von Didyma, für seinen Kult anzueignen ${ }^{281}$. Gerade dieser zweite Teil der Geschichte wirkt wenig glaubhaft, da Dio hier offenbar verschiedene Fakten zusammenwirft. So wissen wir zwar, dass Caligula den Weiterbau des ApolloTempels unterstützte, aber dies besagt noch nichts hinsichtlich seiner möglichen weitergehenden Interessen. Viel wichtiger ist jedoch ein inschriftlicher Beleg, der klar macht, dass an dem Bau des Tempels für Caligula in Milet federführend die wichtigsten Städte der Provinz Asia beteiligt waren; und dort steht nichts von einem direkten Befehl des Kaisers ${ }^{282}$. Es muss jedoch nicht notwendigerweise ein unüberbrückbarer Widerspruch zwischen diesen divergierenden Quellenaussagen vorliegen, denn sie könnten durchaus zwei Facetten desselben Vorganges aus einer jeweils unterschiedlichen Perspektive schildern. So ist es möglich, dass es hinter den Kulissen einen mehr oder minder deutlich ausgesprochenen Wunsch des Kaisers gab, ihm einen Tempel zu errichten, der dann von den Städten Asiens prompt aufgegriffen wurde - Dio hätte dann einfach Letzteres, die Inschrift Ersteres nicht für erwähnenswert gehalten. Das würde zur jeweiligen Ausrichtung dieser Quellen passen, denn Dio interessierte sich nun einmal vor allem für die Person des Kaisers, während die vor Ort errichteten Inschriften die nach außen hin propagierte Fassade des Vorganges aus lokaler Sicht präsentierten. Man kann aber beide Zeugnisse auch wesentlich kritischer betrachten und sich fragen, ob sie die volle Wahrheit wiedergeben. Es ist nämlich nicht ganz unwahrscheinlich, dass Dio aus der ihm bekannten Tatsache, dass unter Caligula in Milet ein Tempel für diesen errichtet wurde, auf einen direkten Befehl des in der historiographischen Tradition als besonders tyrannisch und exzentrisch geltenden Kaisers geschlossen und somit die tatsächliche Initiative umgedreht hat. Auf der anderen Seite ist es durchaus vorstellbar, dass man in der Inschrift den Hinweis auf eine kaiserliche Anordnung einfach deswegen unterschlagen hat, weil man die eigene Leistung bei der Einrichtung des Kults und beim Bau des Tempels herausstreichen wollte, zumal dies den gewohnten Mechanismen im Umgang zwischen den Städten und dem Herrscher besser entsprach ${ }^{283}$.

Wir sollten also davon ausgehen, dass die Kommunikationsprozesse zwischen dem Herrscher und den Untertanen, für die gerade die epigraphischen Zeugnisse unsere wesentliche Quelle darstellen, in gewisser Weise verzerrt dargestellt sind, da in den erhaltenen Inschriften die Initiative von

${ }^{281}$ Cass. Dio 59, 28, 1.

${ }^{282}$ S. IDidyma 148 mit dem Kommentar von Albert Rehm; der terminologische Unterschied zwischen dem temenos des Cassius Dio und dem naos der Inschrift scheint mir dabei nicht so gravierend zu sein. Ein entsprechendes Heiligtum ist allerdings in Milet bislang nicht gefunden worden. Zu den Bauaktivitäten am ApolloTempel von Didyma unter Caligula s. Suet. Cal. 21; IDidyma 107 sowie zusammenfassend Louis Robert, Le culte de Caligula à Milet et la province d'Asie, in: Hellenica 7 (1949) 206-238 und Peter Herrmann, Ein Tempel für Caligula in Milet?, in: MDAI(I) 39 (1989) 191-196 (mit etwas abweichender Meinung). Die Stiftung einer Statue für Caligula durch die neopoioi in Didyma (belegt eben durch IDidyma 148) erfolgte eventuell als Dank dafür, dass der Kaiser sich für die Errichtung eines Tempels für seinen Kult in Milet dadurch erkenntlich zeigte, dass er Gelder für den Fortbau des Didymeions bereitstellte.

${ }^{283}$ Vgl. ferner Aloys Winterling, Caligula. Eine Biographie (München 2003) 148 zu der Situation in Alexandria. 
Gemeinden und Einzelpersonen möglicherweise überbetont ist, weil diese dazu neigten, gerade solche Vorgänge inschriftlich aufzuzeichnen, in denen sie selbst eine bestimmende Rolle gespielt hatten oder die sie in einem günstigen Licht erscheinen ließen. Insofern sind die zahllosen Anfragen, die von unten an den Herrscher gerichtet wurden, unverhältnismäßig gut dokumentiert - zumindest in dem Maße, wie sie positiv beschieden wurden. Unter anderem aus solchen Zeugnissen hat Fergus Millar seine These vom „reagierenden Kaiser“ entwickelt, der nicht so sehr von sich aus eine eigene, längerfristig geplante Politik durchzusetzen versuchte, sondern im Einzelfall auf an ihn herangetragene Probleme antwortete und hieraus die Leitlinien seines Regierens entwickelte ${ }^{284}$. Dieses Modell scheint mir in den Grundzügen immer noch richtig zu sein. Werner Eck hat jedoch zu Recht wiederholt darauf aufmerksam gemacht, dass unsere Sichtweise nicht unerheblich von der Art der Quellen, die uns erhalten geblieben sind, beeinflusst wird - und dies trifft in besonderem Maße auf die Inschriften $\mathrm{zu}^{285}$. Diejenigen Anordnungen etwa, die von oben, also vom Kaiser oder der Zentralverwaltung, an einzelne Städte oder gar an alle Gemeinwesen des Reiches gerichtet worden waren, wurden häufig nicht in Stein übertragen, sondern lediglich auf vergänglichem Material in den Städten zur Schau gestellt und dann im Archiv verwahrt (s. oben Kap.2). Davon hat sich naturgemäß kaum etwas erhalten, und somit ist dieser gesamte Bereich für uns schwer zu fassen. Das wiederum hat nicht unwesentlich zu unserem Bild von einer zumeist nicht aktiv handelnden, sondern lediglich reagierenden und darum wenig intensiven Administration beigetragen. Vielleicht haben wir dabei die Möglichkeiten unterschätzt, die auch in einem System wie dem römischen dem Herrscher verblieben, um von sich aus gewisse Vorstellungen und Handlungsanleitungen bei seinen Untertanen zu verbreiten.

Trotz dieser Einschränkungen bilden aber die zahlreichen Inschriften, die in irgendeiner Form Bezug auf den Kaiser nehmen, eine unserer wichtigsten Quellen für die Erforschung des im Imperium Romanum verbreiteten ,Images' des Herrschers und des intensiven Dialogs, der darüber zwischen dem Princeps und der Bevölkerung des Reiches stattfand.

${ }^{284}$ Millar, Emperor (wie Anm. 82) passim; zur Diskussion um dieses Modell vgl. Jochen Bleicken, Zum Regierungsstil des römischen Kaisers. Eine Antwort auf Fergus Millar (Wiesbaden 1982) und zuletzt Sebastian Schmidt-Hofner, Reagieren und Gestalten. Der Regierungsstil des spätrömischen Kaisers am Beispiel der Gesetzgebung Valentinians I. (München 2008) 11-18, 337-344 sowie die Beiträge in: Hans-Ulrich Wiemer (Hg.), Staatlichkeit und politisches Handeln in der römischen Kaiserzeit (Berlin u.a. 2006).

${ }^{285}$ Werner Eck, Kaiserliches Handeln in italischen Städten, in: Ders., Die Verwaltung des römischen Reiches in der hohen Kaiserzeit. Ausgewählte und erweiterte Beiträge, Bd. 2 (Basel 1998) 297-320; ders., Zur Einleitung. Römische Provinzialadministration und die Erkenntnismöglichkeiten der epigraphischen Überlieferung, in: Werner Eck (Hg.), Lokale Autonomie und römische Ordnungsmacht in den kaiserzeitlichen Provinzen vom 1. bis 3. Jahrhundert (München 1999) 1-15. 